\title{
Application of Bayesian and Geostatistical Modeling to the Environmental Monitoring of CS-137 at the Idaho National Laboratory
}

Kara G. Eby

August 2010

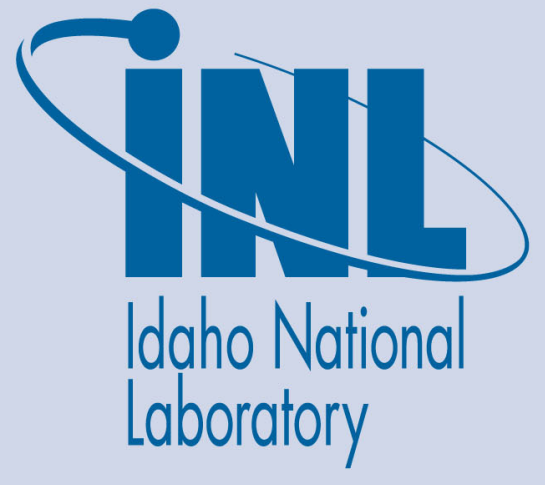

The INL is a U.S. Department of Energy National Laboratory operated by Battelle Energy Alliance 
INL/EXT-10-19532

\title{
Application of Bayesian and Geostatistical Modeling to the Environmental Monitoring of CS-137 at the Idaho National Laboratory
}

\author{
Kara G. Eby
}

August 2010

\begin{abstract}
Idaho National Laboratory
Idaho Falls, Idaho 83415
\end{abstract}

http://www.inl.gov

\author{
Prepared for the \\ U.S. Department of Energy \\ Assistant Secretary for Environmental Management \\ Under DOE Idaho Operations Office \\ Contract DE-AC07-05ID14517
}




\title{
APPLICATION OF BAYESIAN AND GEOSTATISTICAL MODELING TO THE ENVIRONMENTAL MONITORING OF CS-137 AT THE IDAHO NATIONAL LABORATORY
}

\author{
A Thesis \\ Presented in Partial Fulfillment of the Requirements for the \\ Degree of Master of Science \\ with a \\ Major in Environmental Engineering \\ in the \\ College of Graduate Studies \\ University of Idaho \\ by \\ Kara G. Eby
}

August 2010

Major Professor: Stanley M. Miller, PhD., P.E. 


\begin{abstract}
At the Idaho National Laboratory (INL) Cs-137 concentrations above the U.S. Environmental Protection Agency (EPA) risk-based threshold of $0.23 \mathrm{pCi} / \mathrm{g}$ may increase the risk of human mortality due to cancer. As a leader in nuclear research, the INL has been conducting nuclear activities for decades. Elevated anthropogenic radionuclide levels including Cs-137 are a result of atmospheric weapons testing, the Chernobyl accident, and nuclear activities occurring at the INL site. As a result of these events, environmental monitoring and long-term surveillance of Cs-137 concentrations in INL soils is required to evaluate risk. However, due to the large land area involved, frequent and comprehensive monitoring is limited. Developing a spatial model that predicts Cs-137 concentrations at unsampled locations will enhance the spatial characterization of Cs-137 in surface soils, provide guidance for an efficient monitoring program, and pinpoint areas requiring mitigation strategies. The predictive model presented herein is based on applied geostatistics using a Bayesian analysis of environmental characteristics across the INL site, which provides kriging spatial maps of both Cs-137 estimates and prediction errors. Comparisons are presented of two different kriging methods, showing that the use of secondary information (i.e., environmental characteristics) can provide improved prediction performance in some areas of the INL site.
\end{abstract}




\section{Acknowledgements}

I would like to acknowledge Dr. Stanley Miller, Christopher Oertel, and John Giles for their constant guidance throughout this process, as well as for giving me the opportunity to pursue this research. In addition, I would like to thank my committee members, Dr. Thomas Hess and Dr. Raymond Dezzani for their input and assistance. Finally, thank you to the many members of the INL and GeoEngineers, Inc., who contributed either to my research or to the work that lead up to the final model.

The work presented in this thesis was funded by the Environmental Monitoring Group at the Idaho National Laboratory. 


\section{Table of Contents}

Authorization to Submit

Abstract

Acknowledgements iv

Table of Contents vi vi

Table of Figures viii

Table of Tables $\quad$ xi

Glossary of Terms

1 Introduction and Background 1

1.1 Importance of Monitoring Cs-137 1

1.2 Radionuclide Monitoring at the INL 4

1.3 Project Objectives 5

2 Data Collection and Testing $\quad 7$

$\begin{array}{lll}2.1 & \text { Gamma Ray Spectroscopy } & 7\end{array}$

2.2 Analysis and Quantification of Environmental Radionuclides 8

$\begin{array}{lll}2.3 & \text { Field Sampling Methods } & 10\end{array}$

$\begin{array}{lll}2.4 & \text { Depth Distribution Sampling } & 13\end{array}$

$\begin{array}{lll}2.5 & \text { Analysis of Testing Results } & 15\end{array}$

$3 \quad$ Environmental Factors $\quad 20$

$\begin{array}{lll}3.1 & \text { Soil Type } & 21\end{array}$

$\begin{array}{lll}3.2 & \text { Elevation } & 21\end{array}$

$\begin{array}{lll}3.3 & \text { Slope } & 22\end{array}$

$\begin{array}{lll}3.4 & \text { Aspect } & 23\end{array}$ 
$\begin{array}{lll}3.5 & \text { Wind } & 24\end{array}$

$\begin{array}{lll}3.6 & \text { Cs-137 Concentrations } & 29\end{array}$

3.7 GIS Maps of Environmental Factors 28

4 Application of An Adapted Bayesian Analysis 30

4.1 Conditional Probabilities 30

4.2 Calculation of Bayesian Scores 33

$5 \quad$ Correlation of Environmental Factors with Cs-137 36

5.1 Application of Geographic Weighted Regression 36

5.2 Application of Bayesian Score 37

$6 \quad$ Geostatistical Estimation of Cs-137 41

6.1 Spatial Dependence Modeling 42

6.2 Ordinary Kriging 44

6.3 Kriging with Exhaustive Secondary Information (KESI) 45

$\begin{array}{lll}6.4 & \text { Kriging Results } & 47\end{array}$

6.5 Assessment of Kriging Performance 53

7 Conclusions and Recommendations $\quad 59$

$\begin{array}{lll}7.1 & \text { Primary Results and Conclusions } & 60\end{array}$

7.2 Recommendations for Cs-137 Field Sampling Program 62

7.3 Recommendations for Future Work 63

$\begin{array}{ll}\text { References } & 65\end{array}$

Appendix A. In Situ Sampling Locations 67

Appendix B. Environmental Factor Classification 77

Appendix C. Spatial Dependence Modeling for the 2009 Cs-137 Data 83 


\section{Table of Figures}

Figure 1.1 INL site location in eastern Idaho 2

Figure 1.2 Cs-137 decay scheme 3

Figure 2.1 High Purity Germanium (HPGe) detector 8

$\begin{array}{lll}\text { Figure 2.2 INL facility locations } & 11\end{array}$

$\begin{array}{lll}\text { Figure 2.3 HPGe configuration for in situ measurements } & 12\end{array}$

$\begin{array}{lll}\text { Figure 2.4 Soil puck sampling scheme } & 14\end{array}$

$\begin{array}{lll}\text { Figure 2.5 Soil depth distribution }(\alpha / \rho) & 16\end{array}$

Figure 2.6 Gamma spectrum collected by HPGe detector 17

Figure 2.7 Statistical summary of Cs-137 data collected in $2006 \quad 17$

Figure 2.8 Statistical summary of Cs-137 data collected in $2007 \quad 18$

Figure 2.9 Statistical summary of Cs-137 data collected in $2008 \quad 18$

Figure 2.10 Statistical summary of Cs-137 data collected in 2009

$\begin{array}{lll}\text { Figure } 3.1 \quad \text { Aspect classification system } & 23\end{array}$

Figure 3.2 Generic example facility wind rosette 25

Figure 3.3 Scaled wind ellipse for the ARA facility 26

Figure 4.1 Example of Mathcad $^{\circledR}$ calculations for conditional probabilities $\quad 32$

$\begin{array}{lll}\text { Figure 4.2 Bayrank map } & 35\end{array}$

Figure 5.1 Scatterplot of 2009 Cs-137 values vs. bayrank values 38

Figure 5.2 Postplot of bayrank values at Cs-137 sampling locations 39

Figure 5.3 Postplot of Cs-137 values at sampling locations $\quad 40$

Figure 6.1 A typical variogram plot depicting spatial dependence 42

Figure 6.2 A typical spatial covariance plot depicting spatial dependence 43 
Figure 6.3 Cs-137 point kriging estimate map (pCi/g)

Figure 6.4 Cs-137 point kriging error map (pCi/g)

Figure 6.5 Cs-137 KESI estimate map (pCi/g)

Figure 6.6 Cs-137 KESI error map $(\mathrm{pCi} / \mathrm{g})$

Figure 6.7 Comparison of measured Cs-137 value and point kriging estimate 54

Figure 6.8 Comparison of measured Cs-137 value and KESI estimate $\quad 54$

Figure 6.9 Statistical summary of point kriging residuals 55

Figure 6.10 Statistical summary of KESI residuals 55

Figure 6.11 Postplot of point kriging residuals (pCi/g) 57

Figure 6.12 Postplot of KESI residuals (pCi $/ \mathrm{g}) \quad 58$

$\begin{array}{lll}\text { Figure A.1 In situ measurement locations at MFC facility } & 67\end{array}$

Figure A.2 In situ measurement locations at NRF facility 68

Figure A.3 In situ measurement locations at RTC facility 69

$\begin{array}{lll}\text { Figure A.4 In situ measurement locations at TAN facility } & 70\end{array}$

Figure A.5 In situ measurement locations at RWMC facility 71

$\begin{array}{lll}\text { Figure A.6 In situ measurement locations at INTEC facility } & 72\end{array}$

Figure A.7 In situ measurement locations at CITRC facility 73

$\begin{array}{lll}\text { Figure A.8 In situ measurement locations at ARA facility } & 74\end{array}$

Figure A.9 In situ Large Grid measurement locations 75

$\begin{array}{lll}\text { Figure A.10 All In situ sampling locations } & 76\end{array}$

$\begin{array}{lll}\text { Figure B.1 Soil classification map } & 77\end{array}$

$\begin{array}{lll}\text { Figure B.2 } & \text { Elevation classification map } & 78\end{array}$

$\begin{array}{lll}\text { Figure B.3 Slope classification map } & 79\end{array}$ 
$\begin{array}{lll}\text { Figure B.4 Aspect classification map } & 80\end{array}$

$\begin{array}{lll}\text { Figure B.5 Wind classification map } & 81\end{array}$

$\begin{array}{lll}\text { Figure B.6 Cs-137 classification map } & 82\end{array}$

Figure C.1 Complementary covariance plot at $35^{\circ}$ (major range) 83

Figure C.2 Complementary covariance plot at $125^{\circ}$ (minor range) 83

Figure C.3 Fitted range ellipse for directional complementary covariance $\quad 84$ 


\section{Table of Tables}

$\begin{array}{lll}\text { Table 2.1 Soil depth distribution calculation } & 15\end{array}$

$\begin{array}{lll}\text { Table } 3.1 & \text { Soil classifications across the INL study area } & 21\end{array}$

$\begin{array}{lll}\text { Table } 3.2 & \text { Elevation classifications } & 22\end{array}$

$\begin{array}{lll}\text { Table } 3.3 & \text { Slope classifications } & 23\end{array}$

$\begin{array}{lll}\text { Table } 3.4 & \text { Aspect classifications } & 24\end{array}$

Table 3.5 Summary of wind-factor ellipse modeling 27

$\begin{array}{lll}\text { Table } 3.6 & \text { Wind factor classifications } & 28\end{array}$

Table $3.7 \quad$ Cs-137 classifications 29

$\begin{array}{lll}\text { Table 5.1 Results of regression analysis } & 37\end{array}$ 


\section{Glossary of Terms}

\begin{tabular}{|c|c|}
\hline ARA & Auxiliary Reactor Area \\
\hline CITRC & Critical Infrastructure Test Range Complex \\
\hline DOE & Department of Energy \\
\hline DEM & Digital Elevation Model \\
\hline EBR & Experimental Breeder Reactor \\
\hline EPA & Environmental Protection Agency \\
\hline GIS & Geographic Information System \\
\hline GPS & Global Positioning System \\
\hline GWR & Geographic Weighted Regression \\
\hline HPGe & High Purity Germanium \\
\hline INL & Idaho National Laboratory \\
\hline INTEC & Idaho Nuclear Technology and Engineering Center \\
\hline KESI & Kriging with Exhaustive Secondary Information \\
\hline MFC & Material Fuel Complex \\
\hline NIST & National Institute of Standards and Technology \\
\hline NOAA & National Oceanic and Atmospheric Administration \\
\hline NRF & Naval Reactor Facility \\
\hline PBF & Power Burst Facility \\
\hline RWMC & Radioactive Waste Management Complex \\
\hline RTC & Reactor Technology Complex \\
\hline TAN & Test Area North \\
\hline USGS & United States Geological Survey \\
\hline
\end{tabular}




\section{INTRODUCTION AND BACKGROUND}

Continuing experimental research and operation of nuclear activities will require advanced environmental monitoring techniques to comply with rigorous environmental regulations. In an effort to reduce costs, but maintain compliance standards, the Idaho National Laboratory (INL) desires the ability to optimize its environmental monitoring program. Current environmental monitoring is expensive, tedious, and potentially hazardous. Refining the monitoring scheme could reduce time, costs, and risks associated with environmental monitoring, and allow available resources to target areas with the highest priority.

The Idaho National Laboratory (INL) is a United States government facility overseen by the Department of Energy (DOE). The INL site is located in southeast Idaho (Figure 1.1) and covers approximately $2300 \mathrm{~km}^{2}\left(890 \mathrm{mi}^{2}\right)$. It is a center for scientific research, including projects focused on nuclear power and energy. As part of the INL mission to ensure national energy security with safe, competitive, and sustainable energy systems, the INL is required by the DOE to conduct on-site environmental monitoring of anthropogenic radionuclides, including Cs-137 (US DOE, 2008).

\subsection{Importance of Monitoring Cs-137}

Within the past 70 years, nuclear activities such as atmospheric weapons testing, the Chernobyl accident, and radioactive spent fuel reprocessing, have resulted in the release of significant amounts of anthropogenic radionuclides into the environment, including Cs-137 (ICRU, 1994). As a primary product of the fission of U-235, Cs-137 is present in INL soils due to atmospheric weapons testing and nuclear activities that have occurred at the INL site 
since the late 1940s. The presence of Cs-137 in the environment raises particular concern because of its persistence and its ability to emit penetrating gamma radiation.

\section{Idaho National Laboratory Location}
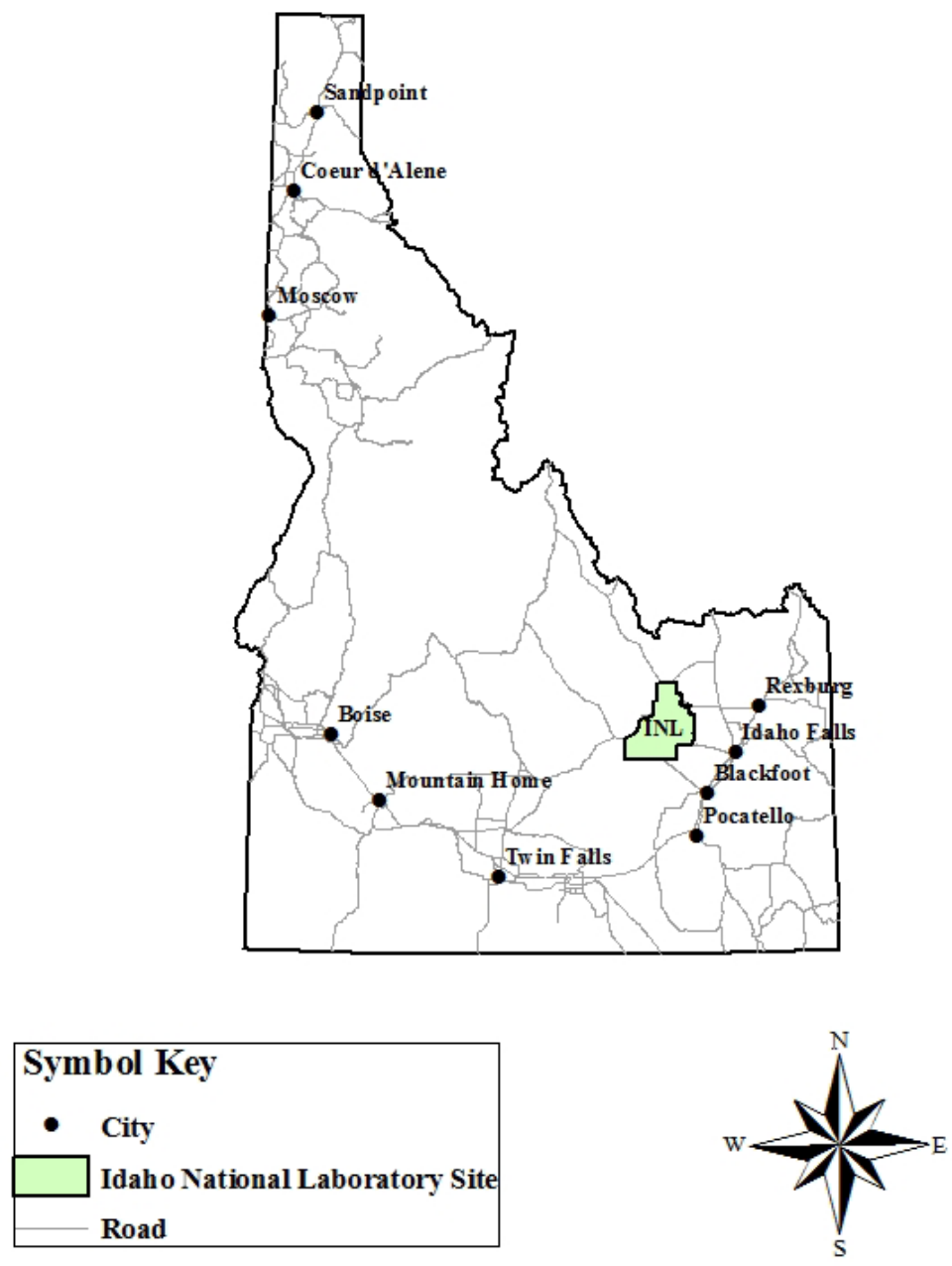

Figure 1.1. INL site location in eastern Idaho. 
Ionizing radiation like the gamma rays released in the radioactive decay of Cs-137 can cause serious damage to living tissue. Gamma rays are high-energy photons of very high frequency. Unlike other forms of radiation, the probability of gamma radiation interacting with matter is low. However, when gamma rays collide with matter, a large amount of energy is transferred, creating ionized electrons and causing secondary ionizations. If the interacting material is living tissue, the reactionary chain of secondary ionization results in cell damage. With a half-life of over thirty years, Cs-137 lingers long enough in the environment to pose a significant threat to living organisms by increasing the likelihood of cancer imposed by cell mutations caused by secondary ionizations.

As a source of gamma radiation, the radioactive decay of Cs-137 is a two-stage process. Initially, Cs-137 undergoes beta decay to produce short lived Ba-137m. Within seconds, Ba-137m emits $661.66 \mathrm{KeV}$ of gamma radiation to as it transitions to stable Ba-137 (Figure 1.2) (Oertel and Giles, 2007).

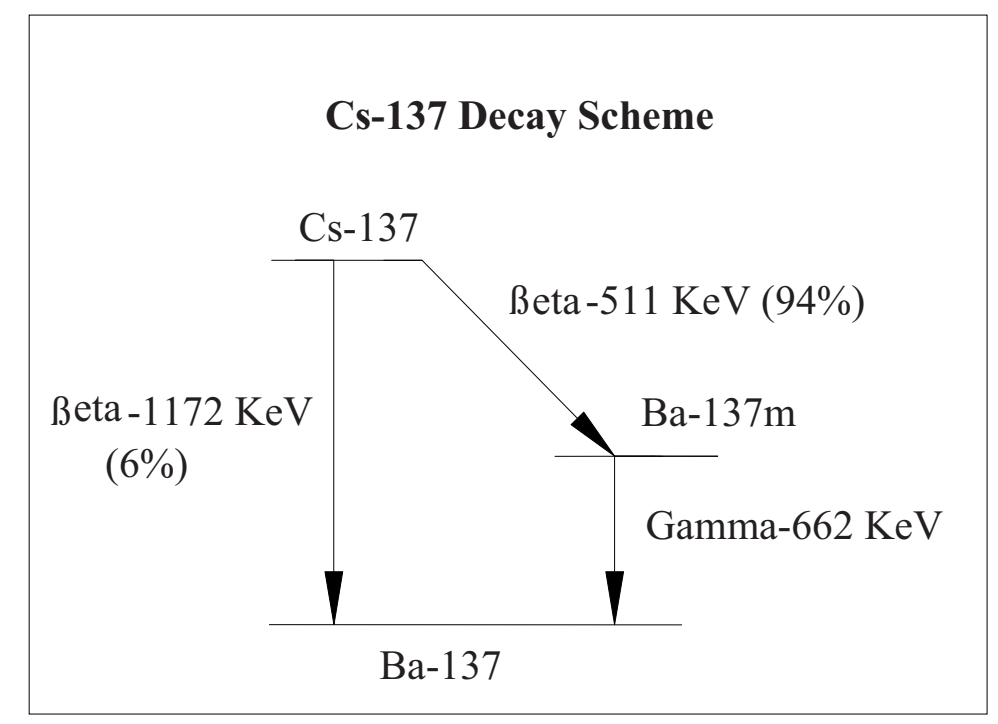

Figure 1.2. Cs-137 decay scheme. 
Since Cs-137 emits gamma radiation, it is considered an environmental hazard. For INL soils, the Environmental Protection Agency (EPA) has defined a risk threshold of 0.23 pCi/g of Cs-137. This threshold was established based on the probability of exceeding a 1.0 E-06 likelihood of premature death induced by cancer in a 30-year external exposure residential scenario (Fromm, 1996). Even though the INL is required to meet this standard, a study conducted in 1996 reported Cs-137 soil concentrations in certain areas well above the threshold at $0.44 \mathrm{pCi} / \mathrm{g}$ (Hood et al., 1996). Areas exceeding the established threshold potentially require additional monitoring or mitigation proceedings.

\subsection{Radionuclide Monitoring at the INL}

Environmental monitoring of radionuclides has been conducted throughout the history of the INL. For example, in 1949 the Health and Safety Division of the Idaho Operations of the Atomic Energy Commission performed a background analysis of radionuclides in the soil before the presence of nuclear reactors. Then in 1959, 1965, 1974, 1982, and 1990, aerial radiological surveys were conducted to characterize radioactivity at facilities and surrounding areas (US DOE, 2008). Recently, in situ monitoring utilizing standard gamma ray spectroscopy has been used to quantify Cs-137 soil concentrations (Oertel and Giles, 2007). Actual field sampling of Cs-137 began in the 1980's and continues to be the current protocol for environmental radionuclide monitoring because of its ability to accurately characterize low-level radiation.

Current in situ sampling occurs on an annual basis at locations specified by a preferential sampling configuration. The locations of sampling were selected based on historical placement and vehicle accessibility, because the rugged landscape with minimal 
roads and restricted access limits measurement capabilities to approximately 300 sampling locations during the available field monitoring season (June to September). In 2006, the sampling program included 290 locations. In 2007 and 2008, 342 locations were sampled each year. The new locations added after 2006 were strategically placed to improve the overall site monitoring coverage (Oertel and Giles, 2007).

In accordance with the INL mission and DOE standards, monitoring results are presented in annual reports. Prior to 2006, sampling results were reported with basic statistics that included global means and standard deviations. In 2006, geostatistical methods were applied to the Cs-137 data to investigate spatial dependence and compute estimates at unsampled locations. In 2007 and 2008, more substantial geostatistical analysis techniques were applied to the data including statistical declustering methods. It must be noted however, that reported data obtained prior to 2006 may be unreliable due to unavailable or uncertain documentation on data collection procedures and analysis (Oertel and Giles, 2007).

\subsection{Project Objectives}

The goal of this project is to increase the understanding of Cs-137 distribution at the INL through spatial analysis and mapping, which can lead to more efficient sampling programs. The specific objectives of this thesis project were the following:

1. Collect and analyze Cs-137 spectrum and soil samples for 2008 and 2009;

2. Develop a GIS database of particular environmental factors that may influence Cs137 concentrations in soils;

3. Use GIS to process Bayesian calculations for Cs-137 concentrations and environmental factors, leading to a spatial estimation map of Cs-137 "severity"; 
4. Conduct geostatistical analyses and point kriging to map Cs-137 concentrations and compare these results to those of another kriging method that can incorporate secondary information in the form of the environmental Bayesian scores; and

5. Provide recommendations to enhance future environmental sampling procedures. 


\section{DATA COLLECTION AND TESTING}

In accordance with project objectives, in situ gamma ray spectroscopy techniques were used to collect and analyze Cs-137 spectrum and soil samples for 2008 and 2009. For several decades, gamma ray spectroscopy has been used for environmental monitoring, environmental remediation, and other processes requiring the measurement of radioactivity in the environment. As a result, in situ gamma ray spectroscopy is a widely accepted technique for measuring gamma emitting radionuclides in soil and air (ICRU, 1994).

\subsection{Gamma Ray Spectroscopy}

A gamma ray spectroscopy system is a highly complex analytical tool. At the INL, the gamma ray spectroscopy system consists of several components including, a high purity germanium (HPGe) detector, an electronic pulse amplification mechanism, an electronic pulse height analysis mechanism, and a computer for data processing (ICRU, 1994).

Specific HPGe detectors are used for environmental monitoring at the INL because they are able to distinguish and identify distinct radionuclides like Cs-137 (Figure 2.1). Germanium detectors are comprised of germanium crystals attached to a vacuum cryostat and a Dewar vessel filled with liquid nitrogen. Essentially, HPGe detectors operate as reversed biased semi-conductor diodes that interact with the energy released from the radioactively decaying material (ICRU, 1994). Energy (photons) released from the radioactive material produce electron-hole pairs in the germanium crystals of the HPGe detectors (Knoll, 2000). The multichannel analyzer attached to the detector identifies the voltage and converts it to a digital signal. Further analysis calculates the concentration of radioactive material from the number of digitized signals at specific energy intervals using a 
specialized software program (ICRU, 1994). The liquid nitrogen cools the detectors while the system is operating to prevent system failure due to overheating.

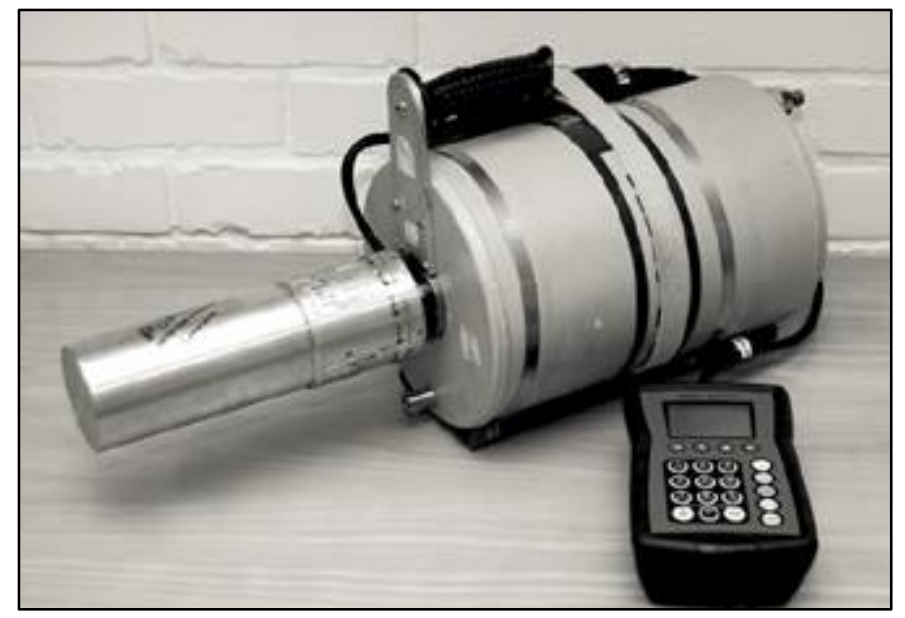

Figure 2.1. High Purity Germanium (HPGe) detector.

\subsection{Analysis and Quantification of Environmental Radionuclides}

The analysis of radionuclides in soil is performed using a multiple-stage process.

First, a calibrated spectrum must be acquired and analyzed for energy and peak characteristics. Next, in situ field sampling must be conducted to obtain count rate per unit energy. Finally, analysis can be performed by using Beck's method by applying a calibration factor to the raw count rate to calculate a concentration per unit mass (Ortec, 2007). 
The calibration factor is affected by the configuration of the detector, the characteristics of the source, and the relationship between the source and the detector. The total calibration factor is given by Equation 2.1:

$$
\frac{N_{f}}{A_{m}}=\frac{N_{0}}{\varphi} \cdot \frac{N_{f}}{N_{0}} \cdot \frac{\varphi}{A_{m}}
$$

In this equation, $\frac{N_{f}}{A_{m}}$ is the peak count rate per unit concentration at field conditions, $\frac{N_{0}}{\varphi}$ is the count rate per unit fluence rate calculated using National Institute of Standards and Technology (NIST) traceable sources at laboratory conditions (detector dependent), $\frac{N_{f}}{N_{0}}$ is the angular correcting factor (detector and source dependent), and $\frac{\varphi}{A_{m}}$ is the fluence rate at the detector per unit concentration (source dependent). The angular correction factor accounts for the reduction of gamma ray detection with increasing distance from the detector. The fluence rate at the detector per unit concentration is estimated by a function of the source distribution $\left(\frac{\alpha}{\rho}\right)$ which is incorporated within the photon attenuation term, $\left(\frac{\varphi}{A_{m}}\right)$ in the equation. The source distribution includes the radionuclide soil depth distribution caused by non-uniform dispersion. For anthropogenic radionuclides like Cs-137 the soil depth distribution usually follows an exponentially declining function. In specific situations however, an exponential function may be unrealistic due to environmental characteristics and meteorological influences (Sowa et al., 1989). As a result, the depth distribution can be calculated by analyzing soil samples at particular depth intervals for specific activity per mass of soil. 


\subsection{Field Sampling Methods}

To investigate the spatial distribution of Cs-137 across the INL and the association of environmental factors with high levels of Cs-137, the standard INL protocol for environmental radionuclide monitoring was used. In situ gamma spectrum measurements were collected annually at the INL site around eight different facilities (Figure 2.2). The facilities included the Material Fuel Complex (MFC), Naval Reactor Facility (NRF), Reactor Technology Complex (RTC), Test Area North (TAN), Radioactive Waste Management Complex (RWMC), Idaho Nuclear Technology and Engineering Center (INTEC), Critical Infrastructure Test Range Complex (CITRC), and Auxiliary Reactor Area (ARA) (Appendix A). Additional measurements also were acquired systematically across the entire area encompassing the INL site. The term "Large Grid" was used to reference these measurement locations that did not correspond to a specific facility. 


\section{Idaho National Laboratory Site Facilities}

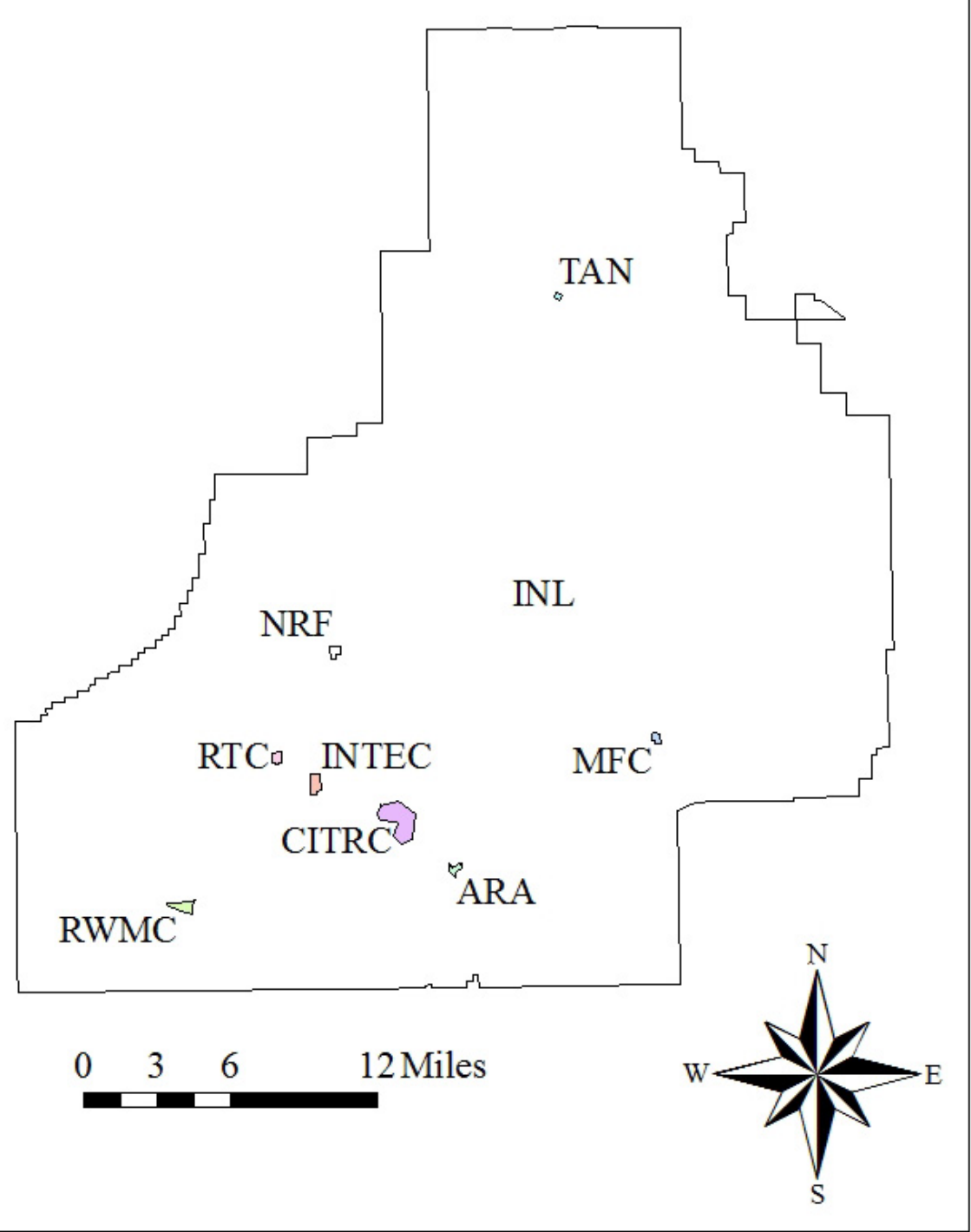

Figure 2.2. INL facility locations. 
At specified measurement locations, HPGe detectors were placed on a tripod $1 \mathrm{~m}$ above the ground surface (Figure 2.3) and allowed to count for 1 hour (3600 seconds). At this configuration, the radial range of detection was approximately $10 \mathrm{~m}$ from the point of measurement.

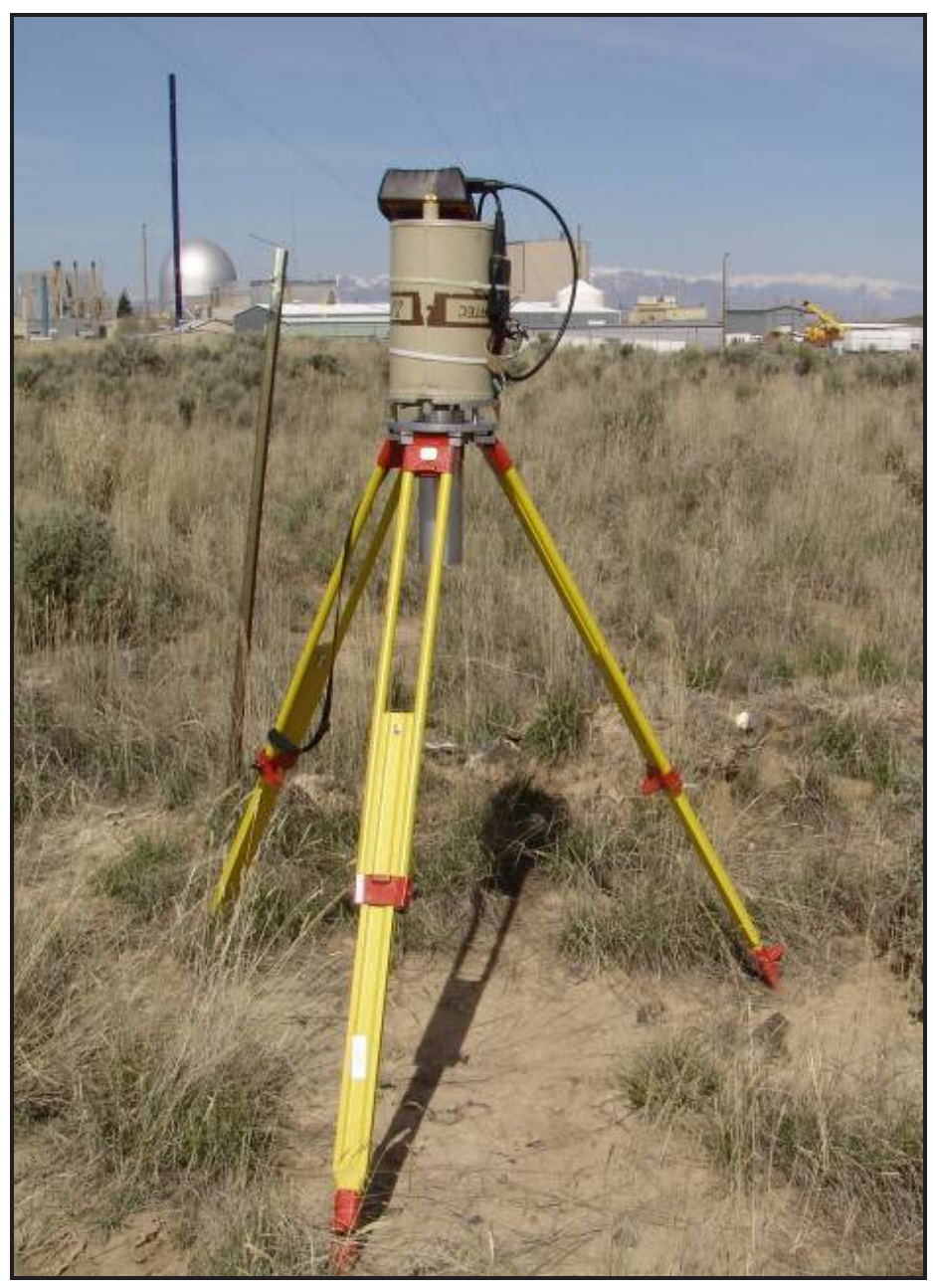

Figure 2.3. HPGe configuration for in situ measurements. 
Strict quality assurance standards were followed for in situ measurements. Yearly calibrations and daily tests with National Institute of Standards and Technology (NIST) traceable sources were performed on all eight HPGe detectors used for measurements. Duplicate measurements with different detectors were also collected and analyzed to ensure accurate results. Approximately 10 percent of the samples are points that were recounted for quality assurance and an additional 10 percent of the points were counted at longer periods of time ranging from 30,000 to 50,000 seconds to improve uncertainty associated with the 1hour count rate.

\subsection{Depth Distribution Sampling}

In order to capture an accurate depiction of the amount of Cs-137 present in soil, the physical distribution of radionuclides as a function of soil depth was also evaluated. Gamma rays emitted deeper in the soil are attenuated by particles therefore reducing the overall concentration calculated. Generally an exponential distribution is assumed for anthropogenic radionuclides, but a more accurate representation of radioisotope concentration can be obtained through soil-depth analysis.

Soil samples were collected at varying in situ spectrum acquisition locations of the Large Grid and all facilities. Samples were collected in a circular pattern at $0 \mathrm{~m}, 2 \mathrm{~m}, 4 \mathrm{~m}$, and $10 \mathrm{~m}$ radii (Figure 2.4). One sample was taken at $0 \mathrm{~m}$ and three samples were taken at $2 \mathrm{~m}, 4 \mathrm{~m}$ and $10 \mathrm{~m}$ for a total of ten samples per location. The ten samples were combined to produce an overall representative sample of soil around each measurement site. 


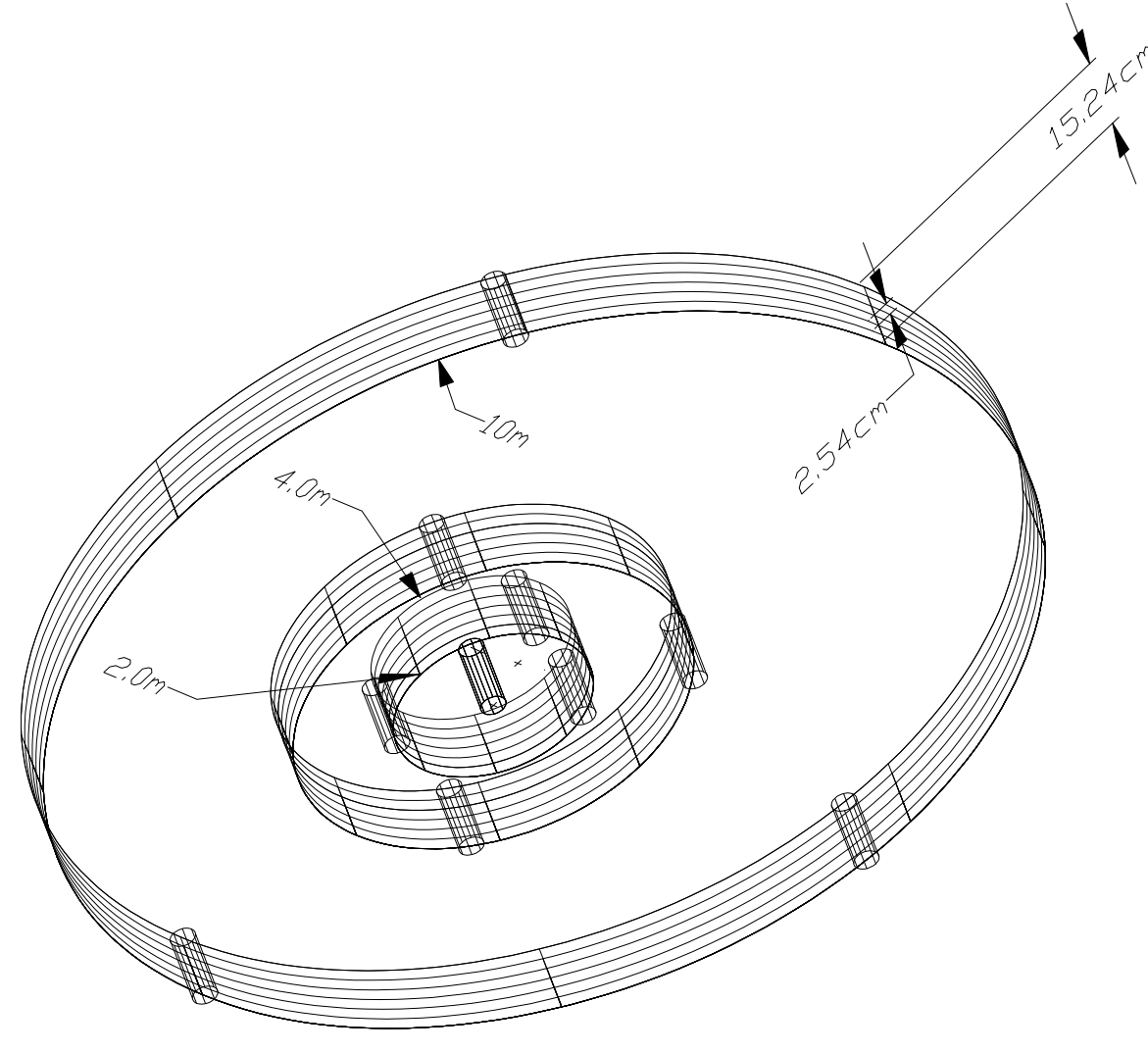

Figure 2.4. Soil puck sampling scheme.

To obtain soil samples, a split-spoon sampling tube attached to a metal rod was driven into the ground to a depth of $15.24 \mathrm{~cm}$ (6 in). The split-spoon apparatus contained plastic rings that divided the soil sample into six $2.54 \mathrm{~cm}(1 \mathrm{in})$ disks. The disks were placed into specimen bags labeled 0-2.54cm (0-1 in), 2.54-5.08cm (1-2in), 5.08-7.62 cm (2-3in), $7.62-10.16 \mathrm{~cm}(3-4 \mathrm{in}), 10.16-12.70 \mathrm{~cm}(4-5 \mathrm{in})$, and $12.70-15.24 \mathrm{~cm}(5-6 \mathrm{in})$. In the laboratory each specimen bag was weighed. Afterwards, an aliquot of each specimen was formed into a soil puck and weighed again. Then, one at a time, each soil puck was placed in a columinated (shielded) gamma spectroscopy system for spectra acquisition and analysis. The 
puck analysis provided specific activity for each puck per unit mass of soil in the soil puck. Multiplying the specific activity per unit mass of the soil puck by the total sample mass yielded the depth total activity. This procedure was followed for each depth interval for each soil puck measurement location.

\subsection{Analysis of Testing Results}

The overall total activity was calculated by taking the summation of all depth specific activities and converted to factional activity of each depth by dividing the depth total activity by the overall total activity. The mass depth of the sample mass was calculated by dividing by the total sample area $\left(178.10 \mathrm{~cm}^{2}\right)$ of the ten combined samples. Fractional activity below mass depth was calculated by subtracting fractional activity from one (Table 2.1). The fractional activity below mass depth was plotted versus mass depth to give the soil depth distribution. A regression analysis was used to fit the curve to an exponential function for use in the radionuclide concentration calculation (Figure 2.5).

Table 2.1. Soil depth distribution calculation.

\begin{tabular}{|c|c|c|c|c|c|c|c|c|}
\hline \multicolumn{9}{|c|}{ Soil Depth Distribution } \\
\hline $\begin{array}{l}\text { Depth } \\
\text { Interval }\end{array}$ & $\begin{array}{l}\text { Specific } \\
\text { Activity }\end{array}$ & $\begin{array}{c}\text { Sample } \\
\text { Mass }\end{array}$ & $\begin{array}{c}\text { Depth } \\
\text { Total } \\
\text { Activity }\end{array}$ & $\begin{array}{c}\text { Overall } \\
\text { Total } \\
\text { Activity }\end{array}$ & $\begin{array}{c}\text { Total } \\
\text { Sample } \\
\text { Area } \\
\end{array}$ & $\begin{array}{c}\text { Mass } \\
\text { Depth, } \\
\rho z\end{array}$ & $\begin{array}{l}\text { Fraction } \\
\text { Activity }\end{array}$ & $\begin{array}{c}\text { Fractional } \\
\text { Activity } \\
\text { Below } \rho z \\
\end{array}$ \\
\hline$(\mathrm{cm})$ & $(\mathrm{pCi} / \mathrm{g})$ & (g) & (pCi) & (pCi) & $\left(\mathrm{cm}^{2}\right)$ & $\left(\mathrm{g} / \mathrm{cm}^{2}\right)$ & & \\
\hline 2.54 & 1.22 & 572 & 697.84 & & 178.1 & 3.21 & 0.38 & 0.622 \\
\hline 5.08 & 0.811 & 702 & 569.32 & & 178.1 & 7.15 & 0.69 & 0.313 \\
\hline 7.62 & 0.335 & 676 & 226.46 & & 178.1 & 10.95 & 0.81 & 0.19 \\
\hline 10.16 & 0.175 & 650 & 113.75 & & 178.1 & 14.6 & 0.87 & 0.129 \\
\hline 12.7 & 0.113 & 728 & 82.26 & & 178.1 & 18.69 & 0.92 & 0.084 \\
\hline 15.24 & 0.211 & 736 & 155.3 & 1844.9 & 178.1 & 22.82 & 1 & 0.042 \\
\hline
\end{tabular}




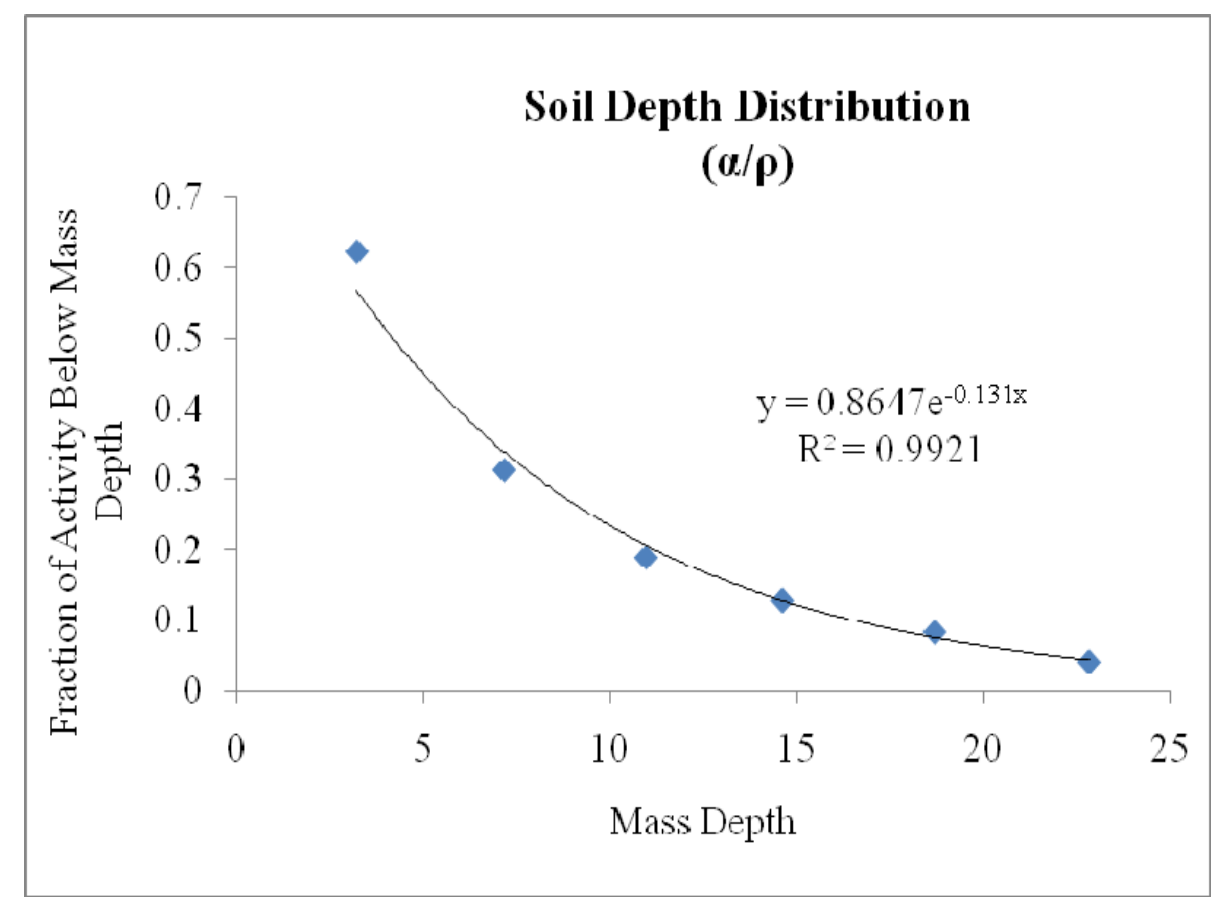

Figure 2.5. Soil depth distribution $(\alpha / \rho)$.

Final values for the Cs-137 concentration based on the gamma ray spectrometry measurements were calculated by dividing the raw count rate captured by the detector at 662 $\mathrm{KeV}$ (Figure 2.6) by the total calibration factor $\frac{N_{f}}{A_{m}}$ (recall Equation 2.1).

The final calculation results for Cs-137 concentrations in soils at the in situ sampling sites are summarized in Figures 2.7 through 2.10 for the field sampling programs conducted in 2006, 2007, 2008, and 2009. These statistical summaries show the relative frequency of Cs-137 measured concentrations the locations of sampling. 


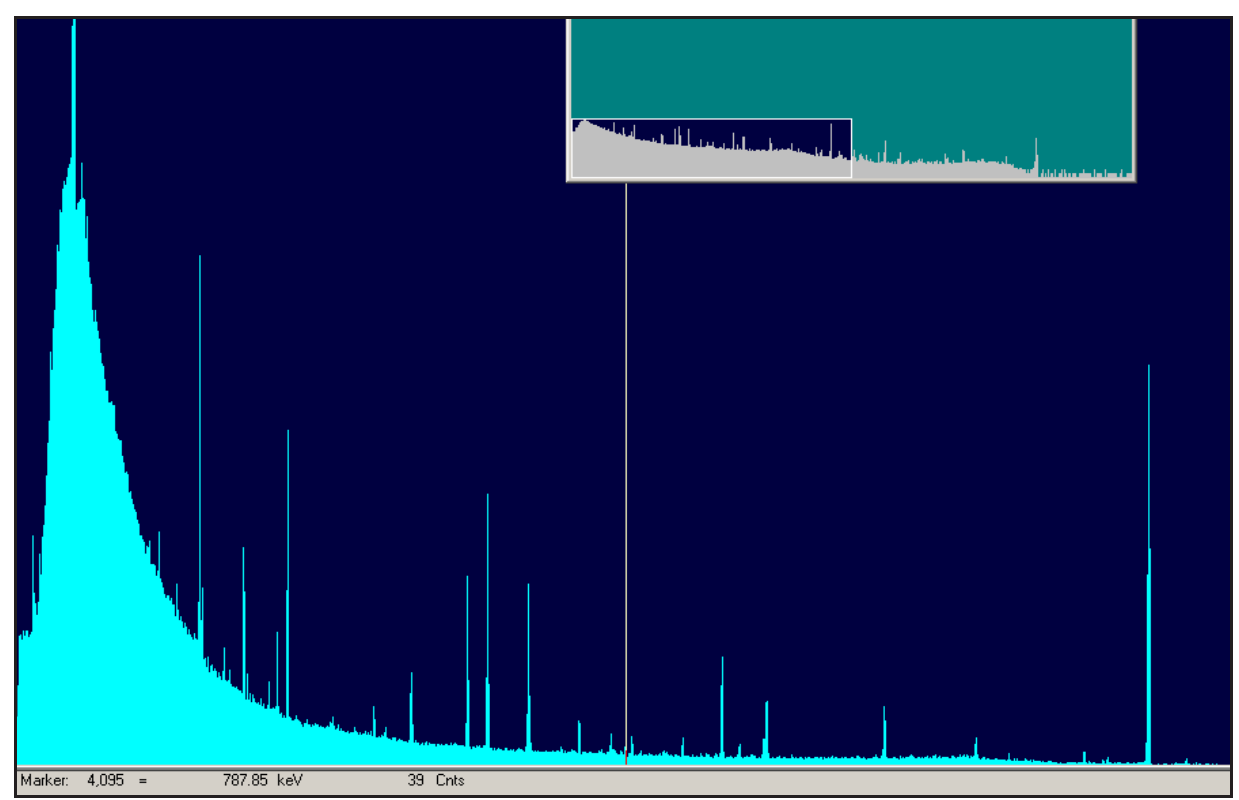

Figure 2.6. Gamma spectrum collected by HPGe detector.

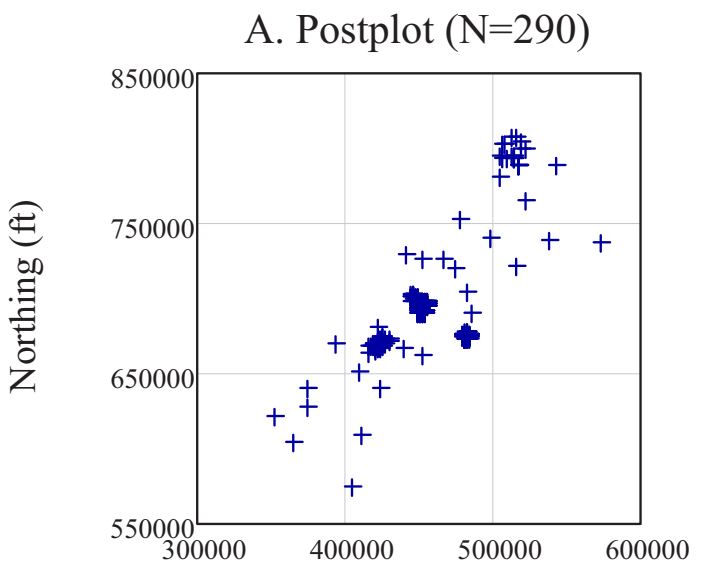

Easting (ft)

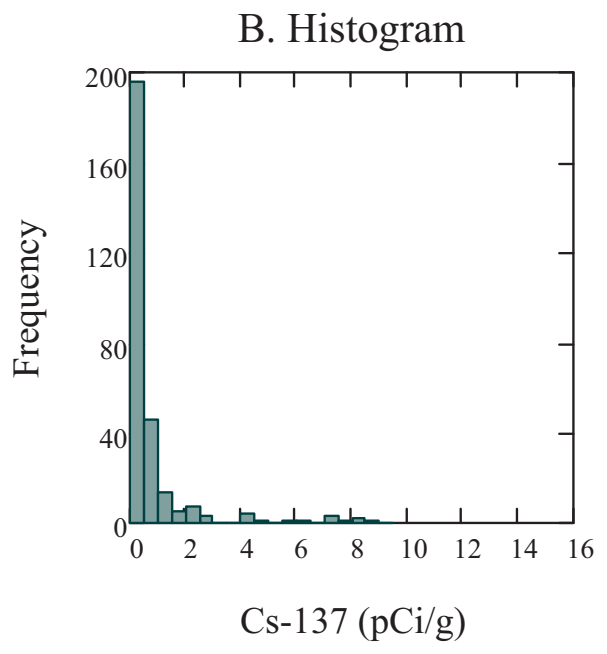

zmin $:=\min (\mathrm{z})=0.00028 \mathrm{pCi} / \mathrm{g} \quad$ zmean $:=\operatorname{mean}(\mathrm{z})=0.952 \mathrm{pCi} / \mathrm{g} \quad$ zmed $:=\operatorname{median}(\mathrm{z})=0.273 \mathrm{pCi} / \mathrm{g}$ zmax:= $\max (\mathrm{z})=17.310 \quad$ pCi $/ \mathrm{g} \quad$ zsd $:=\operatorname{stdev}(\mathrm{z})=2.187 \quad \mathrm{pCi} / \mathrm{g} \quad$ zskew $:=\operatorname{skew}(\mathrm{z})=4.464$

Figure 2.7. Statistical summary of Cs-137 data collected in 2006: A. Postplot of all sampling sites; B. Histogram of all data. 
A. Postplot $(\mathrm{N}=342)$

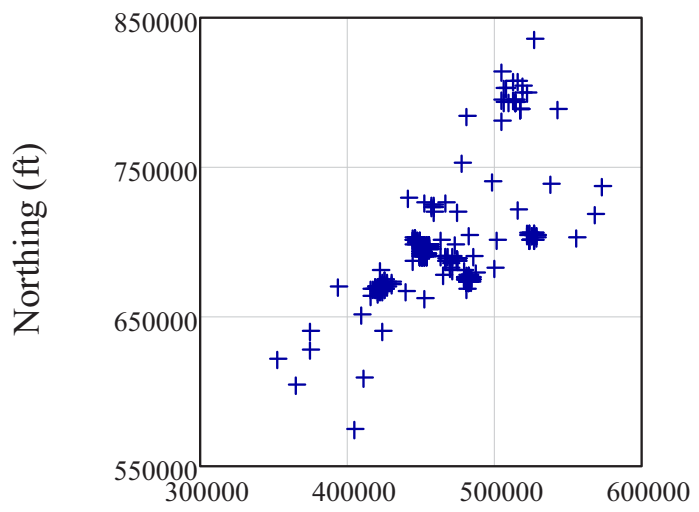

Easting (ft)
B. Histogram

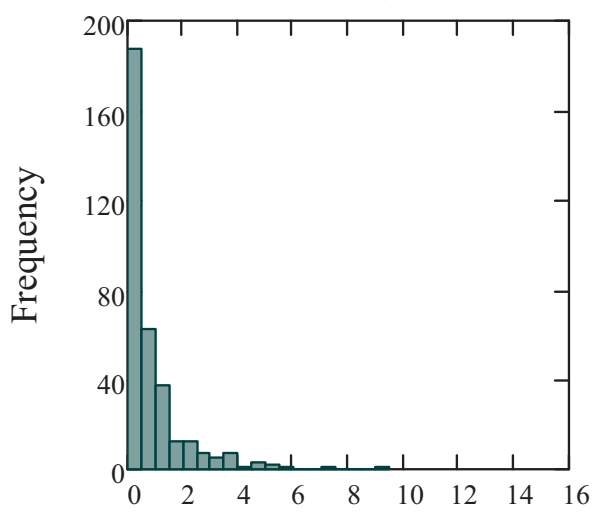

Cs-137 (pCi/g)

$\mathrm{zmin}:=\min (\mathrm{z})=0.02000 \mathrm{pCi} / \mathrm{g} \quad$ zmean $:=\operatorname{mean}(\mathrm{z})=1.019 \mathrm{pCi} / \mathrm{g} \quad \mathrm{zmed}:=\operatorname{median}(\mathrm{z})=0.415 \mathrm{pCi} / \mathrm{g}$

zmax:= $\max (\mathrm{z})=49.000 \quad \mathrm{pCi} / \mathrm{g} \quad \mathrm{zsd}:=\operatorname{stdev}(\mathrm{z})=2.835 \quad \mathrm{pCi} / \mathrm{g} \quad$ zskew $:=\operatorname{skew}(\mathrm{z})=14.416$

Figure 2.8. Statistical summary of Cs-137 data collected in 2007: A. Postplot of all sampling sites; B. Histogram of all data except for an outlier of $49 \mathrm{pCi} / \mathrm{g}$.

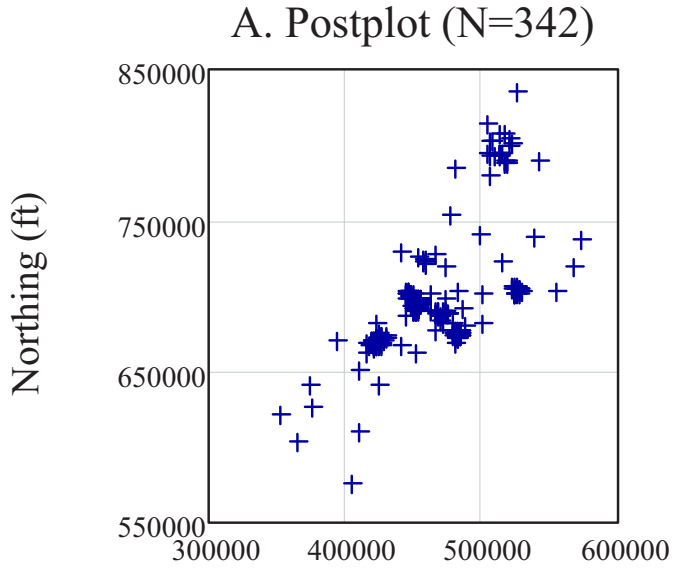

Easting (ft)

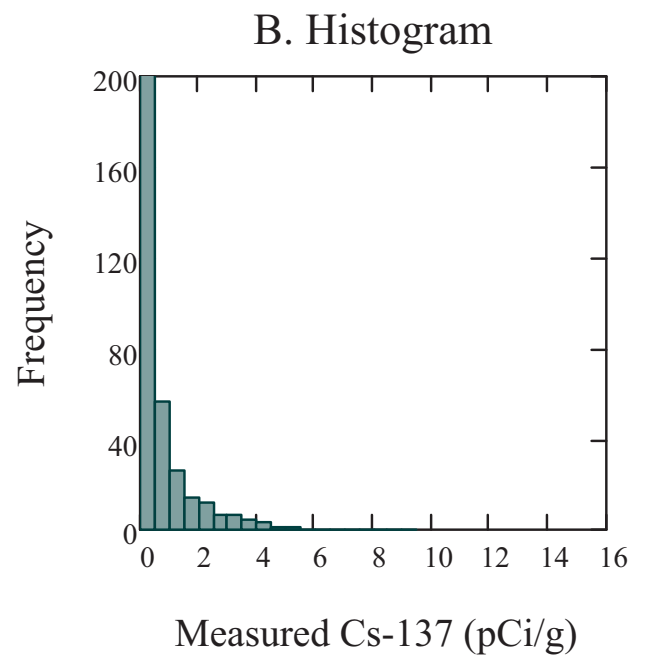

$\begin{array}{lllll}\text { zmin }:=\min (\mathrm{z})=0.01300 & \mathrm{pCi} / \mathrm{g} & \text { zmean }:=\operatorname{mean}(\mathrm{z})=0.738 \mathrm{pCi} / \mathrm{g} & \mathrm{zmed}:=\operatorname{median}(\mathrm{z})=0.242 & \mathrm{pCi} / \mathrm{g} \\ \mathrm{zmax}:=\max (\mathrm{z})=13.390 & \mathrm{pCi} / \mathrm{g} & \mathrm{zsd}:=\operatorname{stdev}(\mathrm{z})=1.129 & \mathrm{pCi} / \mathrm{g} & \text { zskew }:=\operatorname{skew}(\mathrm{z})=5.249\end{array}$

Figure 2.9. Statistical summary of Cs-137 data collected in 2008: A. Postplot of all sampling sites; B. Histogram of all data. 


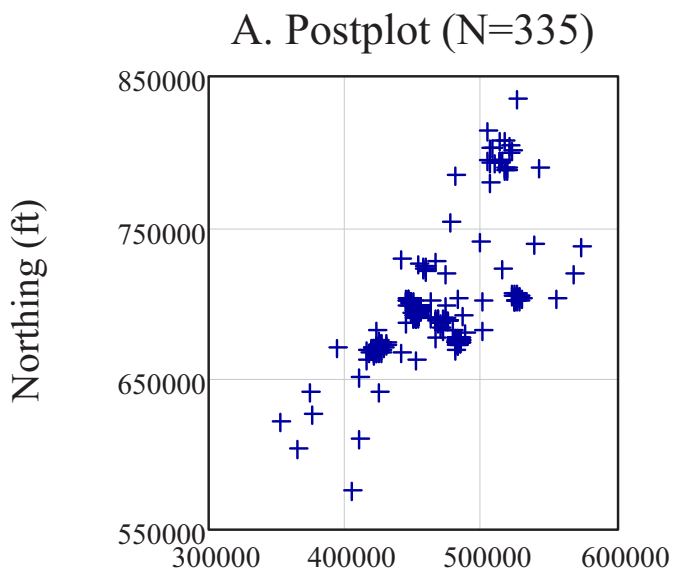

Easting (ft)

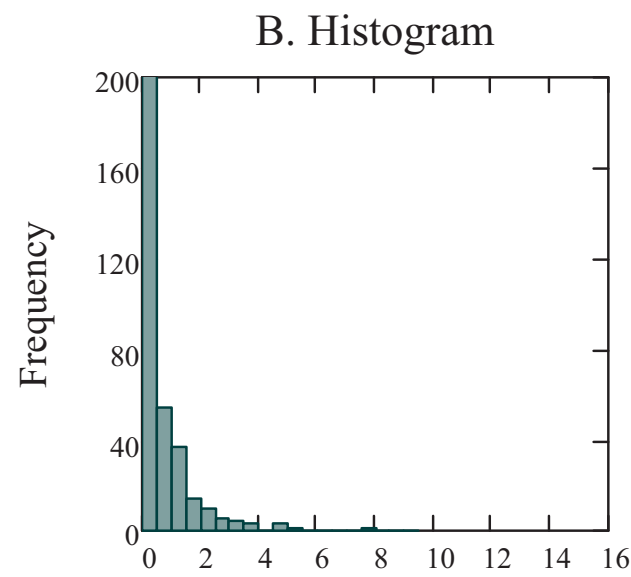

Measured Cs-137 (pCi/g)

$$
\begin{array}{lllll}
\text { zmin }:=\min (z)=0.02945 & \mathrm{pCi} / \mathrm{g} & \text { zmean }:=\operatorname{mean}(\mathrm{z})=0.718 \mathrm{pCi} / \mathrm{g} & \mathrm{zmed}:=\operatorname{median}(\mathrm{z})=0.311 & \mathrm{pCi} / \mathrm{g} \\
\mathrm{zmax}:=\max (\mathrm{z})=7.990 & \mathrm{pCi} / \mathrm{g} & \mathrm{zsd}:=\operatorname{stdev}(\mathrm{z})=0.946 & \mathrm{pCi} / \mathrm{g} & \text { zskew }:=\operatorname{skew}(\mathrm{z})=3.231
\end{array}
$$

Figure 2.10. Statistical summary of Cs-137 data collected in 2009: A. Postplot of all sampling sites; B. Histogram of all data.

In general, comparing individual sampling points of the 2006, 2007, 2008, and 2009 datasets reveals slight deviations from year to year. However, the overall mean concentration for the total area within the INL site differs significantly. This variation could be contributed to the preferential sampling scheme clustering the majority of sampling points around facilities. As a result the overall mean may not be representative of the true Cs-137 concentration and the spatial distribution must be taken in account. Both individual points and the overall mean do not vary significantly for the 2008 and 2009 datasets. As a result, the 2009 dataset will be used for further investigation. 


\section{ENVIRONMENTAL FACTORS}

Environmental factors including soil type, elevation, slope, aspect, and wind are believed to play a large role in the dispersal of Cs-137 across the INL site. To investigate the spatial distribution of Cs-137 across the INL and explore the association of environmental factors with high levels of Cs-137, six data layers were used. A 30-m digital elevation model (DEM) was used as the basis for analysis. The DEM was obtained from the INSIDE Idaho geospatial database. Slope and aspect layers were generated from the DEM using the spatial analyst tool within GIS. The soil information was obtained from INL in a topologically correct polygon shapefile. Wind information was acquired from National Oceanic and Atmospheric Administration (NOAA) weather stations located at the site and used to develop a data layer that incorporated wind direction, magnitude, and distance from facility. The wind direction and magnitude were extracted from NOAA wind records and interpolated to the study area. The wind data was based on an average ten-year time period at eight different weather stations. The Cs-137 soil concentration values were obtained from field measurements that were geographically referenced through GPS coordinates for 2008 and 2009, then converted into a point shapefile.

Before analysis could be conducted, the data layers were processed into a consistent projection. The NAD 83 Transverse Mercator was used as the unifying map projection, and the Cs-137 point measurements were used as the unified unit of analysis. A master file of all of the environmental factors at the Cs-137 sampling points was created using the spatial join and overlay applications. Due to the nature of the raster and polygon data (slope, aspect, elevation, soil, and wind), the information was classified into subgroups before it was extracted to the master file. The environmental factors were chosen based on their spatial 
data availability and their potential influence on Cs-137 transport, deposition, and resulting concentration levels in soils.

\subsection{Soil Type}

Soil characteristics are important to Cs-137 soil concentrations because they influence potential sorption and transport behavior. Soil information was obtained from the GIS department at the INL in a polygon data layer. Soil types were classified into nine categories specified by INL staff. The categories were based primarily on the soil texture and the geologic parent material underneath (Table 3.1).

Table 3.1. Soil classifications across the INL study area.

\begin{tabular}{|ll|}
\hline \multicolumn{2}{|c|}{ Soil } \\
\hline Group & Description \\
\hline 1 & Rocky outcrop (negligible soil cover) \\
2 & Fine-loamy soil over sandy or sand-cobble mix in floodplain regions \\
3 & Moderately deep to very deep silty and loamy windblown deposits \\
4 & Exposed lava or shallow loamy windblown sediments over lava \\
5 & Well drained loamy soils over limestone rubble (variable depth) \\
6 & Deep, fine silty and clayey deposits from ancient lakes \\
7 & Very deep coarse soils on alluvial fans \\
8 & Moderately coarse eolian or alluvial deposits on basalt field (variable depth) \\
9 & Coarse eolian deposits over basalt (variable depth) \\
\hline
\end{tabular}

\subsection{Elevation}

Elevation is important to $\mathrm{Cs}-137$ soil concentrations because it can influence physical characteristics, including the rate particulates undergo atmospheric deposition and the flow direction and rate of surface runoff containing soil particles. Elevation was extracted directly from a digital elevation model (DEM) provided by the United States Geological 
Survey (USGS) at the INSIDE Idaho geospatial database. Elevation was subdivided into nine groups based on the Jenks natural-breaks classification method applied to the data distribution (Table 3.2).

Table 3.2. Elevation classifications.

\begin{tabular}{|clc|}
\hline \multicolumn{3}{|c|}{ Elevation } \\
\hline Group & Range $(\mathrm{m})$ & Range $(\mathrm{ft})$ \\
\hline 1 & $1453-1481$ & $4768-4859$ \\
2 & $1481-1512$ & $4859-4963$ \\
3 & $1512-1542$ & $4963-5061$ \\
4 & $1542-1572$ & $5061-5159$ \\
5 & $1572-1600$ & $5159-5250$ \\
6 & $1600-1630$ & $5250-5348$ \\
7 & $1630-1683$ & $5348-5523$ \\
8 & $1683-1783$ & $5523-5852$ \\
9 & $1783-1996$ & $5852-6551$ \\
\hline
\end{tabular}

\subsection{Slope}

Slope describes the rate of change of elevation over a specific location. Slope has the potential to affect Cs-137 movement by influencing wind phenomena, geologic characteristics, and climate conditions. In the GIS database, slope was computed using the source DEM and the spatial analyst tool. A high slope indicates a rapid or steep incline while zero slope indicates flatness. The slope (in degrees) was subdivided into nine groups based on the Jenks natural-breaks classification method applied to the data distribution (Table 3.3). 
Table 3.3. Slope classifications.

\begin{tabular}{|cc|}
\hline \multicolumn{2}{|c|}{ Slope } \\
\hline Group & Range (Degrees) \\
\hline 1 & $0-0.58$ \\
2 & $0.58-1.75$ \\
3 & $1.75-3.31$ \\
4 & $3.31-5.64$ \\
5 & $5.64-9.55$ \\
6 & $9.55-15.21$ \\
7 & $15.21-22.03$ \\
8 & $22.03-29.83$ \\
9 & $29.82-49.71$ \\
\hline
\end{tabular}

\subsection{Aspect}

Aspect is an important environmental factor because it can have significant effects on local climate by influencing temperature, vegetation, and wind. Geographical aspect refers to the direction a slope faces. At the INL, aspect is believed to contribute to the collection of windblown soils and therefore could be an indicator of Cs-137 concentration in soils. The standard angular descriptions for aspect were input manually in order to reclassify aspect into the nine principal compass directions (Figure 3.1 and Table 3.4).

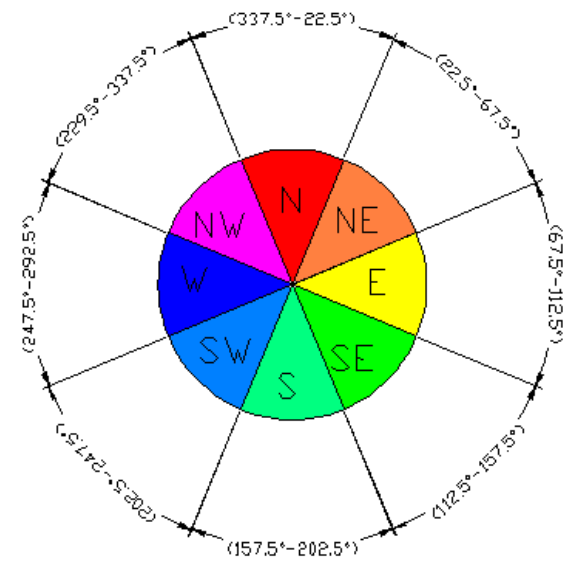

Figure 3.1. Aspect classification system. 
Table 3.4. Aspect classifications.

\begin{tabular}{|cll|}
\hline \multicolumn{2}{|c|}{ Aspect } \\
\hline Group & Description & Range (degrees) \\
\hline 1 & Flat & no slope \\
2 & North & $0.00-22.5$ and $337.5-360$ \\
3 & Northeast & $22.5-67.5$ \\
4 & East & $67.5-112.5$ \\
5 & Southeast & $112.5-157.5$ \\
6 & South & $157.5-202.5$ \\
7 & Southwest & $202.5-247.5$ \\
8 & West & $247.5-292.5$ \\
9 & Northwest & $292.5-337.5$ \\
\hline
\end{tabular}

\subsection{Wind}

Wind is important to the Cs-137concentrations because the primary mode of transport is through windblown soils. At the INL, wind generally displays a northeasterly trend, with a primary prevailing wind out of the southwest and secondary prevailing wind out of the northeast. A computed "wind factor" was developed for this study, based on the available wind rosette graphs for eight facility locations at the INL. The wind factor incorporates the magnitude, average annual distribution of wind directions, and distance from a facility. Raw wind measurements combined in the wind rosettes were extracted from the National Oceanic Atmospheric Administration (NOAA) weather program for the INL. Each wind rosette at each facility record contained at least five years of data obtained during the period of 1993 through 2006. An example of a facility wind rosette is shown in Figure 3.2. 


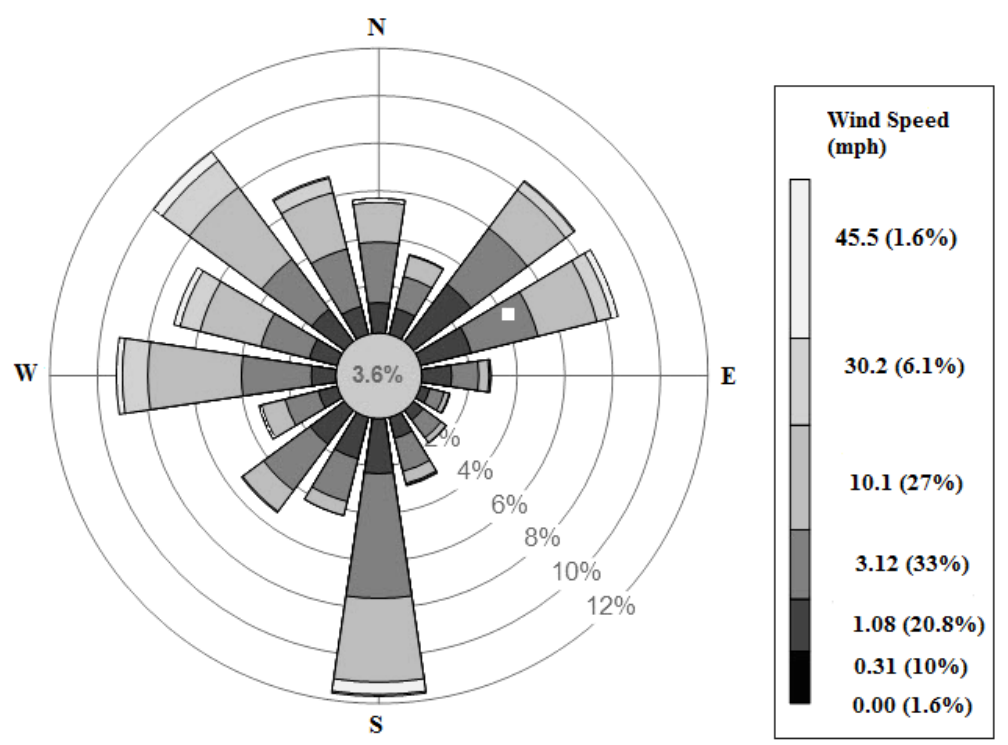

Figure 3.2. Generic example of a facility wind rosette.

The radial, wind-direction bars on each wind rosette were manually scaled to compute overall directional fractions. The direction of the largest single wind-direction bar (i.e., the long-term wind magnitude) was noted for each rosette graph. The facility having this largest magnitude was assigned a "scaled distance factor" of 0.995 out of a possible 1.0. The radial-bar magnitudes and directions from each rosette were plotted on a stereographic projection graph to standardize magnitudes, allowing an ellipse to be fitted visually to the plot.

The result was a scaled wind-factor ellipse for each facility that allowed the following key factors to be obtained: 1) major axis length, 2) minor axis length, 3) axis-anisotropy ratio (ratio of the major axis length divided by the minor axis length), 4) the angle (compass direction) to the major axis, and 5) the upwind shift of the wind ellipse (allows the computation of an upwind factor to scale-down the wind effects when comparing northeasterly to southwesterly wind conditions). An example of a fitted wind ellipse for the ARA facility wind rosette is illustrated in Figure 3.3. 


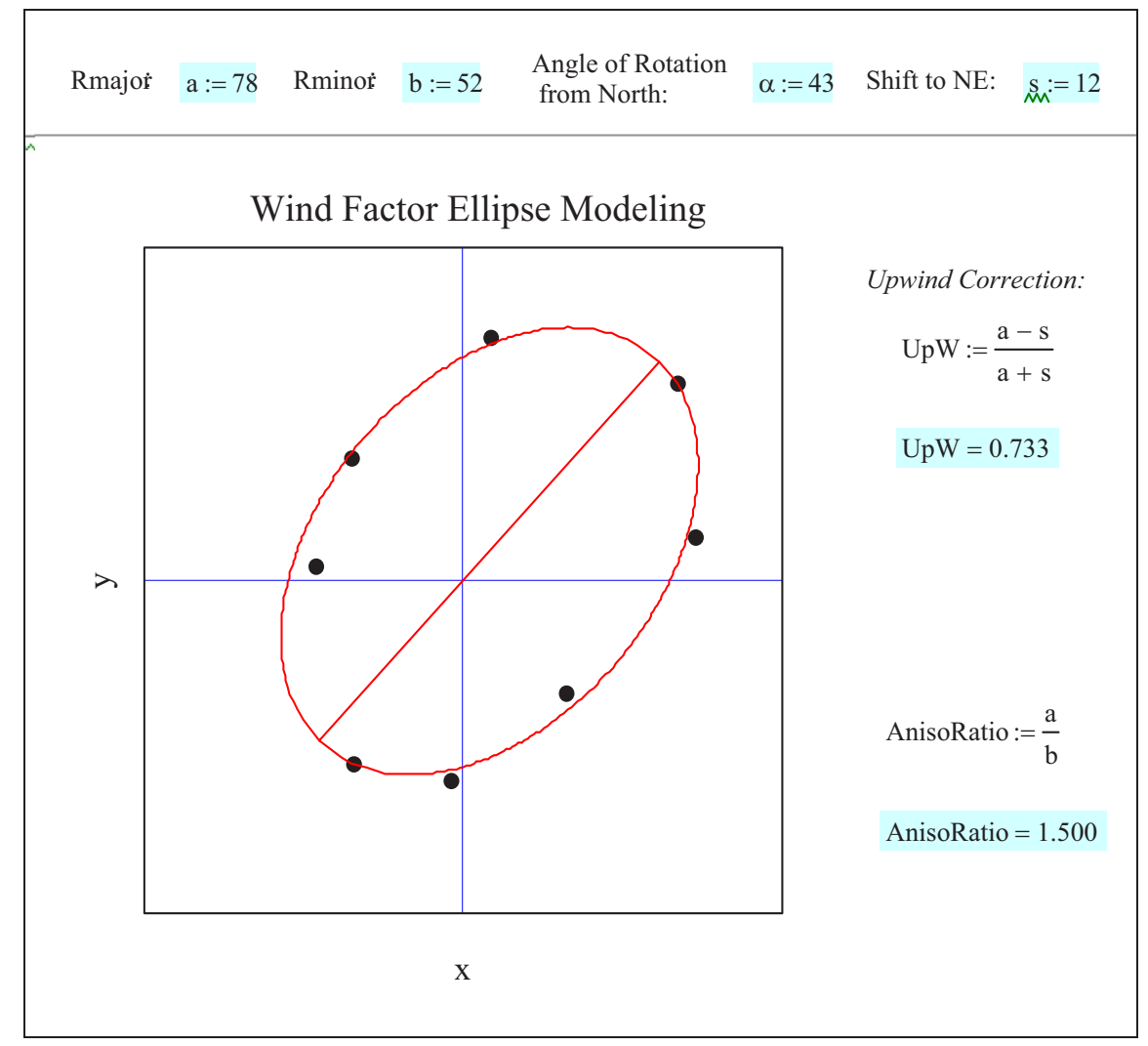

Figure 3.3. Scaled wind ellipse for the ARA facility.

After applying the above process to all eight facilities, the wind-factor ellipse models were obtained and converted to a standardized scale using the "scaled distance factor" as a substitute for the major axis of each ellipse and the axis-anisotropy ratio for the new minor axis of each ellipse. For example, the scaled distance factor for the ARA wind ellipse was 0.898, so this became the new major axis; and the minor axis was computed as:

$$
\text { Minor Axis }=0.898 /(\text { Anisotropy Ratio })=0.898 / 1.5=0.599
$$

Results of the wind-factor ellipse modeling for the eight INL facilities are summarized in Table 3.5. 
Table 3.5. Summary of wind-factor ellipse modeling.

\begin{tabular}{|cccccc|}
\hline Facility & Major Axis & Minor Axis & $\begin{array}{c}\text { Anisotropy } \\
\text { Ratio }\end{array}$ & $\begin{array}{c}\text { Angle to } \\
\text { Major Axis }\end{array}$ & $\begin{array}{c}\text { Upwind } \\
\text { Factor }\end{array}$ \\
\hline ARA & 0.898 & 0.599 & 1.500 & 43 & 0.733 \\
CITRC & 0.893 & 0.643 & 1.389 & 47 & 0.667 \\
INTEC & 0.914 & 0.597 & 1.531 & 42 & 0.648 \\
MFC & 0.995 & 0.600 & 1.658 & 40 & 0.560 \\
NRF & 0.888 & 0.543 & 1.634 & 40 & 0.618 \\
RTC & 0.914 & 0.625 & 1.462 & 45 & 0.634 \\
RWMC & 0.844 & 0.504 & 1.675 & 40 & 0.694 \\
TAN & 0.805 & 0.419 & 1.919 & 30 & 0.759 \\
\hline
\end{tabular}

While the wind factor ellipse modeling captured the characteristic wind effect for each facility, it did not capture the effect across the entire study area. In order to estimate "wind factor" values across the entire INL site, a spatial Gaussian covariance model was used to combine the effect of wind dispersing Cs-137 from each of the eight key facilities and projecting out to the outlying areas. A Mathcad ${ }^{\mathbb{B}}$ program was written to attenuate the wind effect at each facility by using its wind-factor ellipse as a spatial-dependence ellipse (applied to a Gaussian covariance model). The ellipse axes served as a scaling factor using a maximum effective downwind direction, which was selected as $20.9 \mathrm{~km}$ (13 mi) after various trials using distances from $8.0 \mathrm{~km}(5 \mathrm{mi})$ to $32.1 \mathrm{~km}(20 \mathrm{mi})$. The attenuation procedure combined the effects of each wind ellipse influence from adjacent facilities by superposing the ellipse factors of surrounding facilities. The overall wind factors were estimated at a grid spacing of $1524 \mathrm{~m}(5,000 \mathrm{ft})$ across the INL site, with resulting values ranging from 0.0001 to 3.11 . The coarse grid was spatially interpolated using the spatial analyst kriging tool in GIS to provide a complete coverage across the site at the desired 30-m resolution. 
Wind factor values then were subdivided into nine groups based on the Jenks natural-breaks classification method applied to the data distribution (Table 3.6).

Table 3.6. Wind factor classifications.

\begin{tabular}{|cc|}
\hline \multicolumn{2}{|c|}{ Wind Factor } \\
\hline Group & Range of Values \\
\hline 1 & $0.00-0.18$ \\
2 & $0.18-0.43$ \\
3 & $0.43-0.73$ \\
4 & $0.73-1.04$ \\
5 & $1.04-1.38$ \\
6 & $1.38-1.75$ \\
7 & $1.75-2.15$ \\
8 & $2.15-2.61$ \\
9 & $2.61-3.11$ \\
\hline
\end{tabular}

\subsection{Cs-137 Concentrations}

The Cs-137 concentrations from the 2009 sampling period were classified into three groups (Table 3.7) based on initial criteria established by INL staff. The selected groups were based on existing threshold parameters and environmental monitoring compliance procedures. However, these Cs-137 groups are not intended to be fixed for all future investigations and may be modified as ongoing study results are obtained and interpreted. A subjective "severity" value also was assigned to each class to indicate the environmental/health impact due to these Cs-137 concentration levels. 
Table 3.7. Cs-137 classifications.

\begin{tabular}{|cc|c|}
\hline \multicolumn{3}{|c|}{ Cs-137 } \\
\hline Group & Concentration $(\mathrm{pCi} / \mathrm{g})$ & Assigned Severity Value \\
\hline 1 & $0.00-0.23$ & 0.5 \\
2 & $0.23-2.3$ & 0.8 \\
3 & $2.3-15.0$ & 1.0 \\
\hline
\end{tabular}

\subsection{GIS Maps of Environmental Factors}

A summary map for each of the five environmental factors obtained for the INL site was produced within GIS and then plotted using a 30-m grid (cell) size. These maps are presented in Appendix B. 


\section{APPLICATION OF AN ADAPTED BAYESIAN ANALYSIS}

To incorporate the influence the environmental factors, an adapted Bayesian analysis was applied to the five environmental factors in conjunction with the Cs-137 measurements. Given that the environmental attributes are not mutually independent, a strict adherence to the traditional Bayesian theorem is not possible, so an adapted form of traditional Bayesian analysis was used to develop a simple predictive model for Cs-137 concentrations, given available environmental conditions. A Bayesian "score" was developed to capture the aggregated environmental influence. This type of spatial analysis is based on previous work by Miller, et al. (2001) and Miller, et al. (2005).

\subsection{Conditional Probabilities}

To compute a Bayesian score (in contrast to a theoretically correct Bayesian probability), conditional probabilities were calculated for the environmental factors using the field calculator in GIS. Each environmental characteristic (slope, elevation, aspect, soil, and wind factor) was used to calculate the probability of occurrence across the entire study area, as well as the probability of occurrence within the measured Cs-137 locations (i.e., a subset of the entire study area). The probability of an environmental factor category (class) occurring at any cell within the study area was calculated by dividing the number of cells of each environmental class by the total number of cells across the site. This simply involves taking the fraction (percentage) of a given environmental class that occurs across the entire study, such as the following example for Soil group 1:

$$
\mathrm{P}\left(\text { Soil }_{1} \mid \text { Area }_{\text {Total }}\right)=\text { No. of Soil group } 1 \text { cells } / \text { No. of total cells }
$$


Conditional probabilities also were calculated for the occurrence of each environmental factor group at the locations of Cs-137 measurements for each grouping of Cs-137 concentration. These probabilities were calculated by identifying the environmental conditions (classes) occurring at each measured location and dividing the total number of class occurrences in cells by the total number of sampled cells (i.e., measured locations). This was performed for each environmental factor group with each group of measured Cs-137 (group 1, group 2, and group 3). The conditional probabilities were adjusted according to a weighting scheme for the risk associated with the different Cs-137 groups, as illustrated in the Mathcad ${ }^{\circledR}$ example shown in Figure 4.1. Although this example demonstrates the calculations for only five groups for elevation, similar calculations can be completed for the actual nine groups of elevation. 


\section{Example Conditional Weighting for GIS Bayes Scores}

Consider the case for environmental factor of Elevation with 5 groups (classes)

Cs-137 group 1 (assigned value 0.5)

$\mathrm{P}($ Elev1 $\mid$ Cs1 $)=$ No. Cs1 cells of Elev. $1 /$ No. of Cs1 cells in study area $\mathrm{P}($ Elev2 $\mid \mathrm{Cs} 1)=$ No. Cs1 cells of Elev. 2 / No. of Cs1 cells in study area $\mathrm{P}($ Elev3 $\mid$ Cs1 $)=$ No. Cs1 cells of Elev. 3 / No. of Cs1 cells in study area $\mathrm{P}($ Elev4 $\mid \mathrm{Cs} 1)=$ No. Cs1 cells of Elev. $4 /$ No. of Cs1 cells in study area $\mathrm{P}($ Elev5 $\mid \mathrm{Cs} 1)=$ No. Cs1 cells of Elev. 5 / No. of Cs1 cells in study area

Cs-137 group 2 (assigned value 0.8 )

$\mathrm{P}($ Elev1 $\mid$ Cs2 $)=$ No. Cs2 cells of Elev. 1 / No. of Cs2 cells in study area $\mathrm{P}($ Elev2 $\mid$ Cs2 $)=$ No. Cs2 cells of Elev. 2 / No. of Cs2 cells in study area $\mathrm{P}($ Elev3 | Cs2 $)=$ No. Cs2 cells of Elev. 3 / No. of Cs2 cells in study area $\mathrm{P}($ Elev4 | Cs2 $)=$ No. Cs2 cells of Elev. 4 / No. of Cs2 cells in study area $\mathrm{P}($ Elev5 $\mid$ Cs2 $)=$ No. Cs2 cells of Elev. 5 / No. of Cs2 cells in study area

Cs-137 group 3 (assigned value 1.0)

$\mathrm{P}($ Elev1 $\mid$ Cs3 $)=$ No. Cs 3 cells of Elev. $1 /$ No. of Cs 3 cells in study area $\mathrm{P}($ Elev2 $\mid \mathrm{Cs} 3)=$ No. Cs 3 cells of Elev. $2 /$ No. of Cs 3 cells in study area $\mathrm{P}($ Elev3 $\mid$ Cs3 $)=$ No. Cs3 cells of Elev. 3 / No. of Cs3 cells in study area $\mathrm{P}($ Elev4 $\mid \mathrm{Cs} 3)=$ No. Cs 3 cells of Elev. $4 /$ No. of Cs 3 cells in study area $\mathrm{P}($ Elev5 $\mid \mathrm{Cs} 3)=$ No. Cs3 cells of Elev. 5 / No. of Cs3 cells in study area

Prob. sets each sum to 1.0

$$
\begin{aligned}
& \mathrm{P} 11:=0.07 \\
& \mathrm{P} 12:=0.09 \\
& \mathrm{P} 13:=0.36 \\
& \mathrm{P} 14:=0.28 \\
& \mathrm{P} 15:=0.20
\end{aligned}
$$

$\mathrm{P} 21:=0.05$

$\mathrm{P} 22:=0.21$

$\mathrm{P} 23:=0.53$

$\mathrm{P} 24:=0.13$

$\mathrm{P} 25:=0.08$

$\mathrm{P} 31:=0.03$

$\mathrm{P} 32:=0.42$

$\mathrm{P} 33:=0.33$

$\mathrm{P} 34:=0.17$

$\mathrm{P} 35:=0.05$

\section{Weighted calculations:}

$\mathrm{F} 1:=0.5 \cdot \mathrm{P} 11+0.8 \cdot \mathrm{P} 21+1.0 \cdot \mathrm{P} 31=0.1050$

$\mathrm{F} 2:=0.5 \cdot \mathrm{P} 12+0.8 \cdot \mathrm{P} 22+1.0 \cdot \mathrm{P} 32=0.6330$

$\mathrm{F} 3:=0.5 \cdot \mathrm{P} 13+0.8 \cdot \mathrm{P} 23+1.0 \cdot \mathrm{P} 33=0.9340$

$\mathrm{F} 4:=0.5 \cdot \mathrm{P} 14+0.8 \cdot \mathrm{P} 24+1.0 \cdot \mathrm{P} 34=0.4140$

$\mathrm{F} 5:=0.5 \cdot \mathrm{P} 15+0.8 \cdot \mathrm{P} 25+1.0 \cdot \mathrm{P} 35=0.2140$

Sum $:=F 1+F 2+F 3+F 4+F 5=2.3$

Adjusted Probabilities

Pelev1 $:=\frac{F 1}{\text { Sum }}=0.0457 \quad$ Pelev2 $:=\frac{F 2}{\text { Sum }}=0.2752 \quad$ Pelev3 $:=\frac{F 3}{\text { Sum }}=0.4061$

Pelev4 $:=\frac{\mathrm{F} 4}{\text { Sum }}=0.1800 \quad$ Pelev5 $:=\frac{\mathrm{F} 5}{\text { Sum }}=0.0930$

Check: Psum $:=$ Pelev1 + Pelev2 + Pelev3 + Pelev4 + Pelev5 $=1.0000$

Figure 4.1. Example of Mathcad ${ }^{\circledR}$ calculations for conditional probabilities. 


\subsection{Calculation of Bayesian Scores}

After both the total probabilities and conditional probabilities were computed, the Bayesian score was calculated for all cells in the study area using the raster calculator in GIS. The Bayesian score combines both the total and conditional probabilities in a Bayesian scheme to calculate the "probability of Cs-137 severity" at any location, given the environmental conditions at that location. (i.e., the observed environmental factor classes at that location). The Bayesian score calculations are expressed below in Equations 4.2 through 4.4.

["Probability of Cs-137 severity", given the environmental classes at cell $i$ ]

$$
=\mathrm{P}\left(\mathrm{C} \mid \mathrm{V}_{i}\right)=\mathrm{P}\left\{\mathrm{C} \mid\left(\mathrm{G}_{i k} \mathrm{E}_{i k} \mathrm{~S}_{i k} \mathrm{~A}_{i k} \mathrm{~W}_{i k}\right)\right\}
$$

where: $\mathrm{G}_{i k}=$ the event that geologic/soil type class $k$ occurs at cell $i$;

$\mathrm{E}_{i k}=$ the event that elevation class $k$ occurs at cell $i$;

$\mathrm{S}_{i k}=$ the event that slope steepness class $k$ occurs at cell $i$;

$\mathrm{A}_{i k}=$ the event that slope aspect class $k$ occurs at cell $i$;

$\mathrm{W}_{i k}=$ the event that wind-factor class $k$ occurs at cell $i$; $\mathrm{k}=1,2,3 \ldots$ to the number of classes within each environmental attribute.

To obtain this conditional "probability", we can apply the Bayes theorem as follows:

$$
\begin{aligned}
& \mathrm{P}\left(\mathrm{C} \mid \mathrm{V}_{i}\right)=\left[\mathrm{P}\left(\mathrm{V}_{i} \mid \mathrm{C}\right) \mathrm{P}(\mathrm{C})\right] / \mathrm{P}\left(\mathrm{V}_{i}\right) \\
& \quad=\mathrm{P}\left\{\left(\mathrm{G}_{i k} \mathrm{E}_{i k} \mathrm{~S}_{i k} \mathrm{~A}_{i k} \mathrm{~W}_{i k}\right) \mid \mathrm{C}\right\} \mathrm{P}(\mathrm{C}) / \mathrm{P}\left(\mathrm{G}_{i k} \mathrm{E}_{i k} \mathrm{~S}_{i k} \mathrm{~A}_{i k} \mathrm{U}_{i k}\right) \\
& \quad=\mathrm{P}\left\{\left(\mathrm{G}_{i k} \mid \mathrm{C}\right)\left(\mathrm{E}_{i k} \mid \mathrm{C}\right)\left(\mathrm{S}_{i k} \mid \mathrm{C}\right)\left(\mathrm{A}_{i k} \mid \mathrm{C}\right)\left(\mathrm{W}_{i k} \mid \mathrm{C}\right)\right\} \mathrm{P}(\mathrm{C}) /\left\{\mathrm{P}\left(\mathrm{G}_{i k}\right) \mathrm{P}\left(\mathrm{E}_{i k}\right) \mathrm{P}\left(\mathrm{S}_{i k}\right) \mathrm{P}\left(\mathrm{A}_{i k}\right) \mathrm{P}\left(\mathrm{W}_{i k}\right)\right\}
\end{aligned}
$$

The $\mathrm{P}(\mathrm{C})$ term in the above equation is defined as the probability of any cell in the study identified (measured with gamma ray spectroscopy) as having some Cs-137 concentration of 
concern. In other words, $\mathrm{P}(\mathrm{C})$ is estimated as the number of $\mathrm{Cs}-137$ sampling locations with nonzero Cs-137 measurements (333) divided by the total number of pixels in the study area $(2,550,593)$. This calculation, however, considerably underestimates the actual probability value, $\mathrm{P}(\mathrm{C})$, which can only be known if all cells in the study area were to be sampled for Cs137. Thus, this multiplier in Equation 4.4 would cause an unrealistically low probability result if this expression were considered a valid probability expression. Therefore, the final computed result of Equation 4.4 at each cell is not considered to be a valid Bayesian probability, but rather a Bayesian score. These scores represent the impact of local environmental conditions on the prediction of Cs-137 severity. The higher the Bayesian score, the higher the expected concentration of Cs-137 in the surface soils.

Due to the nature of the Bayesian score calculation, these raw scores can vary by several orders of magnitude; therefore, a uniform-rank transform must be applied before using them as secondary information in Cs-137 spatial estimation and mapping schemes. This transform is applied by ranking the raw scores from lowest to highest, then assigning a numerical rank (including all tied values), which then is used to calculated the uniform-rank transform such that all newly transformed values lie between zero and one. This transform is given by the following expression:

$$
\mathrm{U}_{\mathrm{R}}=\mathrm{R} /(\mathrm{N}+1)
$$

where: $U_{R}=$ uniform-rank transformed value;

$\mathrm{R}=$ numerical rank of the sorted original value (including ties);

$\mathrm{N}=$ number of data in the data set.

These transformed values, known as "bayranks", were assigned to each cell across the entire INL study area and then were displayed using GIS mapping methods (Figure 4.2). The bayrank values represent the influence of environmental attributes on expected Cs-137 values 
and can serve as important secondary information in spatial estimation/mapping schemes for Cs-137 concentrations in soils.

\section{Bayranks}
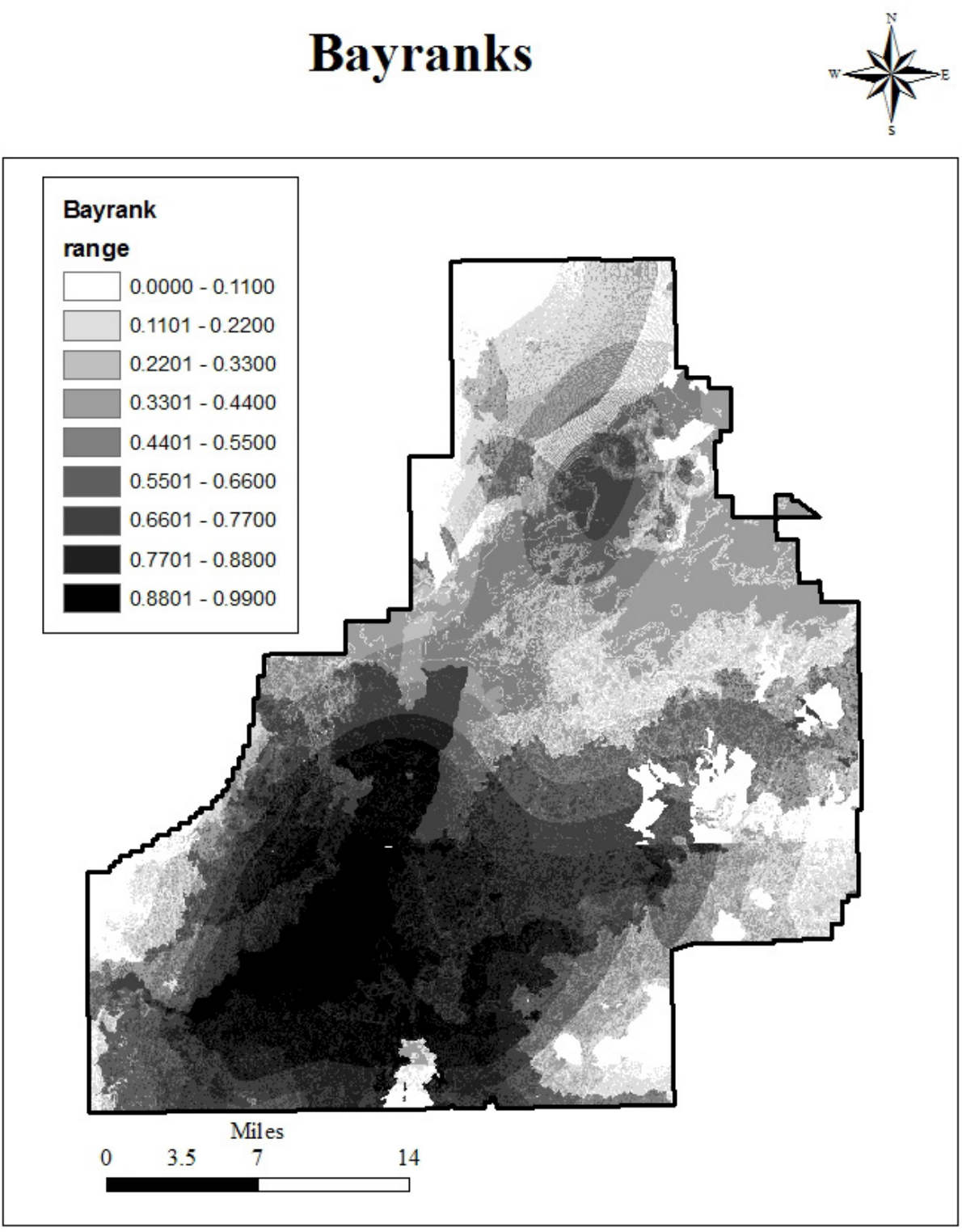

Figure 4.2. Bayrank map. 


\section{CORRELATION OF ENVIRONMENTAL FACTORS WITH Cs-137}

To be able to use environmental factors as a means of predicting Cs-137 concentrations in unsampled locations, there must be a correlation between environmental characteristics and Cs-137 concentrations. A geographic weighted regression (GWR) and a visual inspection of Bayrank scatter plots were used to establish an association of environmental factors with Cs-137 concentrations.

\subsection{Application of Geographic Weighted Regression}

Before the final Bayrank values were calculated, multiple geographic weighted regression (GWR) models were built with the chosen environmental variables to attempt to identify an underlying association with Cs-137 concentrations. The GWR models were built in GIS using point data extracted at the Cs-137 sampling locations for each environmental factor. A masterfile was built of extracted environmental characteristics at measured Cs-137

locations. The masterfile also included the known (measured) Cs-137 value. Multiple GWR models were produced in GIS to attempt to find a correlation with environmental factors and Cs-137 values. The $\mathrm{R}^{2}$ values were used to measure goodness of each model.

The GWR analysis explained some variation from complete randomness (Table 5.1). The most variation, 11.6 percent, was associated with the wind characteristics across the INL site. The least, 8.7 percent, was associated with the soil characteristic. 
Table 5.1. Results of regression analysis.

\begin{tabular}{|lr|}
\hline \multicolumn{2}{|c|}{ GWR Results } \\
\hline Variable & $\begin{array}{c}\text { Variation Explained } \\
\text { (percent) }\end{array}$ \\
\hline Wind & 11.6 \\
Slope & 11.4 \\
Aspect & 9.1 \\
Soil & 8.7 \\
Elevation & 9.4 \\
\hline
\end{tabular}

\subsection{Application of Bayesian Score}

While bayranks were calculated for each cell across the site, the bayranks at the measured Cs-137 sampling locations are of unique importance because they can be used to compare the aggregated environmental effect with the actual measured Cs-137 concentration. A scatterplot of these two attributes (Figure 5.1) generally indicates a direct relationship between the bayrank and actual Cs-137 values. However, significant numbers of data pairs have a high bayrank value but are associated with a low Cs-137 value. This probably implies that the "influence range" of the wind factor may have been set at too great a distance, and the attenuation rate from facilities perhaps was not high enough. 


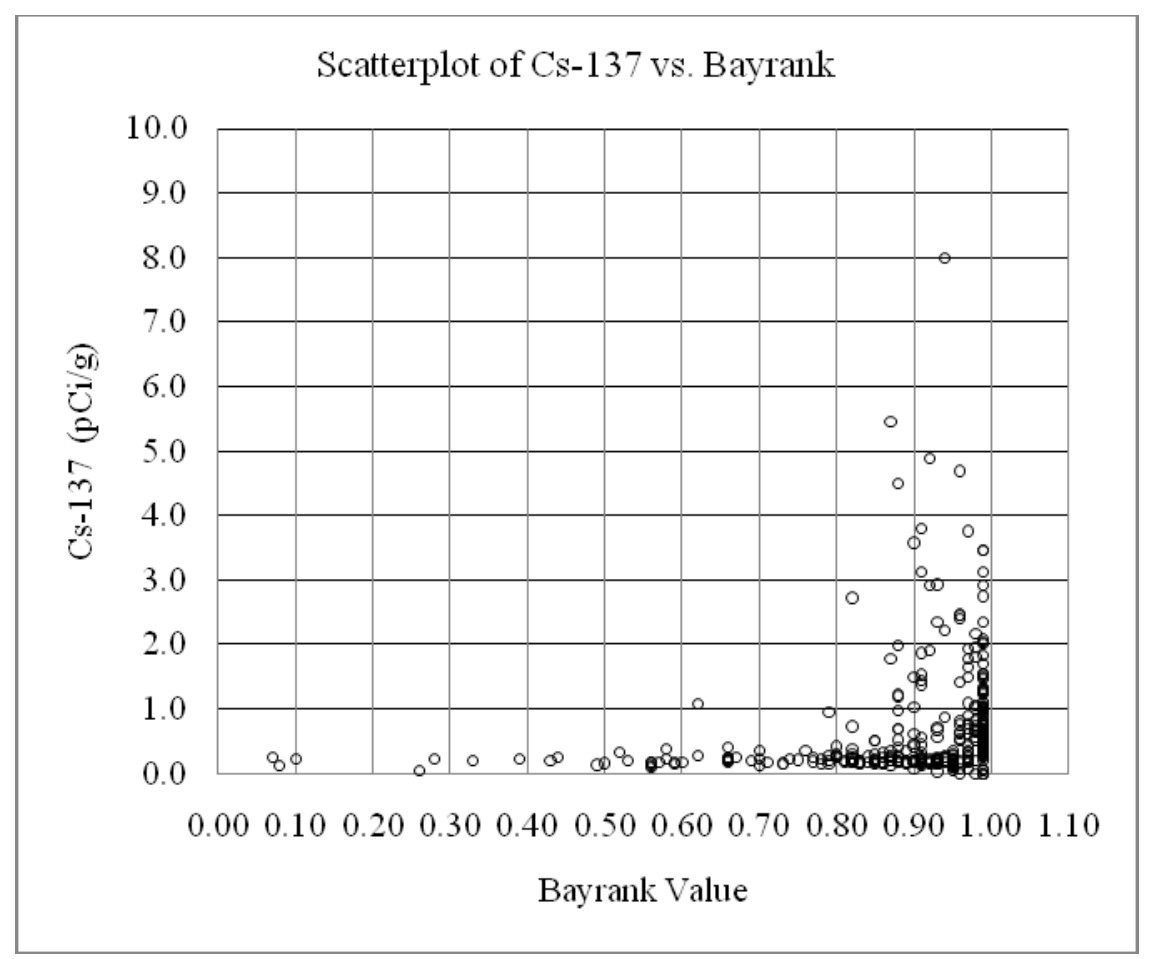

Figure 5.1 Scatterplot of 2009 Cs-137 values vs. bayrank values.

An overall spatial comparison of the two attributes is shown in Figures 5.2 and Figure 5.3. Visual inspection of these two maps shows that the bayrank values are generally good predictors of Cs-137 concentrations across the INL site. Bayrank values are especially good predictors of high concentrations around ARA, INTEC, and of low concentrations for the Large Grid. However, areas poorly predicted by the bayrank values are RWMC and CITRC. This likely is due to the relatively low Cs-137 concentrations at these facilities (for RWMC, 0.102-0.463 $\mathrm{pCi} / \mathrm{g}$; for CITRC, $0.057-0.216 \mathrm{pCi} / \mathrm{g})$. The bayrank values rely heavily on the wind factor, which is computed using proximity to facilities (distance and direction) without regard to Cs-137 values at those facilities. Thus, the quality of the bayrank predictions in the future could be enhanced by including a weighting scheme in the wind factor to account for Cs-137 values at each facility. 


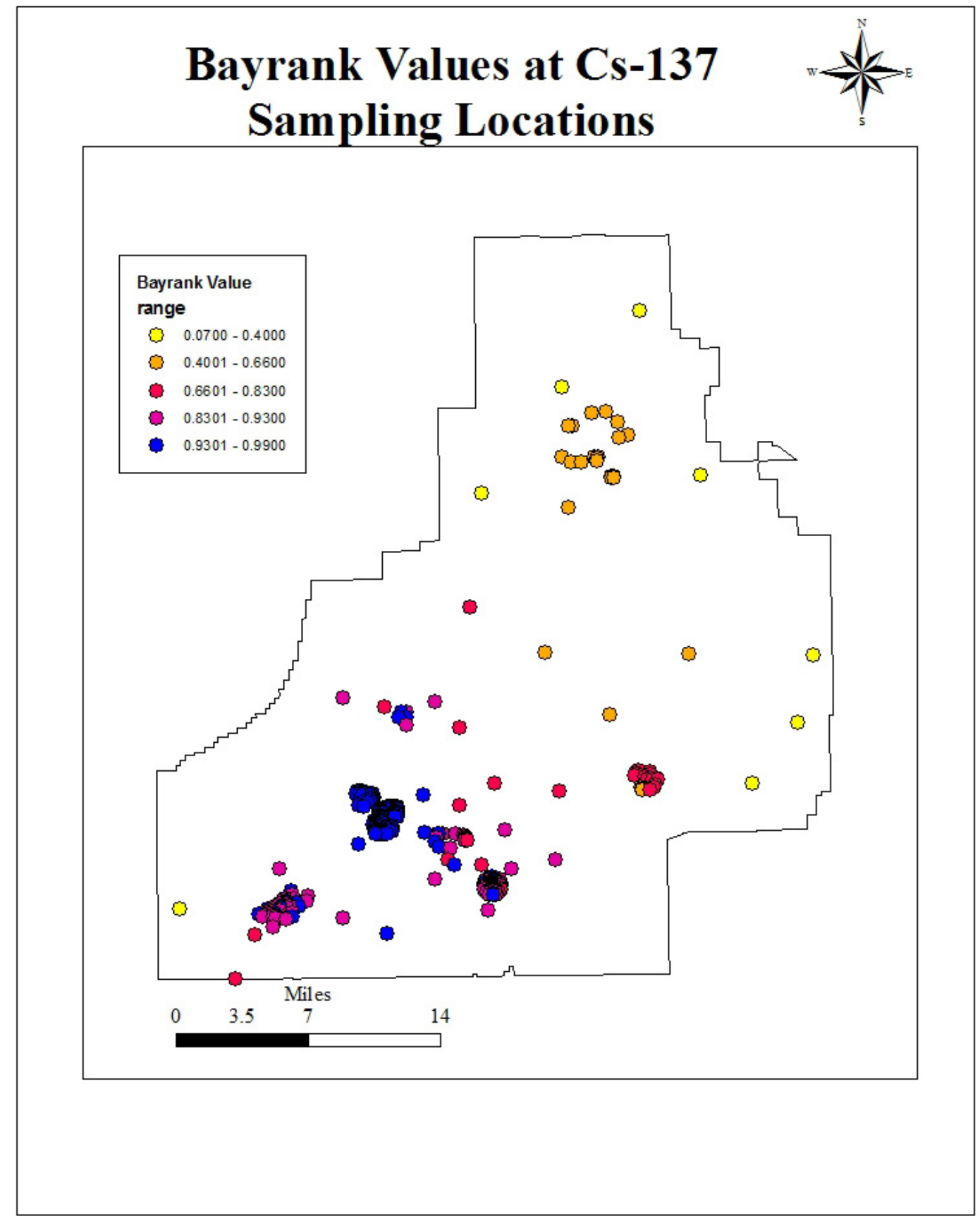

Figure 5.2. Postplot of bayrank values at Cs-137 sampling locations. 


\section{Cs-137 Measured Concentrations (pCi/g) at Sampling Locations}

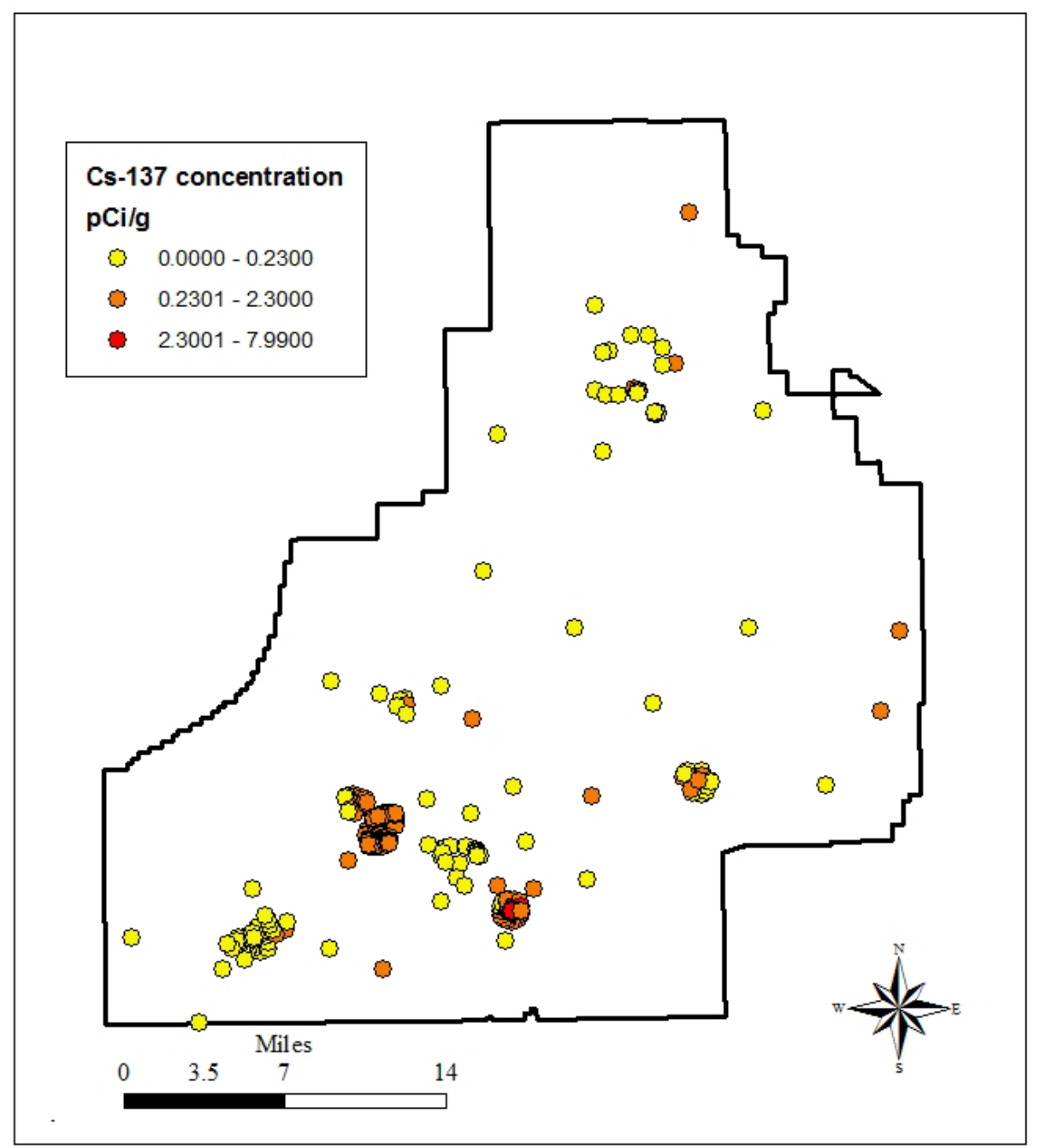

Figure 5.3. Postplot of Cs-137 values at sampling locations. 


\section{GEOSTATISTICAL ESTIMATION OF Cs-137}

To better understand spatial dependence patterns and to calculate unbiased estimates of Cs-137 concentrations in unsampled areas, geostatistical analysis was applied to the raw Cs-137 data and the bayrank values (which represent the overall influence of the five environmental factors see Chapter 3). Specifically, ordinary point kriging (OK) and kriging with exhaustive secondary information (KESI) were applied to the Cs-137 data and the bayrank values using GIS Spatial Analyst tools.

Kriging is a specialized geostatistical method applied to geospatial data whereby unsampled locations are estimated (interpolated) using known, nearby data values (Goovaerts, 1997). Kriging estimation is based on the assumption that observations closer in space are more likely to be similar than observations farther apart, a characteristic known as spatial dependence. Kriging assumes that the spatial variation of an attribute can be captured in the combination of a spatially correlated component, a regionalized trend component, and a random error component (Chang, 2008).

Kriging provides an unbiased, minimum-variance estimate at user-specified locations. Additionally, kriging provides an estimation error (i.e., the kriging standard deviation) at the same user-specified locations as the generated estimate . A powerful analytical tool, kriging differs from other interpolation methods because kriging can assess the quality of estimation through a predicted estimation error. Furthermore, kriging is an exact interpolator meaning that it will predict the known data value when kriging at a known sampling location, and the estimation error will be zero. The kriging errors can be used to compare results from different kriging model assumptions, identify areas with high uncertainty in the estimates (due either 
to sparse data in the area or to highly irregular data values in the area), and evaluate the performance of kriging methods (Burrough and McDonnell, 1998).

\subsection{Spatial Dependence Modeling}

Spatial dependence is a necessary input for kriging and must be described and quantified before further analysis can be conducted. In this study, spatial dependence was established using variograms and spatial complementary covariance models. As one of the tools used to describe spatial dependence in the measured Cs-137 data, the estimated variogram (Figure 6.1) can be calculated as follows:

$$
\gamma(h)=\frac{1}{2 n_{h}} \sum_{i=1}^{n_{h}}\left(x_{i}-x_{i+h}\right)^{2}
$$

where: $\mathrm{x}_{\mathrm{i}}$ and $\mathrm{x}_{\mathrm{i}+\mathrm{h}}=$ data values separated by lag distance $\mathrm{h}, \mathrm{n}_{\mathrm{h}}=$ number of data pairs separated by lag distance $h$.

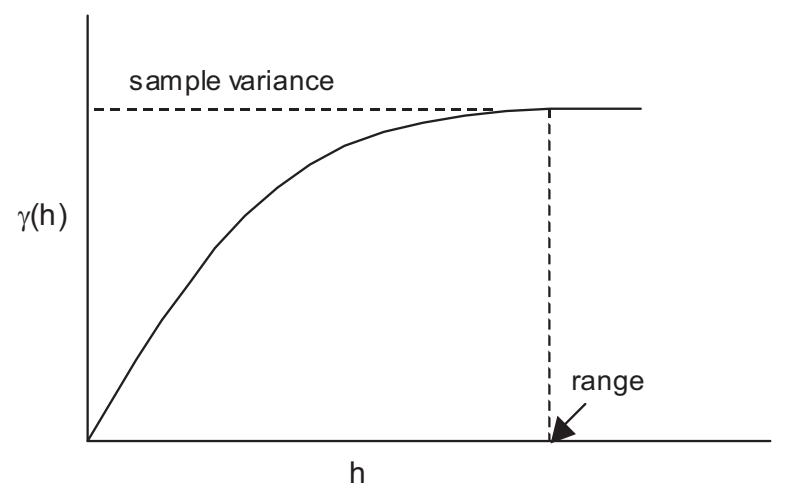

Figure 6.1. A typical variogram plot depicting spatial dependence.

Another way to describe the spatial dependence in a data set is to compute the spatial covariance of the data set (Figure 6.2), which can be defined as: 


$$
C(h)=\frac{1}{n_{h}} \sum_{i=1}^{n_{h}}\left(x_{i}-\bar{x}_{i}\right)\left(x_{i+h}-\bar{x}_{i+h}\right)=\frac{1}{n_{h}} \sum_{i=1}^{n_{h}} x_{i} x_{i+h}-\bar{x}_{i} \bar{x}_{i+h}
$$

where: $\mathrm{x}_{\mathrm{i}}$ and $\mathrm{x}_{\mathrm{i}+\mathrm{h}}=$ data values separated by lag $\mathrm{h}, \mathrm{n}_{\mathrm{h}}=$ number of data pairs separated by lag h, and the $\bar{x}_{i}$ and $\bar{x}_{i+h}$ are the means of the endpoints of data pairs separated by lag h. When this covariance is subtracted from the sample variance, the result is known as the complementary covariance, and can be modeled in a manner similar to modeling variograms.

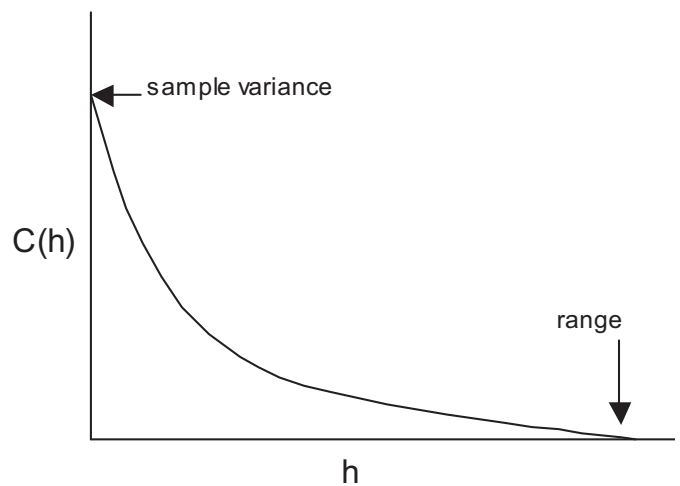

Figure 6.2. A typical spatial covariance plot depicting spatial dependence.

In previous spatial dependence modeling of Cs-137 at the INL, an interactive declustering method was used on the raw data in order to obtain reasonable structure in computed variograms (Miller et al., 2009). However, analysis of the 2009 data showed that spatial covariance plots (using Eqn. 6.2) were able to display spatial dependence for the raw data, and declustering was not deemed necessary.

Directional variograms and complementary covariances were calculated for the 2009 measured Cs-137 data. Spatial dependence was established, but due to noise in the variograms, the directional complementary covariance model was used. Directional covariance computations indicated the maximum range of influence for Cs-137 was in the northeasterly direction. Examples of these directional covariance calculations and an estimated range ellipse are presented in Appendix C. 


\subsection{Ordinary Kriging}

Ordinary kriging at specified grid points, referred to as point kriging, was conducted for Cs-137, using the 2009 data set. The ordinary kriging system of equations to be solved in order to find the kriging weights can be expressed as (Goovaerts, 1997):

$$
\sum_{j=1}^{n} a_{j} C_{i j}+\lambda=C_{B i} \quad \sum_{j=1}^{n} a_{j}=1
$$

where: $C_{i j}=$ spatial covariance between pairs of neighborhood data;

$C_{B i}=$ spatial covariance between each neighborhood datum and the location being estimated (in this case, the location is a point and not a block);

$a_{j}=$ kriging weights as solved by a linear system of equations where $j=1$ to $n$;

$n=$ number of neighborhood data;

$\lambda=$ Lagrange multiplier used in the system of equations as a means to ensure the weights will sum to 1.0 .

In matrix notation, this kriging system of equations is expressed as:

$$
\left[\begin{array}{ccccc}
C_{11} & C_{12} & \cdots & C_{1 n} & 1 \\
C_{21} & C_{22} & \cdots & C_{2 n} & 1 \\
\vdots & \vdots & \ddots & \vdots & 1 \\
C_{n 1} & C_{n 2} & \cdots & C_{n n} & 1 \\
1 & 1 & 1 & 1 & 0
\end{array}\right] \cdot\left[\begin{array}{c}
a_{1} \\
a_{2} \\
\vdots \\
a_{n} \\
\lambda
\end{array}\right]=\left[\begin{array}{c}
C_{B 1} \\
C_{B 2} \\
\vdots \\
C_{B n} \\
1
\end{array}\right]
$$

That is, $\mathbf{C A}=\mathbf{C}_{\mathbf{B i}}$

To solve for the weights, we multiply the inverse of matrix $\mathbf{C}$ times the vector $\mathbf{C}_{\mathbf{B i}}$ :

$$
\mathbf{A}=\mathbf{C}^{-1} \mathbf{C}_{\mathbf{B i}}
$$

Thus, the estimated value at the location of interest is obtained by calculating the weighted average of the $n$ data in the neighborhood:

$$
\hat{V}=\sum_{i=1}^{n} \hat{a}_{i} x\left(u_{i}\right) \quad \text { where } x\left(u_{i}\right) \text { is the neighborhood data value at location } i \text {. }
$$


Ordinary kriging provides an estimate of the "prediction error" (or estimation error). The prediction error also is known as the "kriging variance":

$$
\sigma_{K}^{2}=C_{B B}-\sum_{i=1}^{n} \hat{a}_{i} C_{B i}-\hat{\lambda}
$$

For point kriging, the block covariance $\mathrm{C}_{\mathrm{BB}}$ is given by the sample variance, $\mathrm{s}^{2}$. The kriging standard deviation is equal to the square root of the kriging variance:

$$
\sigma_{K}=\sqrt{\sigma_{K}^{2}}
$$

This kriging standard deviation will have the same measurement units as the data. Results of the point kriging at INL are presented later in this chapter.

\subsection{Kriging with Exhaustive Secondary Information (KESI)}

After point kriging was performed on the 2009 measured Cs-137 data, an additional kriging method was applied to take advantage of the bayrank information to help estimate Cs-137 at unsampled locations. This type of analysis, known as kriging with exhaustive secondary information (KESI), or kriging with external drift (KED), uses a secondary attribute (bayranks) to help predict a value for the primary attribute (Cs-137). In order for KESI to be conducted, the secondary must be available at every location to be kriged. As stated previously, the bayrank values were computed from the Bayesian score that incorporated the five environmental characteristics and three Cs-137 groups at each 30-m cell across the INL site (Figure 4.2, Bayrank map). The KESI method of kriging only uses the spatial dependence of the primary attribute (variogram or complementary covariance model), but still incorporates the influence of the secondary attribute.

The KESI kriging system of equations to be solved in order to find the kriging 
weights can be expressed as (Goovaerts, 1997):

$$
\sum_{j=1}^{n} a_{j} C_{i j}+\lambda+\lambda^{\prime} y\left(u_{j}\right)=C_{B i} \quad \sum_{j=1}^{n} a_{j}=1 \quad \sum_{j=1}^{n} a_{j} y\left(u_{j}\right)=y_{o}
$$

where: $C_{i j}=$ spatial covariance between pairs of neighborhood data;

$C_{B i}=$ spatial covariance between each neighborhood datum and the location being estimated (in this case, the location is a point and not a block); $y\left(u_{j}\right)=$ value of secondary attribute at $\mathrm{j}$-th location in the neighborhood; $y_{o}=$ value of secondary attribute at the kriging location;

$a_{j}=$ kriging weights as solved by a linear system of equations where $j=1$ to $n$; $n=$ number of neighborhood data;

$\lambda$ and $\lambda^{\prime}=$ Lagrange multipliers used in the system of equations as a means to ensure the weights will sum to 1.0 and provide an unbiased estimator.

In matrix notation, the KESI system of equations is expressed as:

$$
\left[\begin{array}{cccccc}
C_{11} & C_{12} & \cdots & C_{1 n} & 1 & y_{1} \\
C_{21} & C_{22} & \cdots & C_{2 n} & 1 & y_{2} \\
\vdots & \vdots & \ddots & \vdots & \vdots & \vdots \\
C_{n 1} & C_{n 2} & \cdots & C_{n n 2} & 1 & y_{n} \\
1 & 1 & \cdots & 1 & 0 & 0 \\
y_{1} & y_{2} & \cdots & y_{n} & 0 & 0
\end{array}\right] \cdot\left[\begin{array}{c}
a_{1} \\
a_{2} \\
\vdots \\
a_{n} \\
\lambda \\
\lambda^{\prime}
\end{array}\right]=\left[\begin{array}{c}
C_{B 1} \\
C_{B 2} \\
\vdots \\
C_{B n} \\
1 \\
y_{o}
\end{array}\right]
$$

That is, $\mathbf{C A}=\mathbf{C}_{\mathbf{B i}}$

To solve for the weights, we multiply the inverse of matrix $\mathbf{C}$ times the vector $\mathbf{C}_{\mathbf{B i}}$ :

$$
\mathbf{A}=\mathbf{C}^{-1} \mathbf{C}_{\mathbf{B i}}
$$

Therefore, the estimated value at the location of interest is obtained by calculating the weighted average of the $n$ data in the neighborhood:

$$
\hat{V}=\sum_{i=1}^{n} \hat{a}_{i} x\left(u_{i}\right) \quad \text { where } x\left(u_{i}\right) \text { is the neighborhood data value at location } i
$$


KESI also provides an estimate of the kriging variance:

$$
\sigma_{K}^{2}=C_{B B}-\sum_{i=1}^{n} \hat{a}_{i}\left(C_{B i}+\hat{\lambda}^{\prime} y_{i}\right)-\hat{\lambda}
$$

The block covariance $\mathrm{C}_{\mathrm{BB}}$ is set equal to the sample variance of the available Cs-137 data.

\subsection{Kriging Results}

Due to the size and the amount of data associated with the INL study area (over 2.5 million cells) kriging was conducted on a subarea within the INL site to allow reasonable computational time. The subarea used for kriging was located in the middle of the INL site and incorporated most of the site facilities. Within this subarea, a $609.6 \mathrm{~m} \mathrm{(2000} \mathrm{ft)} \mathrm{spaced}$ grid was developed for use in both types of kriging. A Mathcad ${ }^{\circledR}$ program was developed to compute kriging estimates and errors across the specified grid for both kriging methods.

Results from the point kriging are shown in Figures 6.3 and 6.4. The estimation map clearly indicates significant influence of prevailing wind on the measured and estimated Cs137 values (recall that environmental characteristics are not used in point kriging of Cs-137). The point kriging estimation error map shows the influence of sample locations, as the lowest errors are located in the vicinity of known data values. However, errors can be high in the facility areas when low and high Cs-137 measurements may be located in fairly close proximity. Visual inspection of the point kriging estimate map shows that, in general, high values of Cs-137 are predicted around INL facilites and low values of Cs-137 are predicted across the Large Grid. However, some anomalies in the point kriging are displayed in the southern region of the INL site, where high values are predicted despite the absence of a facility or sampling location. Additionally, another anomaly occurred in the northeastern corner of the INL boundary where mid range Cs-137 concentrations are predicted even 
though the space is part of the Large Grid. Comparing the point kriging estimate map and the point kriging error map, the greatest estimation errors are seen in the southeastern corner and the least errors are seen around facilities (as expected since kriging is an exact interpolator and most sampling locations occur clustered around facilities).

Results from the KESI are shown in Figures 6.5 and 6.6. The KESI estimate map displays much more variability (i.e., less smoothing) than the point kriging estimate map (Figure 6.3). Less smoothing is likely representative of the impact of the secondary attribute, bayrank, and the significant influence of wind factor incorporated within the bayrank values. The kriging error map also shows greater dispersion "scatter" of error around facilities unlike that shown in the point kriging error map (Figure 6.4). Visual inspection of the KESI estimate map shows that high values of Cs-137 are predicted very near INL facilites and low values of Cs-137 are predicted around the outer regions of the INL site. Comparison of the KESI estimate map with the KESI error map shows the greatest estimation errors are seen in the area occupied by the Large Grid and the least errors are seen in the vicinity of facilities.

The comparison of the point kriging and KESI estimates indicates fairly similar results overall. However, KESI seems to have removed the previously metioned anomalies from the point kriging model near the southern boundary and the northeastern corner of the site. Furthermore, the KESI estimation map provides a more realistic picture of the spatial distribution of Cs-137 by incorporating the local influence of bayrank and minimizing the smoothing inherent in ordinary kriging estimators. 


\section{Point Kriging Estimate}
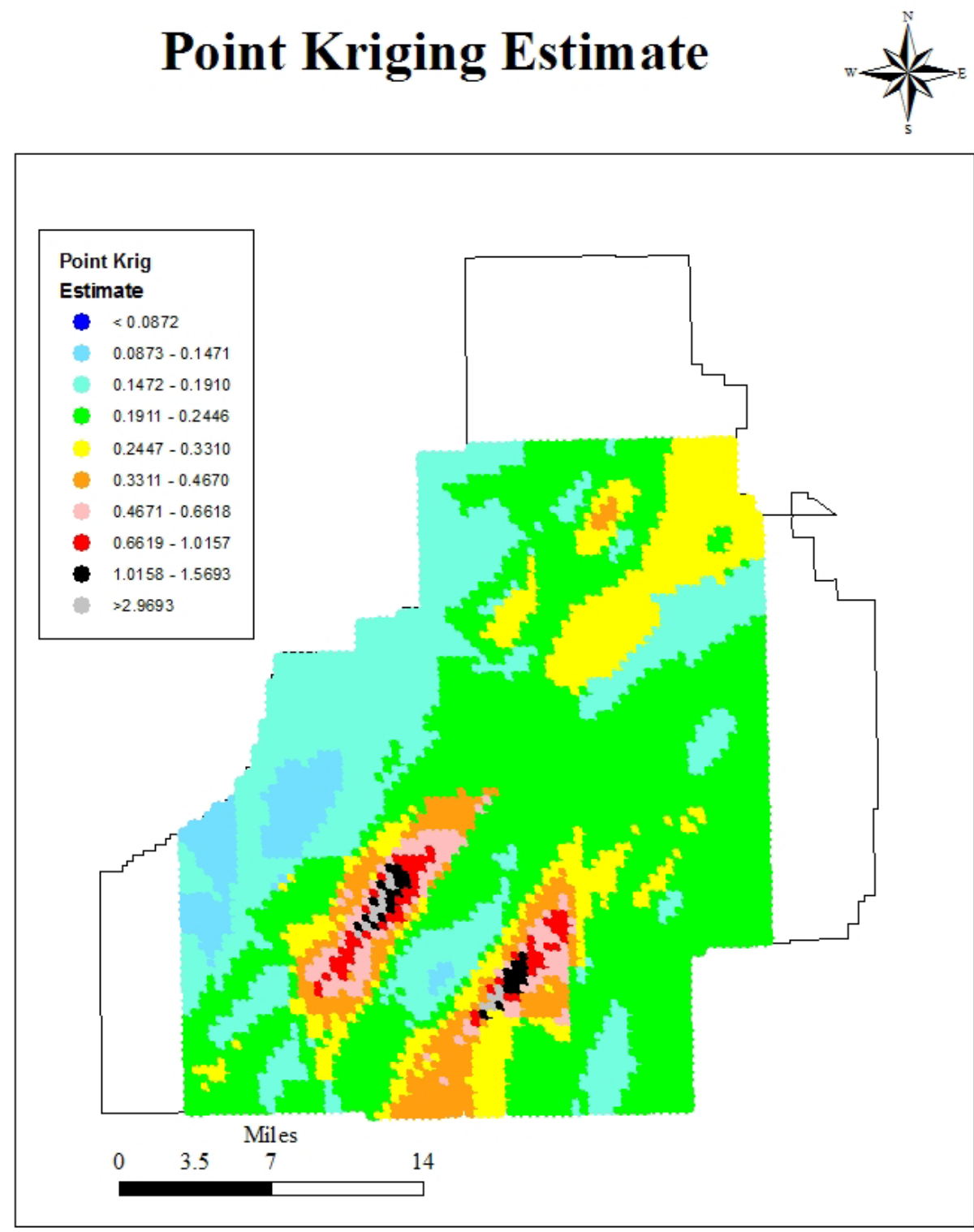

Figure 6.3. Cs-137 point kriging estimate map (pCi/g). 


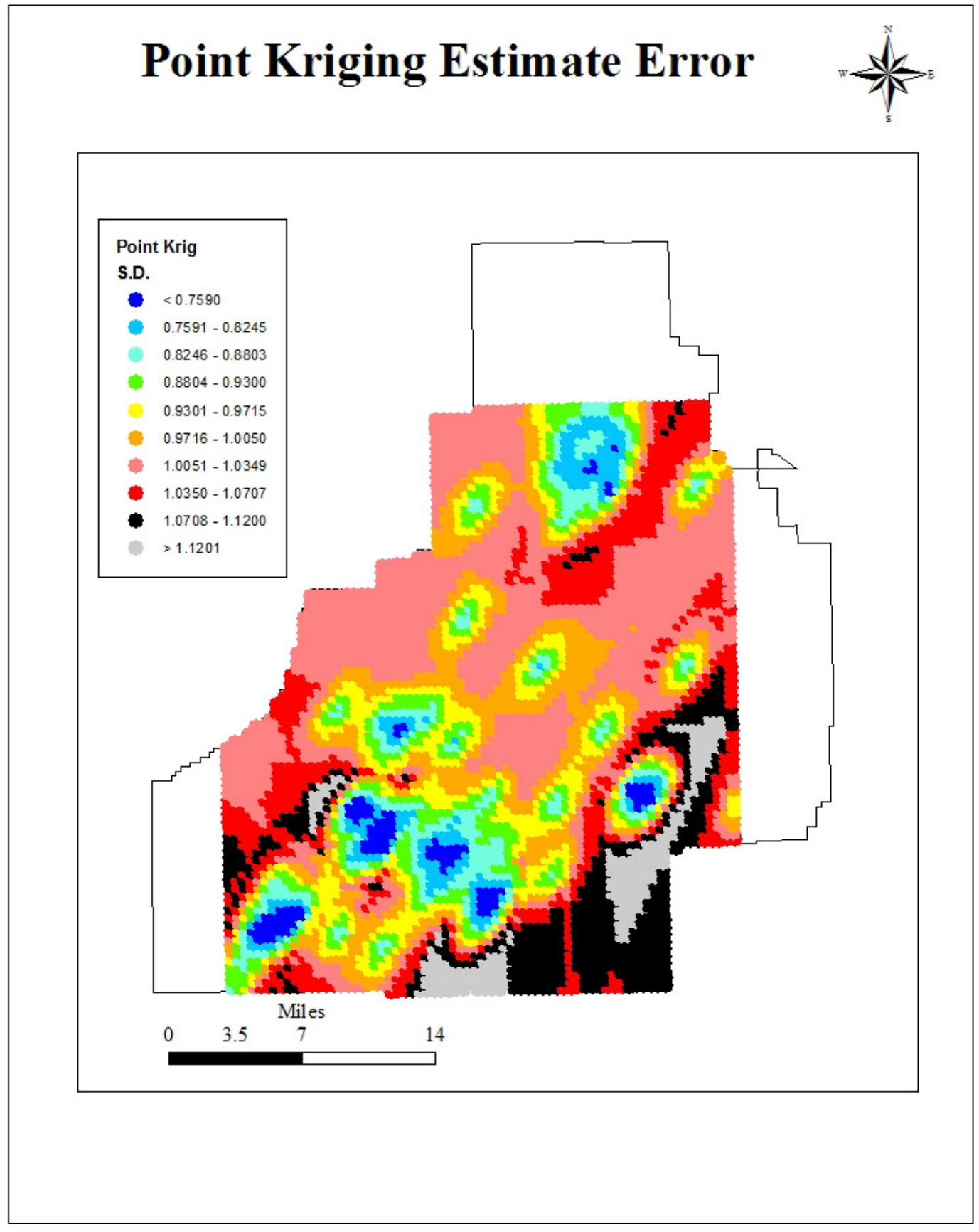

Figure 6.4. Cs-137 point kriging error map (pCi $/ \mathrm{g})$. 


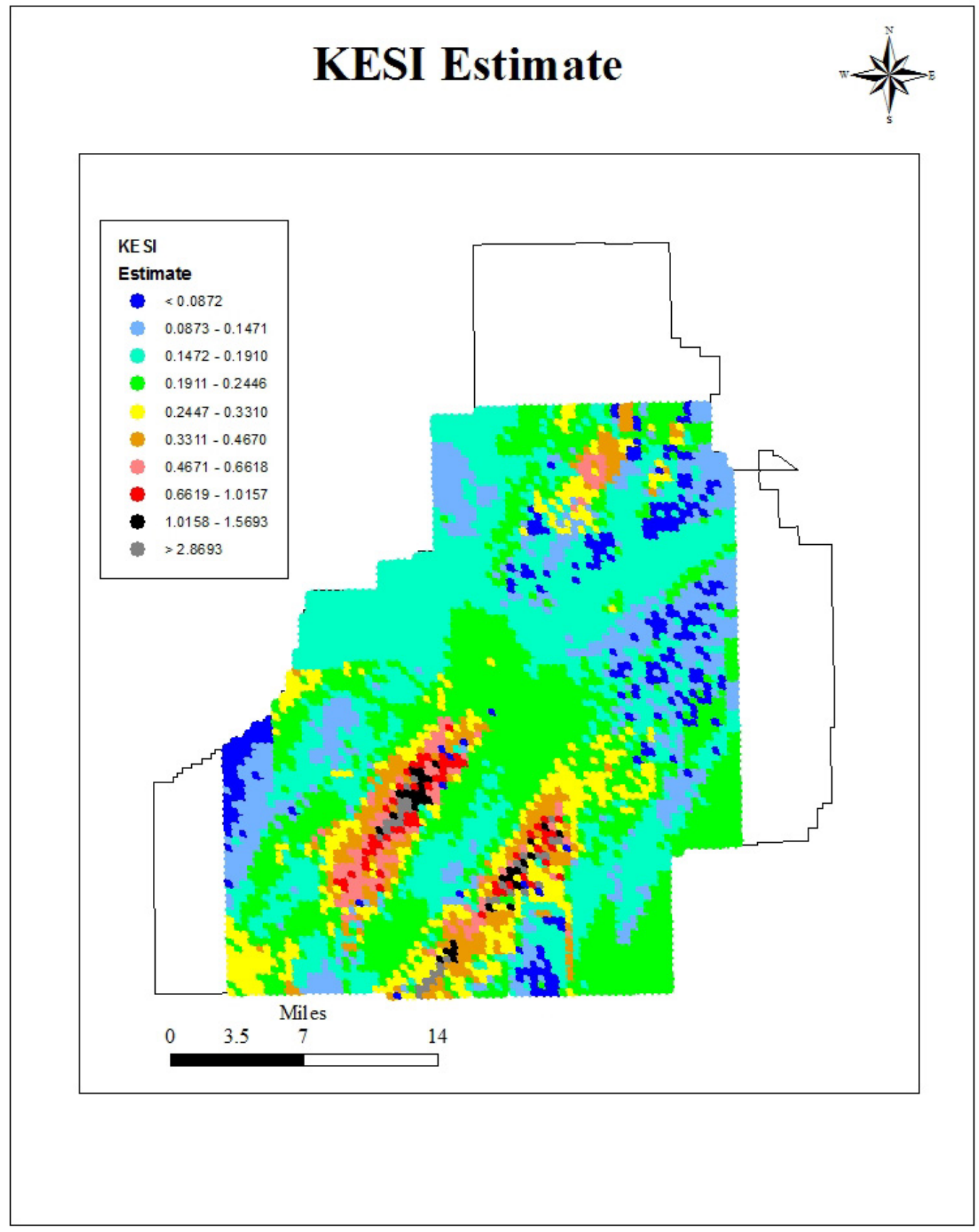

Figure 6.5. Cs-137 KESI estimate map (pCi/g). 


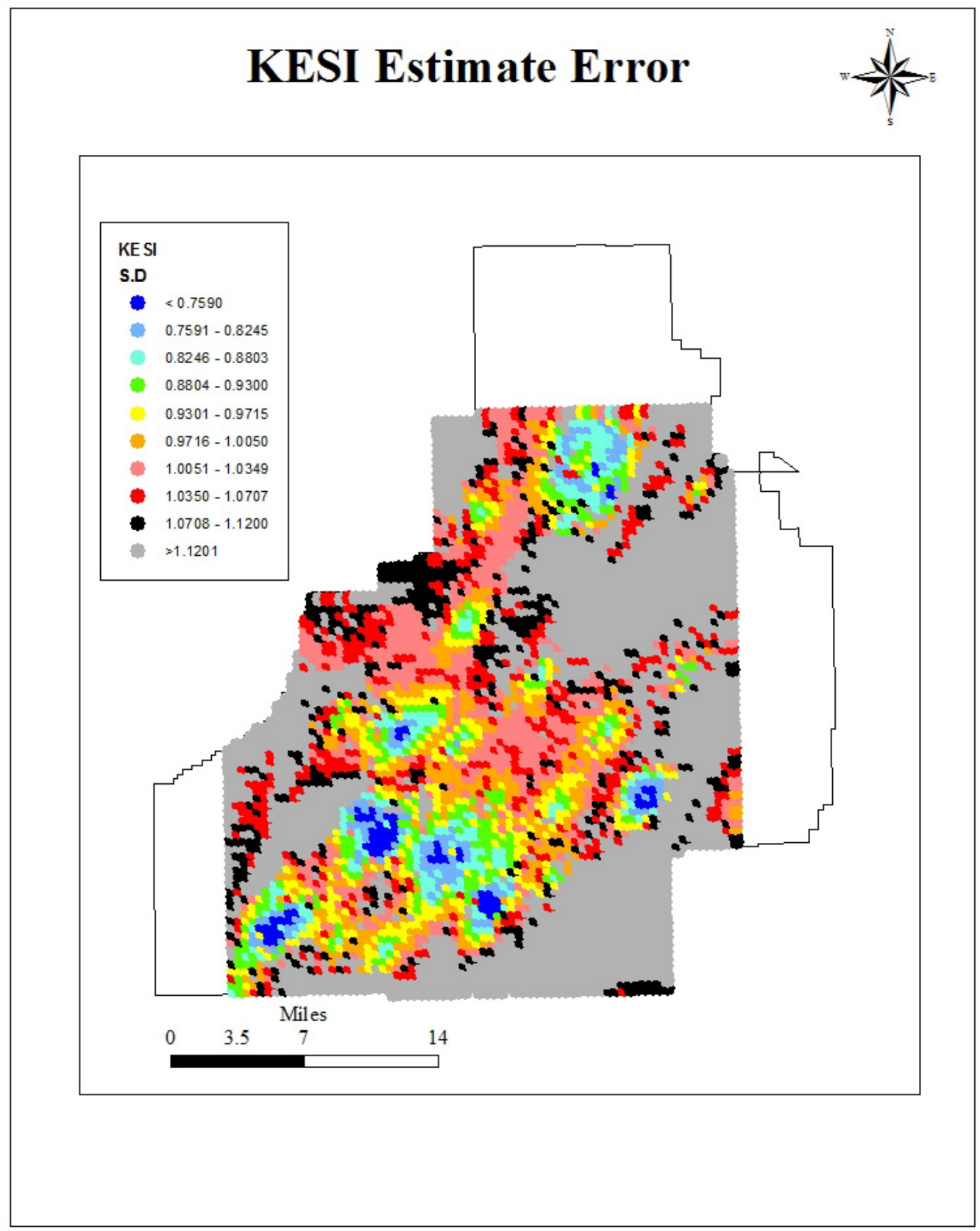

Figure 6.6. Cs-137 KESI error map (pCi/g). 


\subsection{Assessment of Kriging Performance}

To assess the performance of the kriging methods, several trials were conducted to evaluate the ability of both geostatistical methods (point kriging and KESI) to predict Cs-137 values at known locations, but with the data values at those locations removed prior to kriging. In these trials, a subset of random Cs-137 values was removed from the data set used for kriging. Of the 30 points removed, 24 were from sampling locations around facilites and 6 were from sampling locations in the Large Grid region. Once these points were removed, both point kriging and KESI kriging were performed to estimate Cs-137 values at the "blinded" sampling locations. Therefore, the kriged estimates could be compared with the actual known measurements to assess the performance of the geostatstical estimators. Results from three trials, each with 30 random estimation locations, were combined to provide a set of 90 residuals for each kriging method. Scatterplotts of the measured values versus the kriged estimates are shown in Figures 6.7 and 6.8. The residuals ( differences between actual values and kriged estimates) were also compared in frequency diagrams and posttplots (Figures 6.9 - 6.12).

Inspection of the two scatterplots (Figure 6.7 and 6.8) shows tight clustering around the $45^{\circ}$ line, meaning that there is strong $1: 1$ correlation between the estimate and the actual value. Both the point kriging and KESI diagrams seem to display similar clustering patterns. However, the KESI scatterplot appears to exhibit a somewhat tighter clustering pattern, meaning it is a slighty better predictor of Cs-137 values. Both methods provided significant underestimates for the measured value of $7.99 \mathrm{pCi} / \mathrm{g}$. 


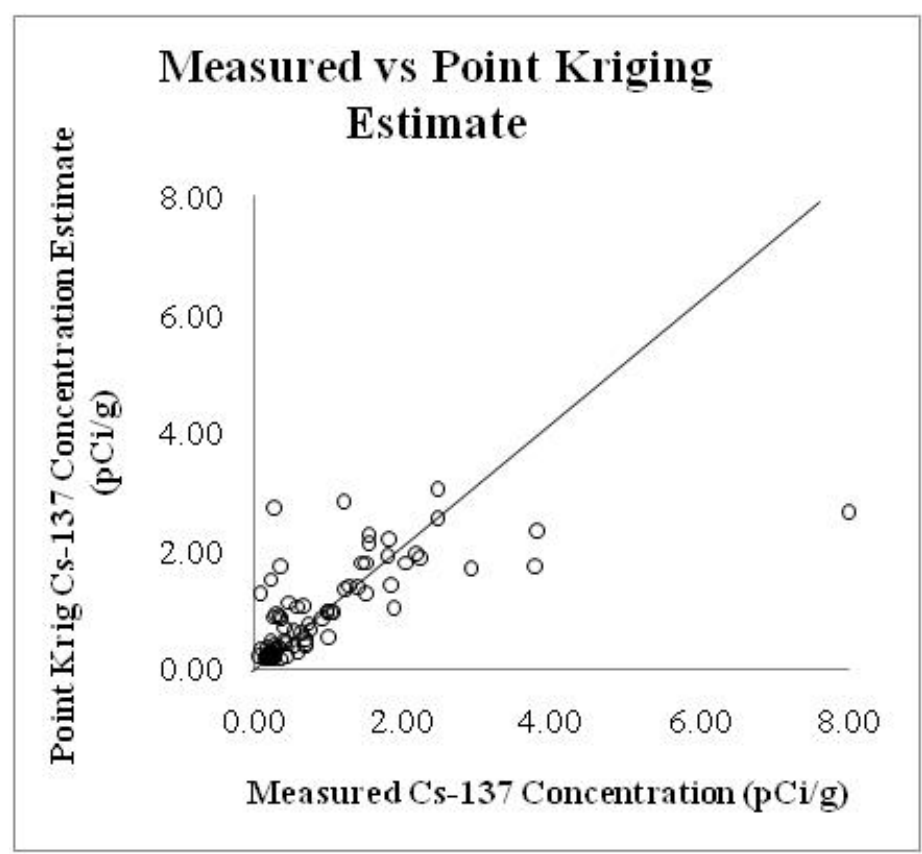

Figure 6.7. Comparision of measured Cs-137 value and point kriging estimate.

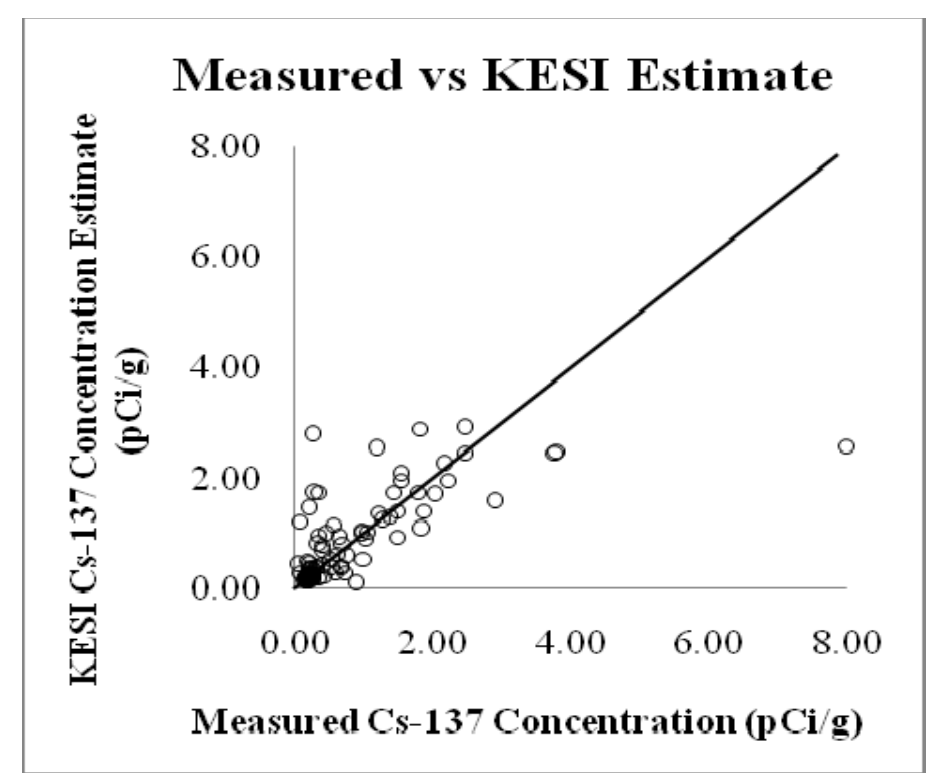

Figure 6.8. Comparision of measured Cs-137 value and KESI estimate. 


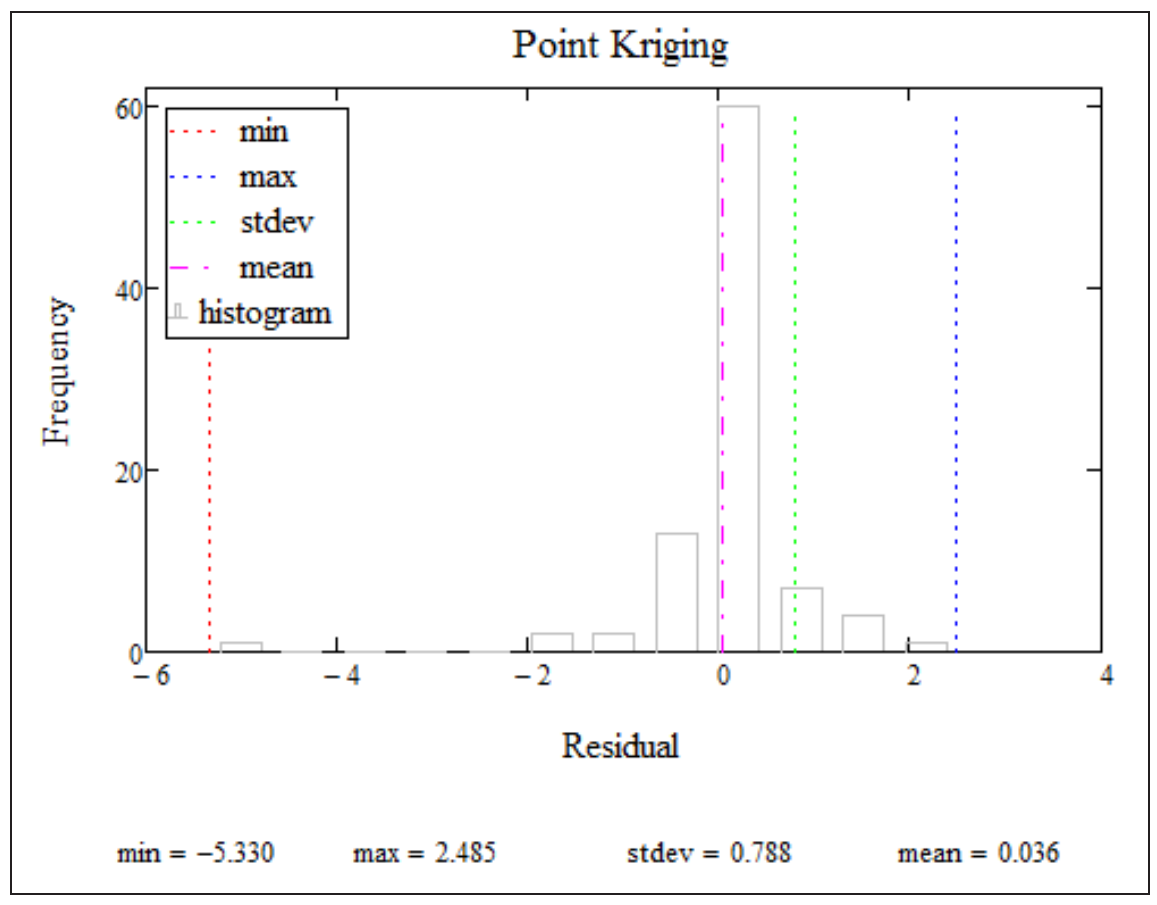

Figure 6.9. Statistical summary of point kriging residuals.

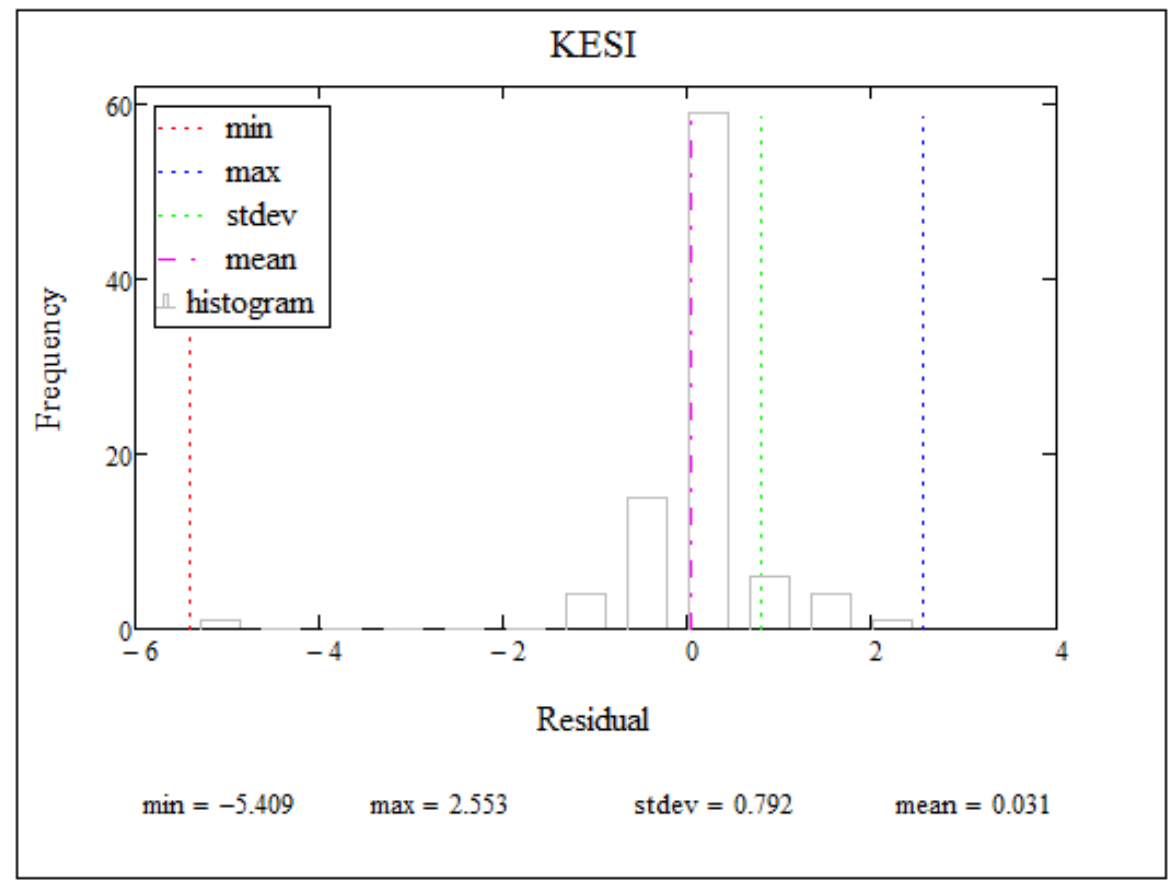

Figure 6.10. Statistical summary of KESI residuals. 
As displayed in the statistical summary diagrams, the mean residual value for all three trials for point kriging was $0.036 \mathrm{pCi} / \mathrm{g}$, while for $\mathrm{KESI}$ the mean residual was $0.031 \mathrm{pCi} / \mathrm{g}$. The range of residuals (maximum value to minimum value) was fairly consistent, as was the standard devation for both point kriging and KESI.

Postplots of residual values were generated in order to visualize locations of high and low deviation from actual measured values. Visual inspection of Figure 6.11 and Figure 6.12 shows high residuals (both negative and positive) in areas surrounding INL facilities and low residuals in areas occupying the Large Grid. The greastest descrepancy in estimation between point kriging and KESI occurs in the Large Grid region. For point kriging the residual is very high (black), but for KESI, the residual is low (yellow). Overall, KESI has lower residuals across the entire study area shown by the presence of more orange points than the point kriging. From the performance tests, both point kriging and KESI seem to be good predictors for Cs-137 concentrations in unsampled areas. However, the KESI model appears to estimate values closer to the true measurements, as shown by lower residuals (errors) across the study site. 

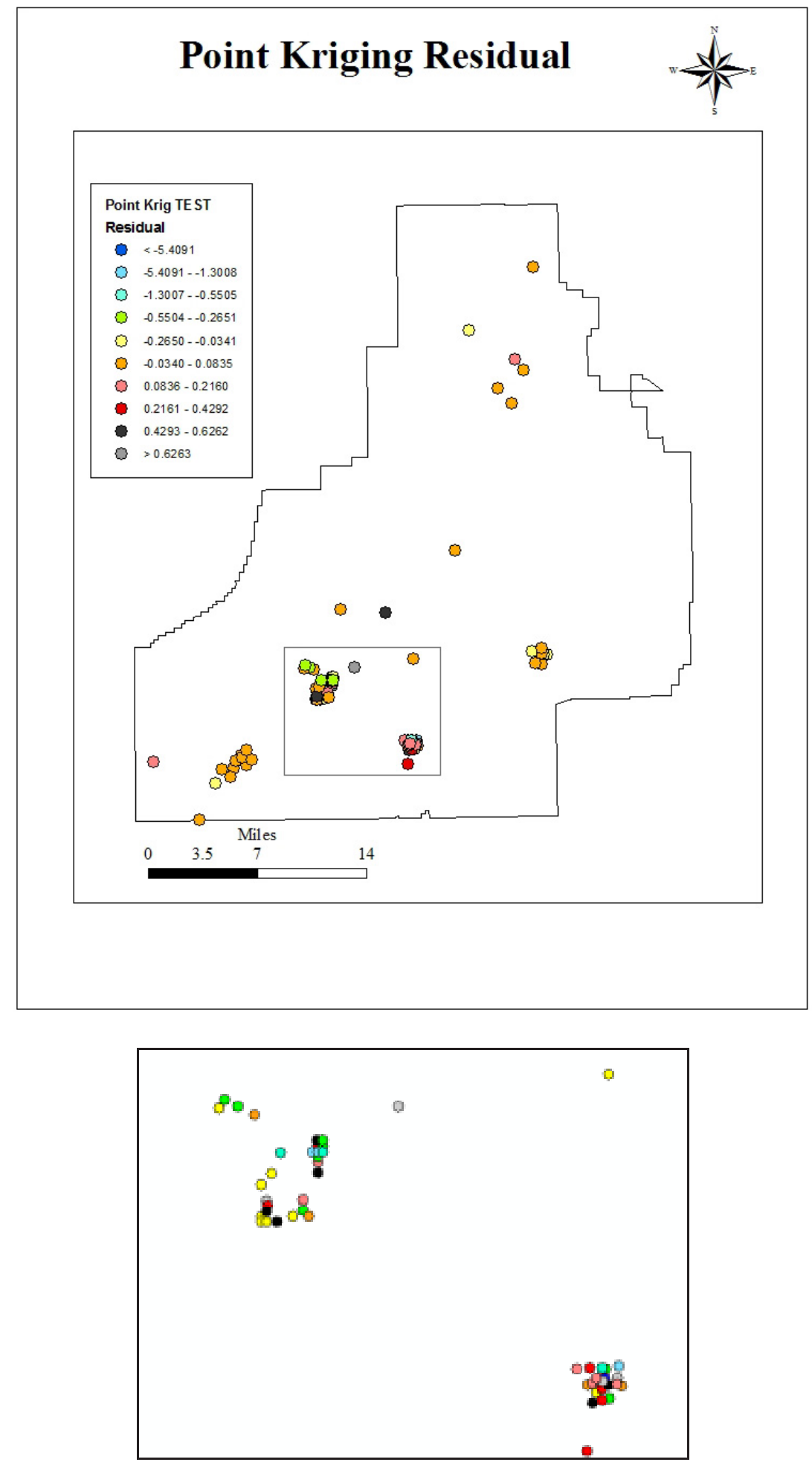

Figure 6.11. Postplot of point kriging residuals (pCi/g). 


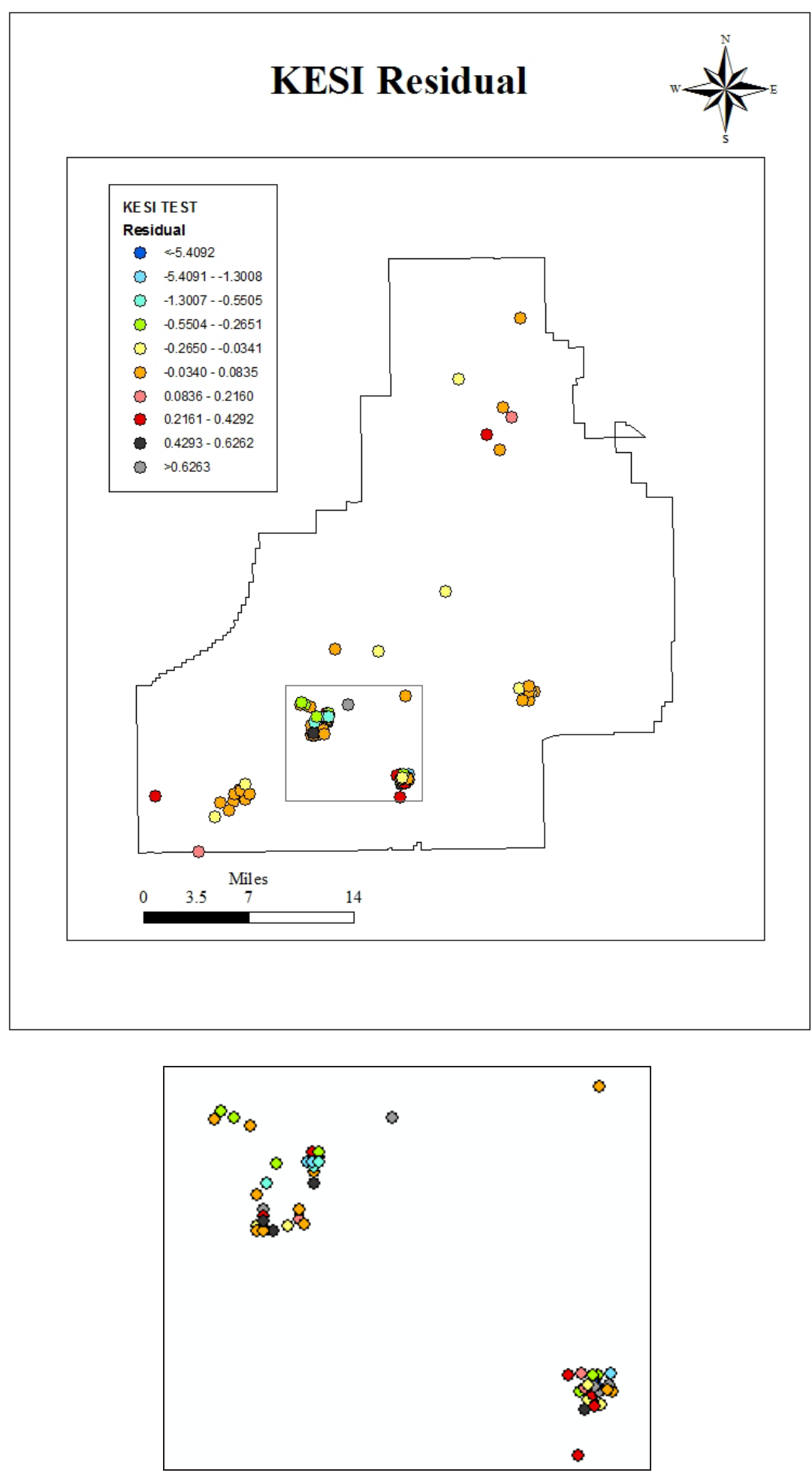

Figure 6.12. Postplot of KESI residuals (pCi/g). 


\section{CONCLUSIONS AND RECOMMENDATIONS}

Since the anthropogenic radionuclide Cs-137 emits gamma radiation, it is considered an environmental hazard and is monitored at the INL to assess human health risks resulting from exposure. Concentrations above the EPA risked-based threshold of $0.23 \mathrm{pCi} / \mathrm{g}$ may increase the potential for premature death in long-term, external exposure scenarios. As a result, field sampling of Cs-137 at the INL began in the 1980's and continues to be the preferred protocol for monitoring environmental anthropogenic radionuclides because of its ability to accurately characterize low-level radiation and to be applied to health risk analysis.

For this current project, environmental monitoring of Cs-137 concentrations in soils at the INL was performed with in situ gamma ray spectroscopy. Field samples (energy spectra and soil specimens) were collected during the summers of 2008 and 2009 at predetermined environmental sampling locations. Soil samples were analyzed to develop a depth-distribution model of Cs-137 concentrations within the soil profile. Subsequently, the concentrations of Cs-137 in surface soils at each sampling location were calculated using the gamma ray counts obtained from the energy spectra and a depth-distribution factor derived from the soil samples. Due to the large land area involved within the INL boundary, frequent and comprehensive monitoring is limited. For this project, a spatial model that predicts Cs137 concentrations at unsampled locations was developed to enhance the spatial characterization of Cs-137 in surface soils. A database was constructed within GIS for five environmental characteristics believed to influence Cs-137 concentrations. A Bayesian score was calculated to describe expected Cs-137 severity across the INL site, based on impacts from the known environmental factors. Bayesians scores were normalized to a uniform-rank transform value (bayrank) and used to generate a Cs-137 severity map for the INL. Spatial 
dependence within the Cs-137 data was estimated using complementary covariance models and then used in further analysis. Geostatistical spatial interpolation (i.e., ordinary point kriging and kriging with exhaustive secondary information) was used to estimate Cs-137 concentrations at unsampled locations in order to better understand the spatial distribution, to generate estimation and error maps, and to develop recommendations for improvement of future environmental sampling programs of Cs-137 concentrations at the INL.

\subsection{Primary Results and Conclusions}

Throughout each stage of the project, insights were gained which directed further investigations. The most important results and conclusions are summarized below:

1. Early evaluation of the 2008 and 2009 datasets revealed that local and global concentrations may vary significantly. The values appeared to be exponentially distributed within each representative sample. Additionally both had an overall mean concentration of about $0.72 \mathrm{pCi} / \mathrm{g}$ for Cs-137 data. However, due to the preferential sampling scheme that included clustered sampling locations near facilities, the overall mean Cs-137 concentration likely was overestimated and not representative of the entire study area. Declustering of high density sampling locations may help resolve this issue and provide more representative statistical results.

2. Maintaining flexibility in the GIS database proved to be the most difficult part of the project. Early GIS data used for analysis contained data fragmentation that skewed calculations. As a result, correctly registering data into a GIS database became a pivotal point in the project. Maintaining a unified map projection, a standard cell resolution, and consistent data format was vital for accurate analysis. Allowing for 
data manipulation also became a requirement as data continued to be adjusted. For example, halfway through the project, a new DEM with a different map projection and resolution was implemented, which changed the overall projection scheme for the project's database. The wind factor information also continued to be adjustment throughout the course of the project, as the influence range was manipulated to obtain reasonable behavior that concurred with known information about the INL area. As a result, a raster dataset was developed for each environmental factor individually, allowing for each dataset to be manipulated without having to change the entire database.

3. To quantify the influence of an aggregated environmental effect on Cs-137 concentrations, conditional probabilities were calculated for each environmental characteristic and used to develop an adapted Bayesian score for each cell in the study area. Comparing Bayesian score values across the entire INL study area proved to be difficult because of the wide range in values (several orders of magnitude). A uniform rank transform (bayrank) was developed in order to normalize data for further evaluation. Bayranks at the measured Cs-137 sampling locations were used to compare the aggregated environmental effect with the actual measured Cs-137 concentration. In general, a direct relationship between bayrank values and actual Cs137 values was observed. However, there were a significant number of data pairs with low Cs-137 concentrations and high bayrank values.

4. Restricted computational capacity limited the ability to perform geostatisical analysis (point kriging and KESI) across the entire INL site. As a result, a sub-area incorporating most of the facilities was used to predict Cs-137 at unsampled 
locations. While point kriging used known Cs-137 data to provide estimates at unsampled locations, KESI techniques also incorporated environmental characteristics (through the bayrank values) to provide greater information for the estimation process. In general, high values of Cs-137 were predicted around INL facilities and low values Cs-137 were predicted across the Large Grid region. As expected, KESI results seemed to be less smoothed than the point kriging results, indicating the influence of the aggregated environmental effect.

5. The application of advanced geostatistical kriging methods on the environmental monitoring of Cs-137 provided insight to the spatial distribution of Cs-137 across the INL site. To assess the performance of each kriging method, a random subset of 30 known values was removed from the analysis dataset, then both forms of kriging were conducted on the dataset with the removed values. Then, the estimation errors (residuals) were analyzed statistically, using three separate trials of 30 points each. Based on the performance evaluation and residual values, the KESI method provided better overall estimation in that its mean residual was less than that for the point kriging method.

\subsection{Recommendations for Cs-137 Field Sampling Programs}

One of the objectives of this project was to provide feedback for the improvement of the current environmental monitoring program at the INL. Recommendations based on this current study include the following:

1. The number of sampled points around facilities can be reduced by as much as 40 to 50 percent. Prior, declustering studies have indicated that the annual sampling 
program reduced by the above amount will still provide adequate statistical sampling coverage but eliminate redundant information that skews global averages.

2. Several new sampling locations (3-5) should be added near the southern boundary of the INL and in the northeastern corner to investigate the anomalies shown in the point kriging analysis. Within each of these areas, the new sampling locations should have a minimum spacing of about $610 \mathrm{~m}$ (2000ft) spacing.

3. An additional 8 to 10 sampling locations should be established at variable distances across the INL site. Key target locations will be in-between the facility cluster spacing and the remote Large Grid spacing in order to better understand the attenuation of Cs-137 concentrations extending outward from each facility. These sampling locations will help reduce kriging errors in these areas of interest.

Given the above recommendations, the long-term implication to the environmental sampling program would be reducing the number of current sampling locations by 150 180, while adding an additional 20 new sampling points. Overall, the number of sampling locations for ongoing monitoring could be reduced by about half.

\subsection{Recommendations for Future Work}

As a follow-up to this study to help develop enhanced strategies for policy and management at the INL, future work should include:

1. An assessment of the sensitivity of the Bayesian score to the particular classifications of environmental characteristics and to the particular weights assigned to the three Cs-137 groups used to describe "severity" of the radionuclide. 
2. An investigation of the role of non-independent parameters and their influence on the Bayesian score focusing especially on amplification and attenuation effects.

3. An application of a facility-specific weighting scheme for wind factor dependent on Cs-137 concentrations at individual facilities; this modified wind factor likely will improve bayrank predictions of Cs-137 severity.

4. An examination of the sensitivity of the wind factor to the influence range of atmospheric distribution and its impacts on the bayrank values.

5. The identification of trends or patterns in Cs-137 concentrations over time by applying the methods developed during this current study to datasets from years earlier than 2008.

6. The automation of all process involved including the environmental classification and kriging estimate generation within a unified GIS framework using any appropriate, compatible programming language. 


\section{REFERENCES}

Burrough, P.A, R.A. McDonnell. Principles of Geographical Information Systems. New York: Oxford Univ. Press. (1998).

Chang, K.. Introduction to Geographic Information Systems. New York: McGraw Hill. 4 (2008): 337-347.

Fromm, J. "Radionuclide Risk-Based Concentration Tables." Internal Memorandum to INEL Waste Area Group Mangers. (1996).

Goovaerts, P. Geostatistics for Natural Resource Evaluation. New York: Oxford Univ. Press. (1997).

Hood, S. M., G. A. Harris, G. J. White. Idaho National Engineering Laboratory. Background Dose Equivalent Rates and Surficial Soil Metal and Radionuclide Concentrations for the Idaho National Engineering Laboratory (1996).

ICRU, International Commission on Radiation Units and Measurements, Gamma-Ray Spectrometry in the Environment. ICRU Report 53 Bethesda, MD. USA.(1994).

Knoll, G. F. Radiation Detection and Measurement. New York: John Wiley \& Sons, Inc. (2000).

Miller, S.M., T.W. Cundy, D.L. Murphy and P.D. Richards. "Using Digital Terrain Data and Conditional Probability to Evaluate Landslide Hazard", Proceedings of the IECA $\underline{32^{\text {nd }}}$ Annual Conference and Expo. Steamboat Springs CO (2001): 153-165.

Miller, S.M., J.L. Market, T.C. Kauhi, and A. Brooks. "An Archaeology Predictive Model Based on Conditional Probability and Geostatistics", Proceedings of the $4^{\text {th }}$ Annual Hawaii International Conference on Statistics, Mathematics and Related Fields. Honolulu HI (2005): 623-635.

Miller, S.M.,C.P. Oertel, and J.R. Giles. "Interactive Declustering of Spatial Environmental Data For Geostatistical Analyses", Proceedings of the $8^{\text {th }}$ Annual Hawaii International Conference on Statistics, Mathematics and Related Fields. Honolulu HI, Paper No. 328, 9 p. (2009).

Oertel, C. P, J. R. Giles. "Use of ArcGIS in Environmental Monitoring at Idaho National Laboratory", Proceeding of the ESRI User Conference. San Diego, CA (2007): 1-17.

Ortec. Isotopic Supervisor: Program for Radioactive Waste Characterization User's Manual. 4 (2007): 232-236. 
Sowa, W., E. Martini, K. Gehrcke, P. Marschner and M.J. Naziry. "Uncertainties of In situ Gamma Spectrometry for Environmental Monitoring", Radiation Protection Dosimetry. 27 (1989): 93-101.

U.S. Department of Energy Idaho Operations Office. Idaho National Laboratory Environmental Monitoring Plan (2008). 
APPENDIX A. In Situ SAMPLING LOCATIONS

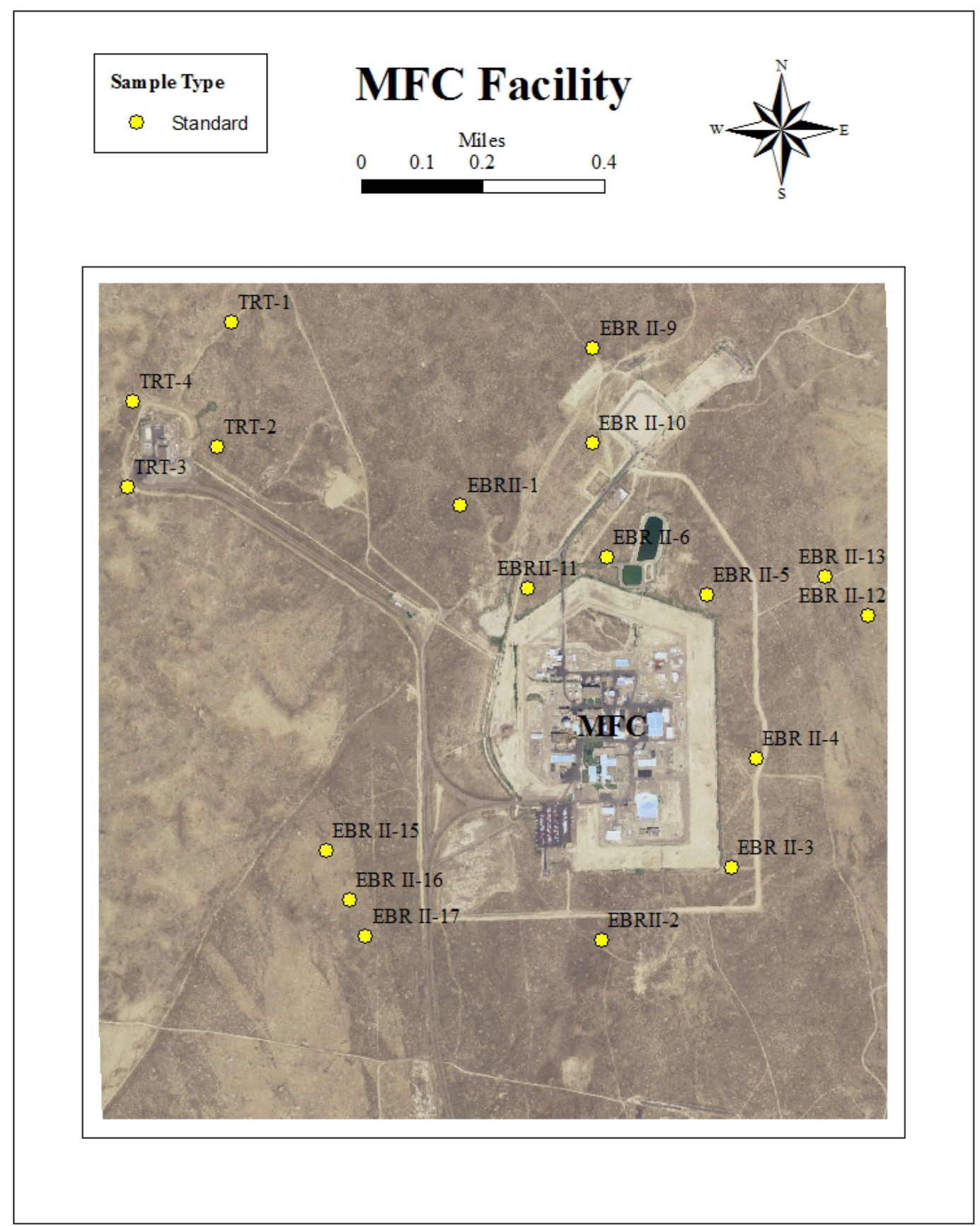

Figure A.1. In situ measurement locations at MFC facility. 


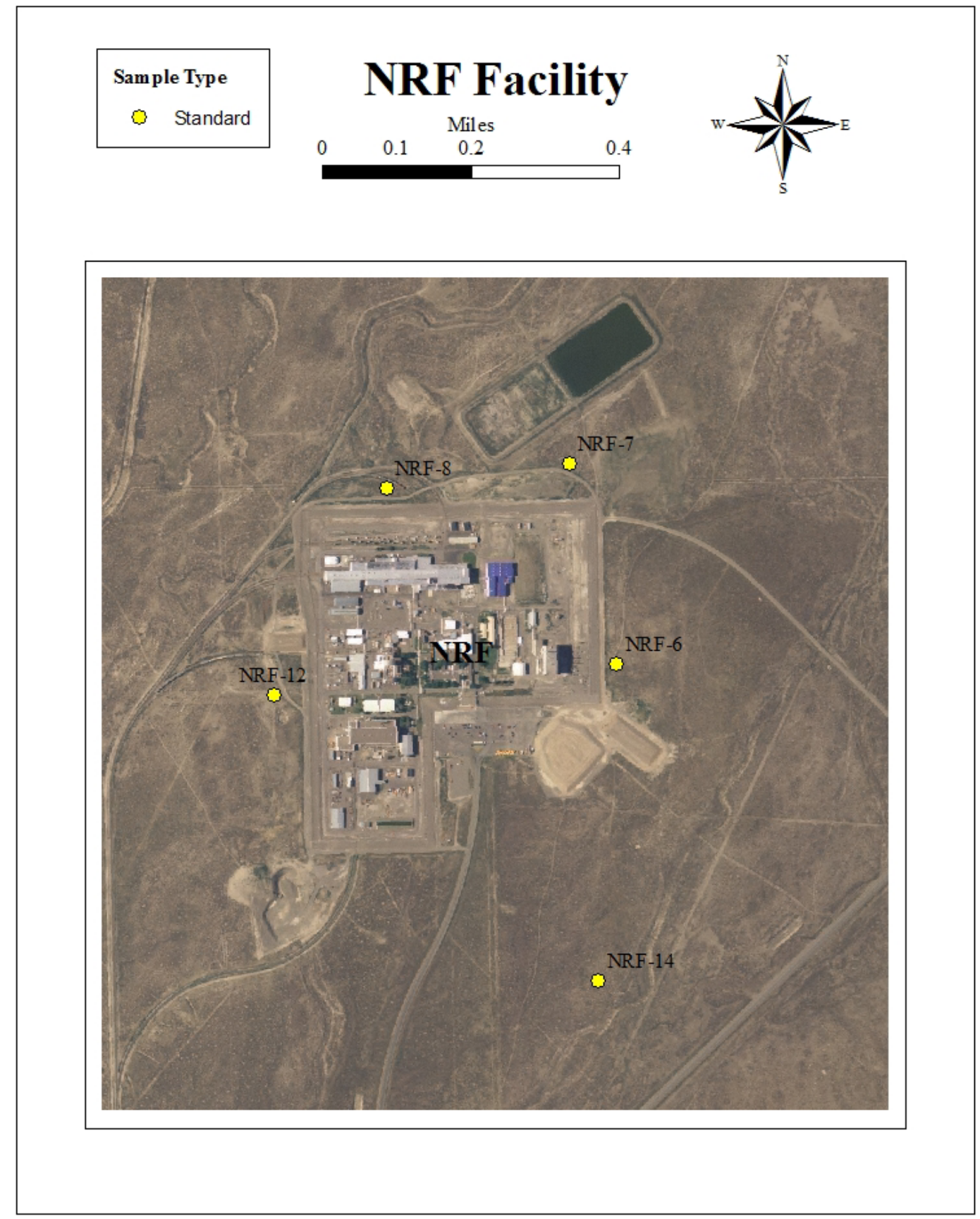

Figure A.2. In situ measurement locations at NRF facility. 


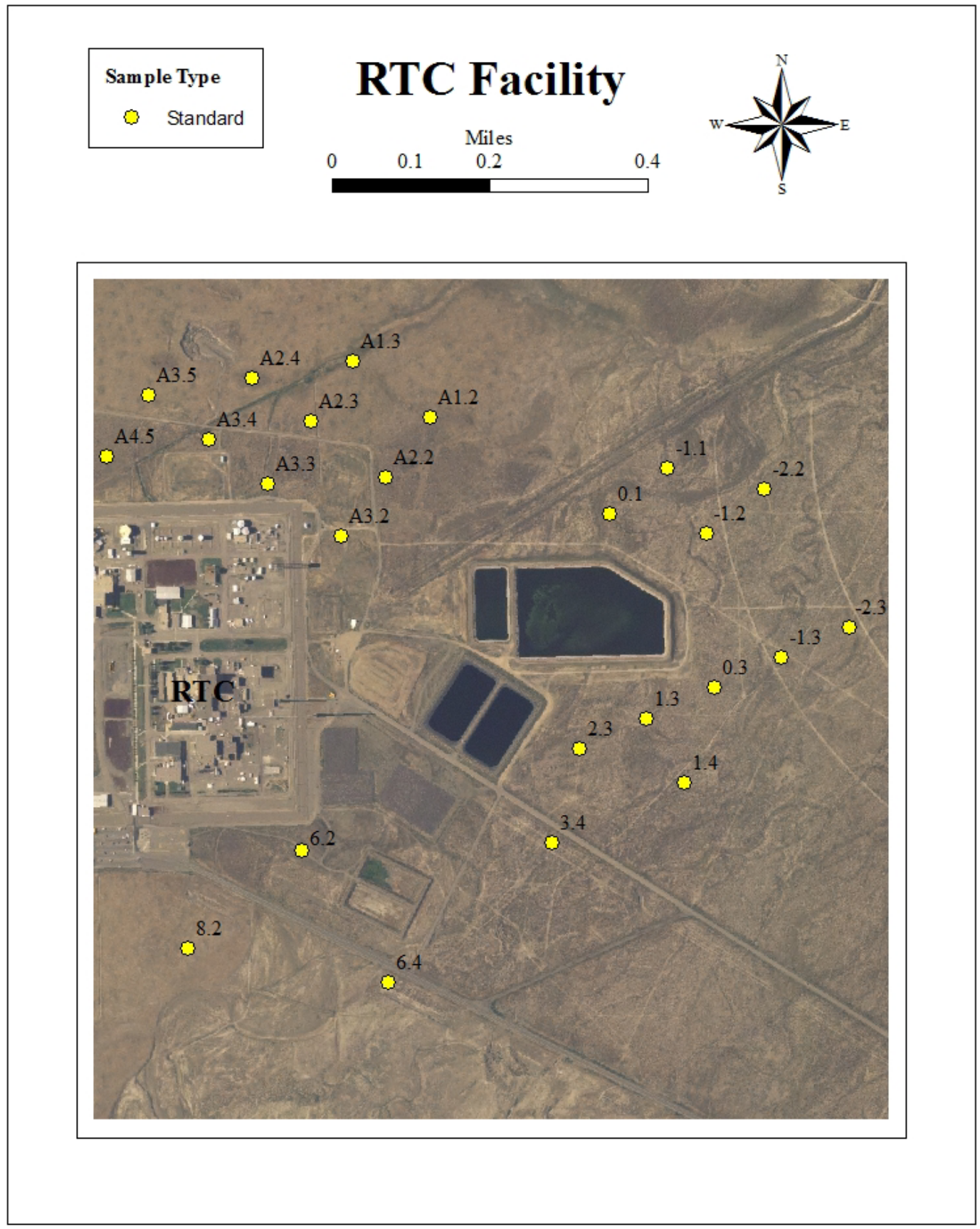

Figure A.3. In situ measurement locations at RTC facility. 


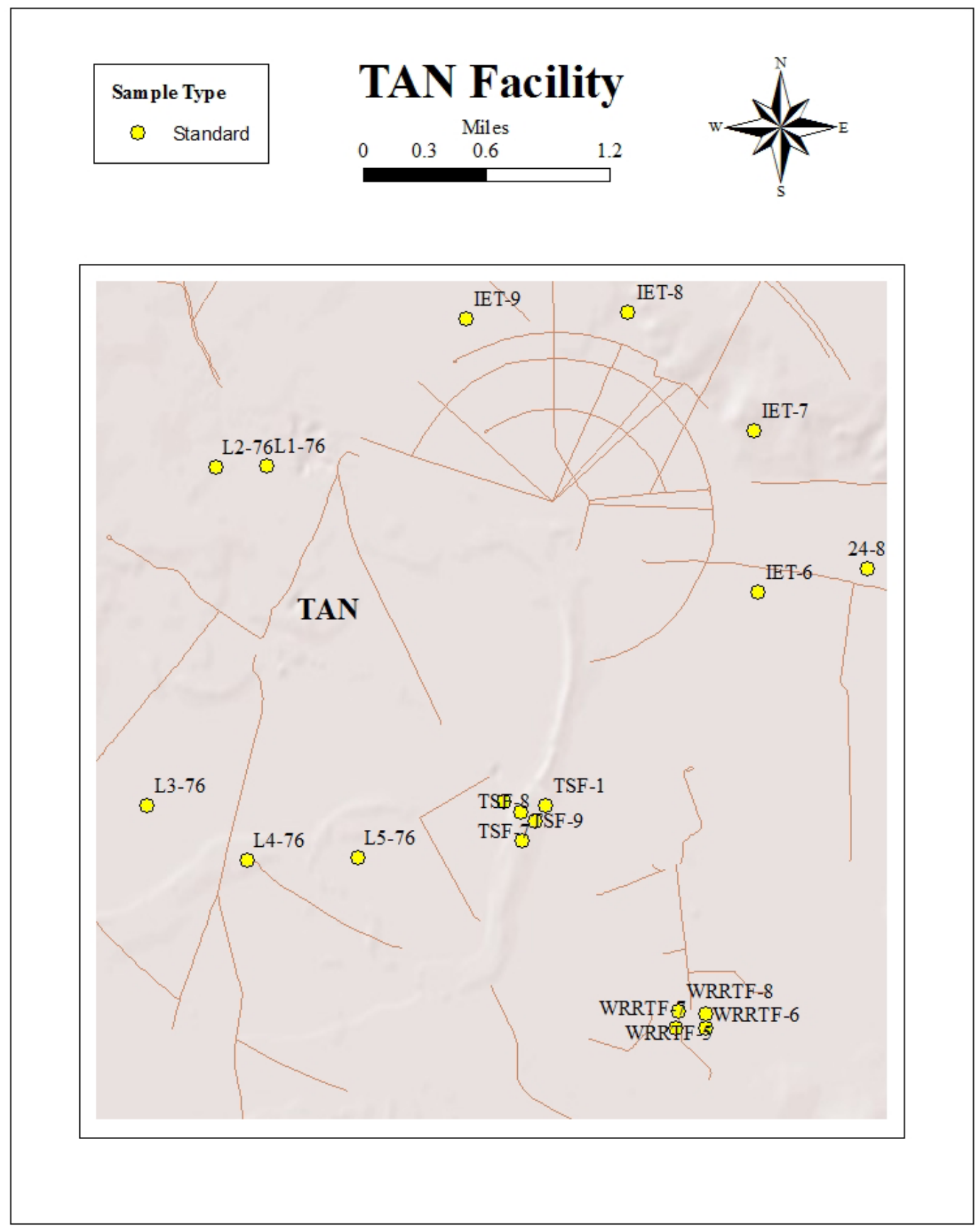

Figure A.4. In situ measurement locations at TAN facility. 


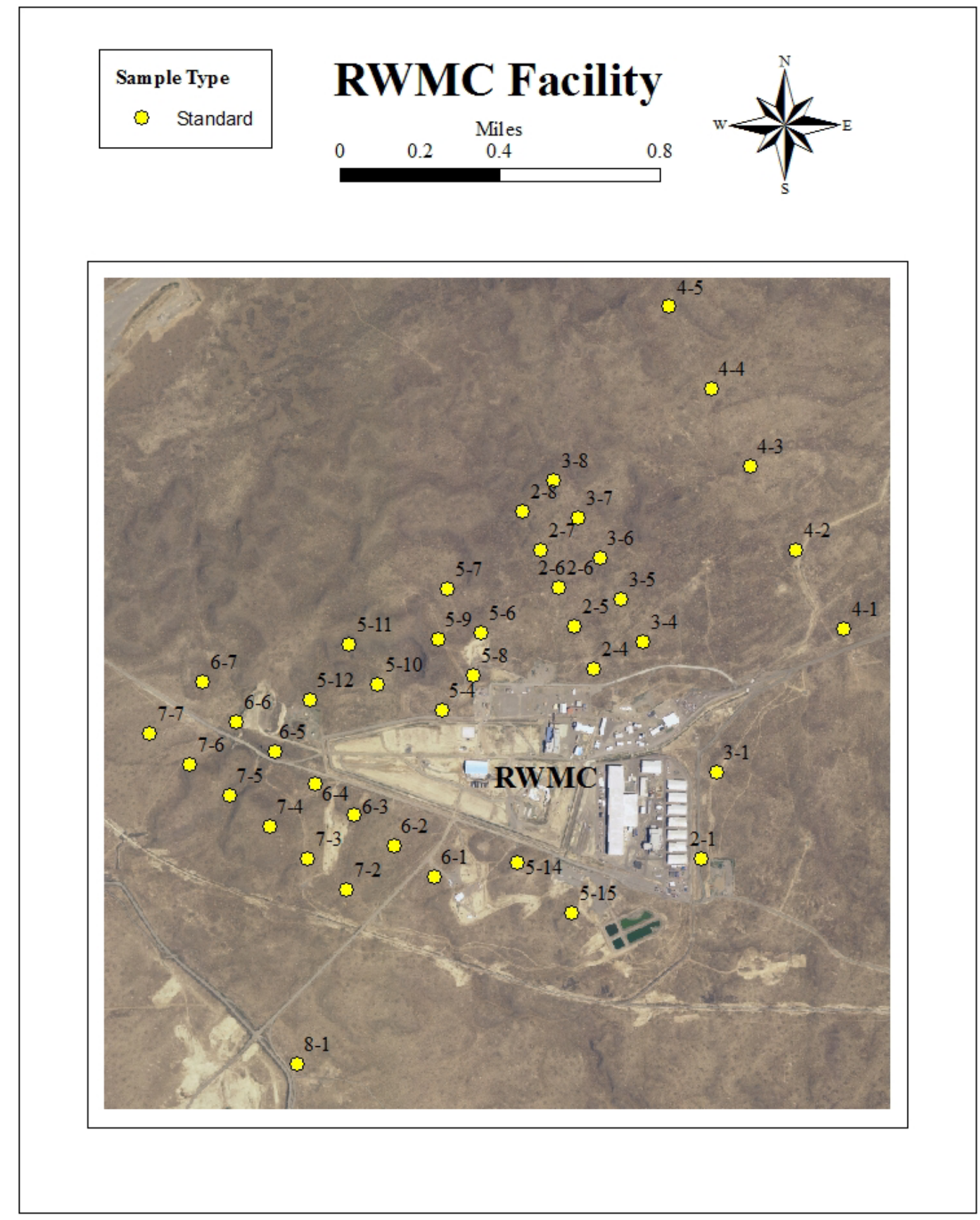

Figure A.5. In situ measurement locations at RWMC facility. 

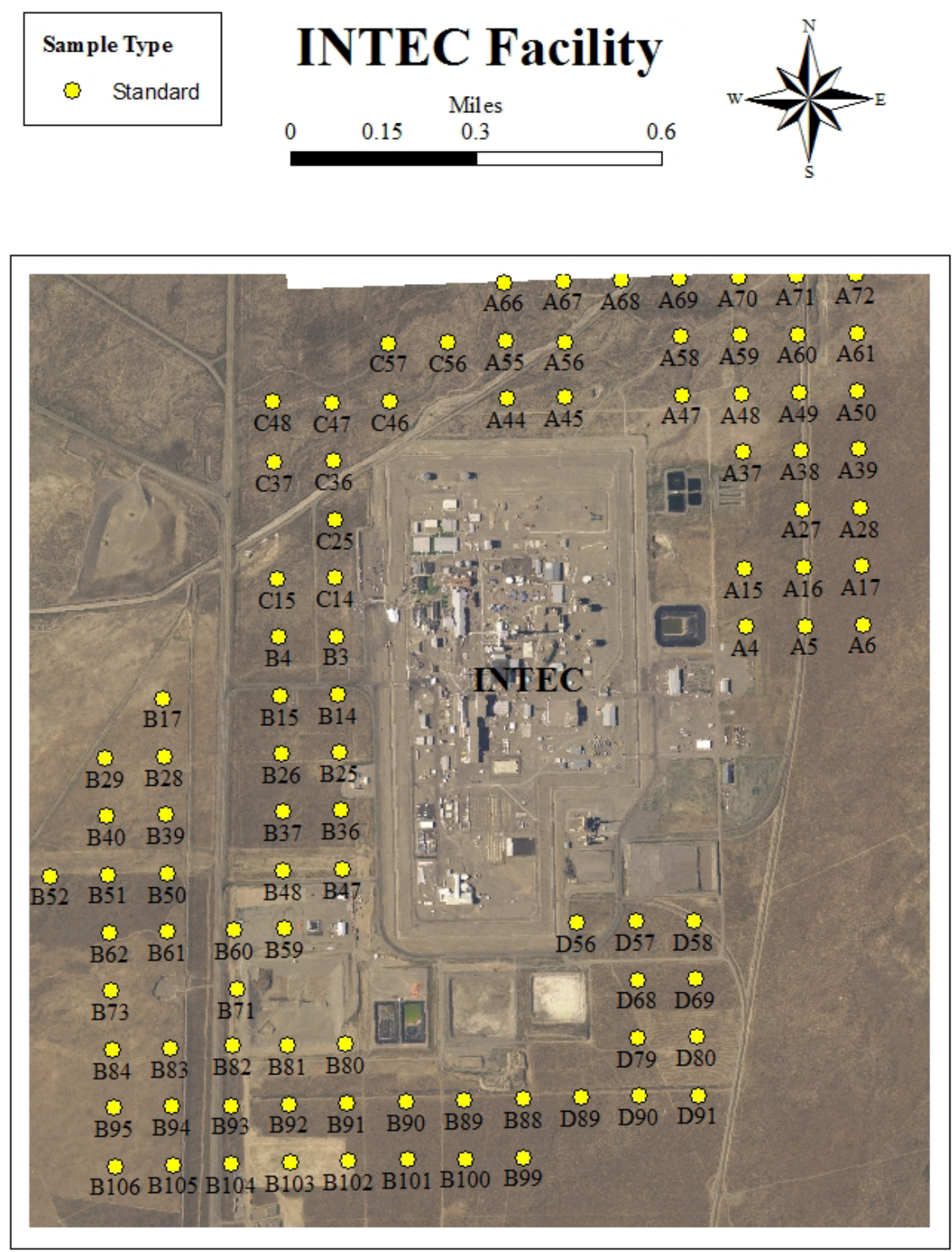

Figure A.6. In situ measurement locations at INTEC facility. 


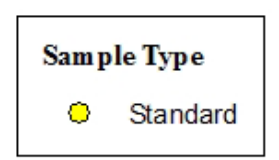

\section{CITRC Facility}
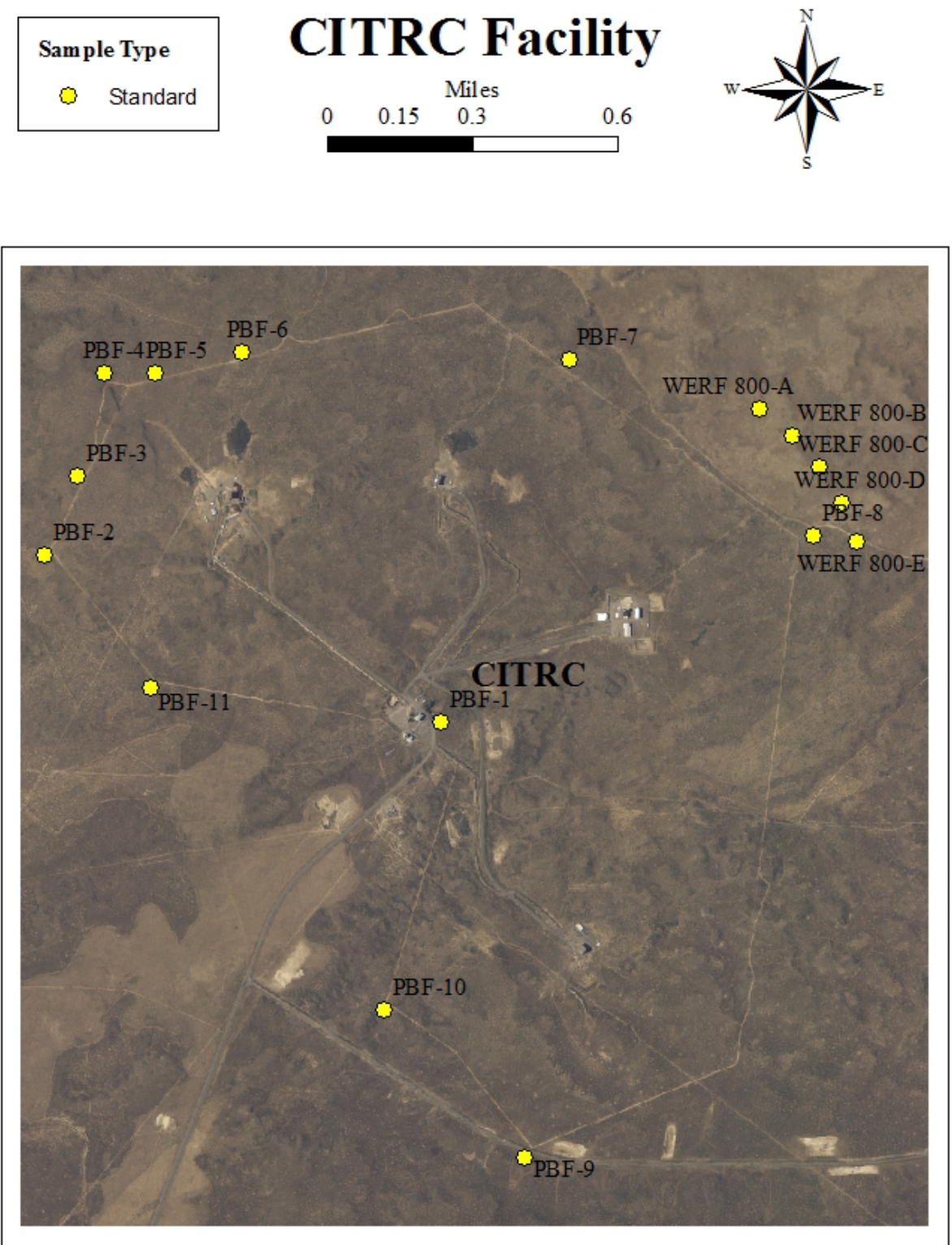

Figure A.7. In situ measurement locations at CITRC facility. 


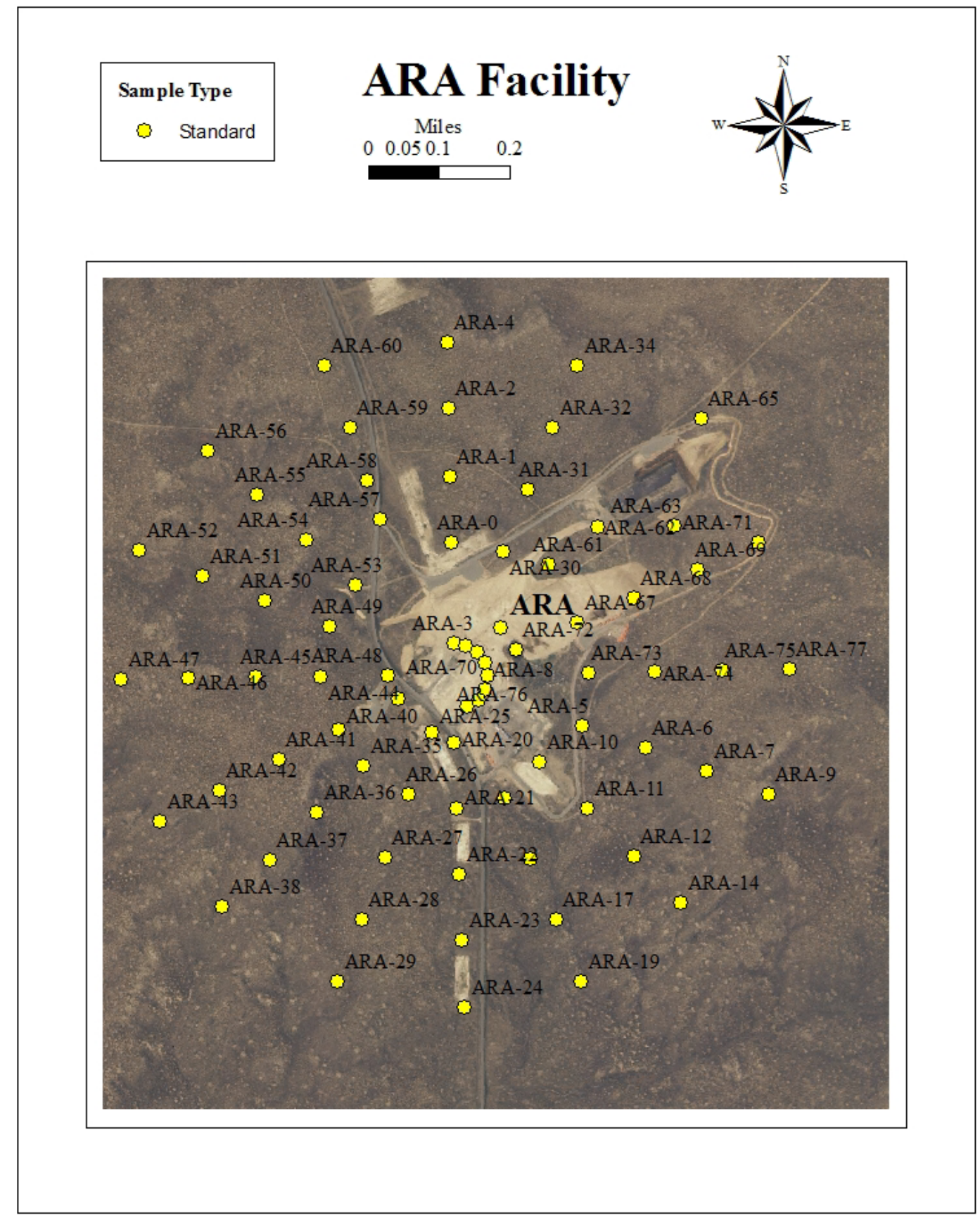

Figure A.8. In situ measurement locations at ARA facility. 


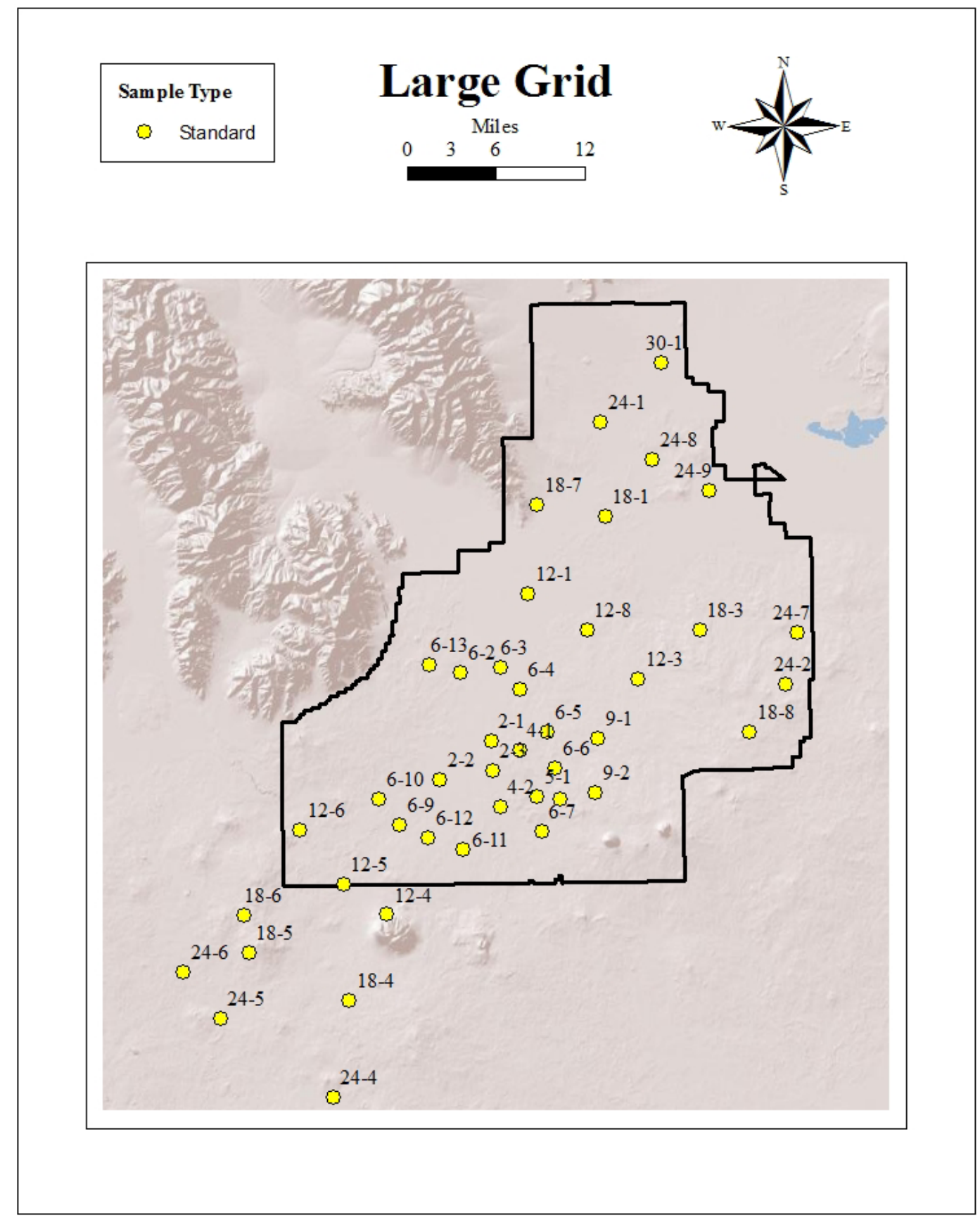

Figure A.9. In situ Large Grid measurement locations. 


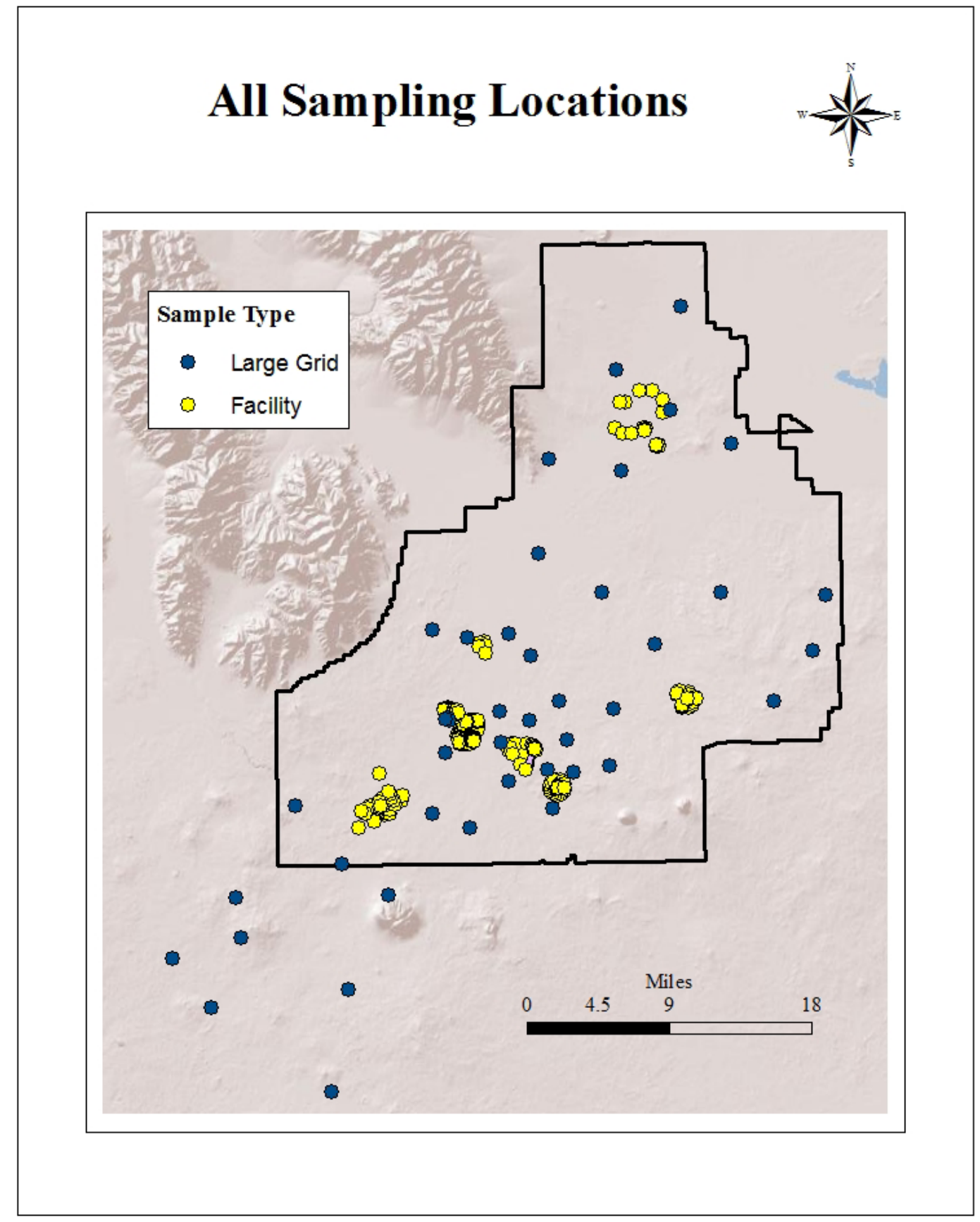

Figure A.10. All in situ sampling locations. 
APPENDIX B. ENVIRONMENTAL FACTOR CLASSIFICATIONS

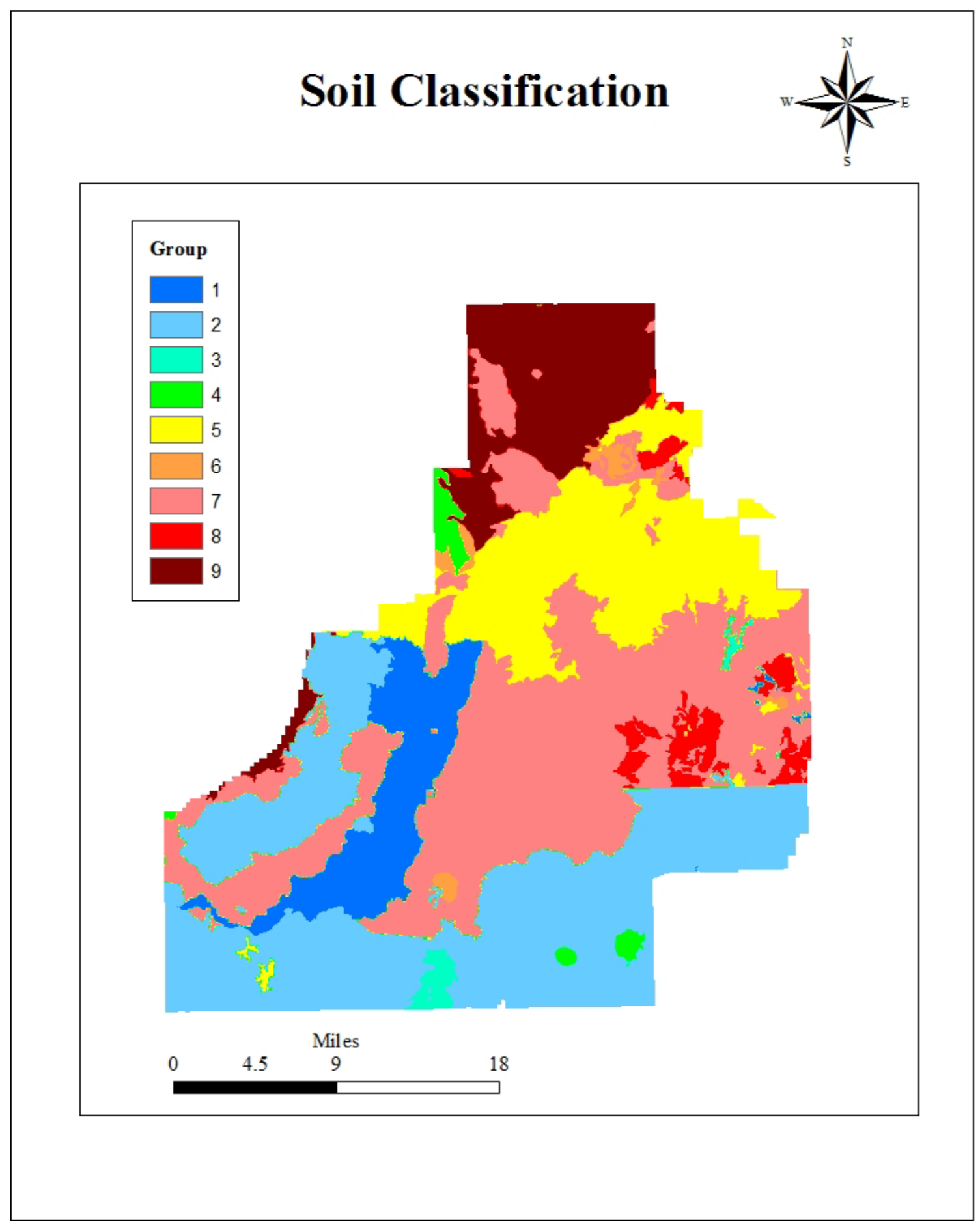

Figure B.1. Soil classification map. 


\section{Elevation Classification

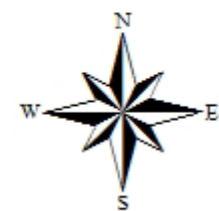

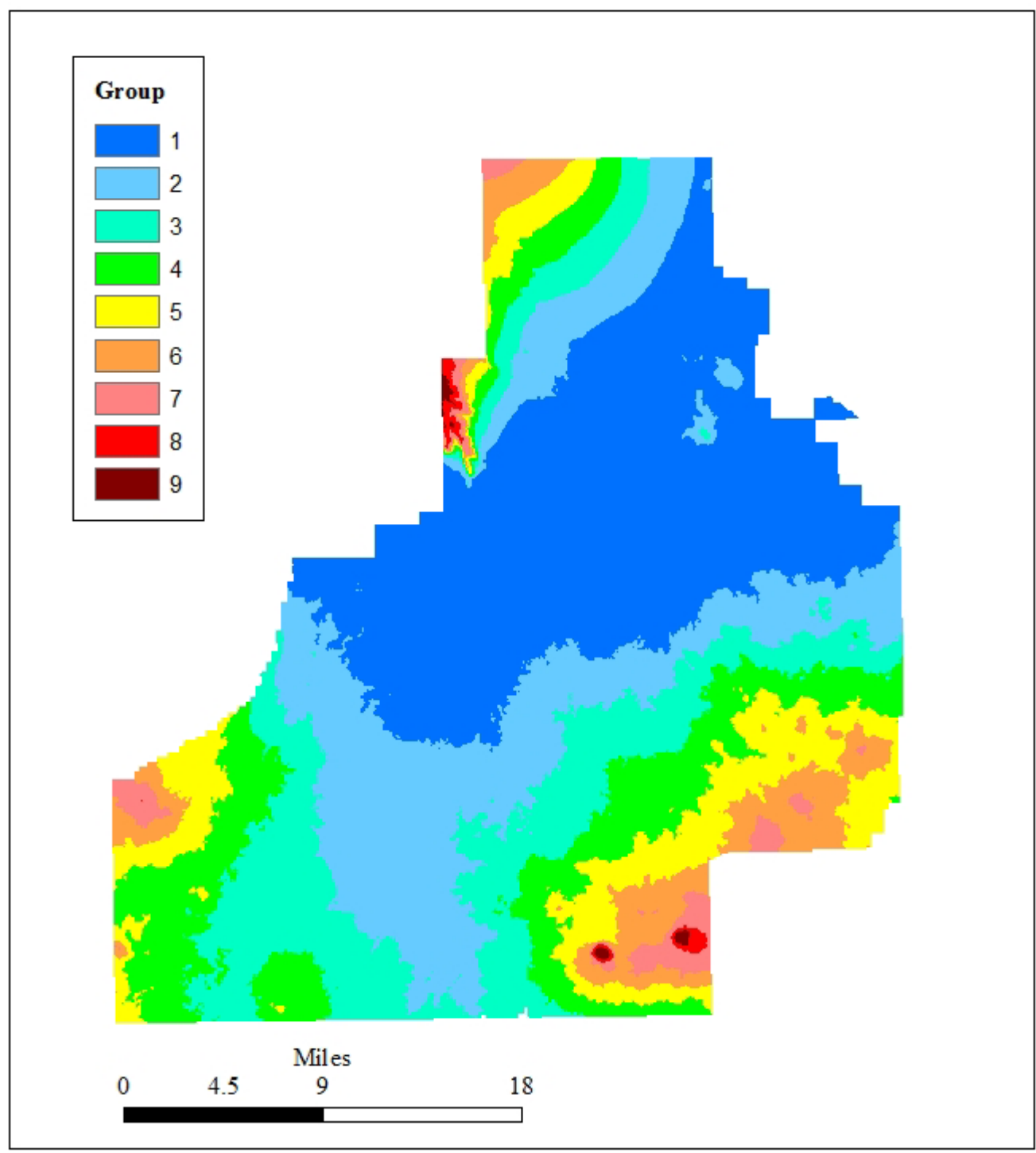

Figure B.2. Elevation classification map. 


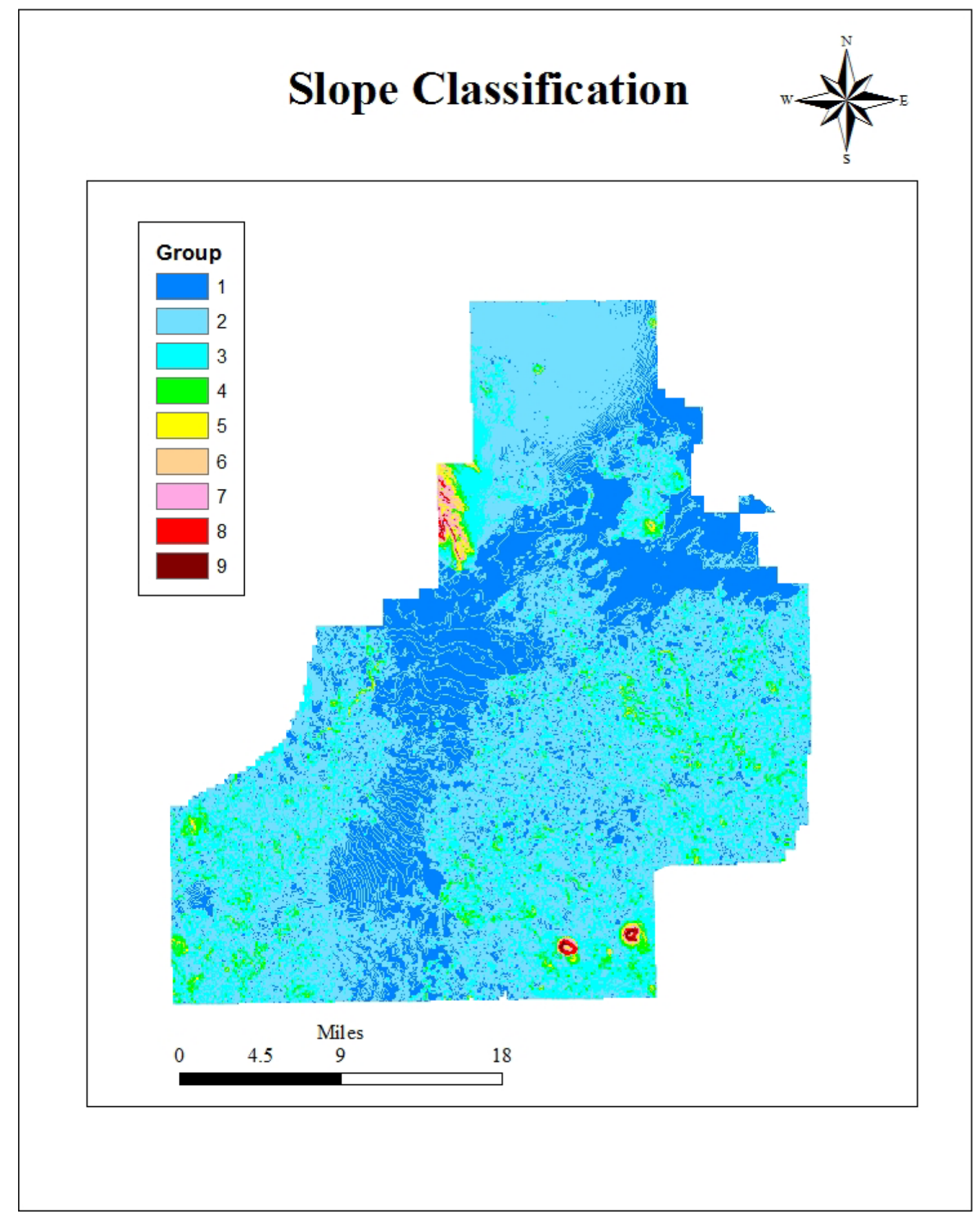

Figure B.3. Slope classification map. 


\section{Aspect Classification}
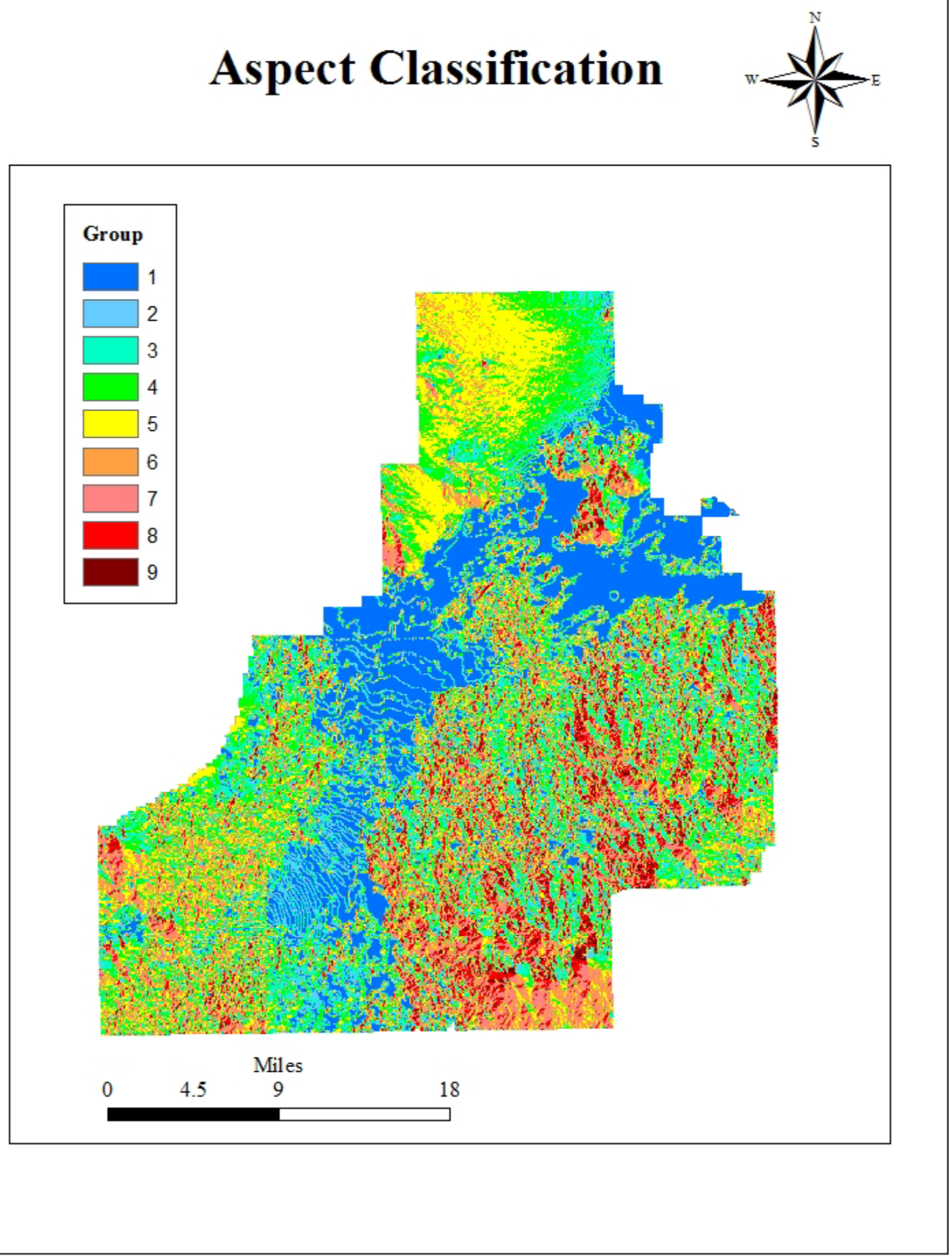

Figure B.4. Aspect classification map. 


\section{Wind Classification}
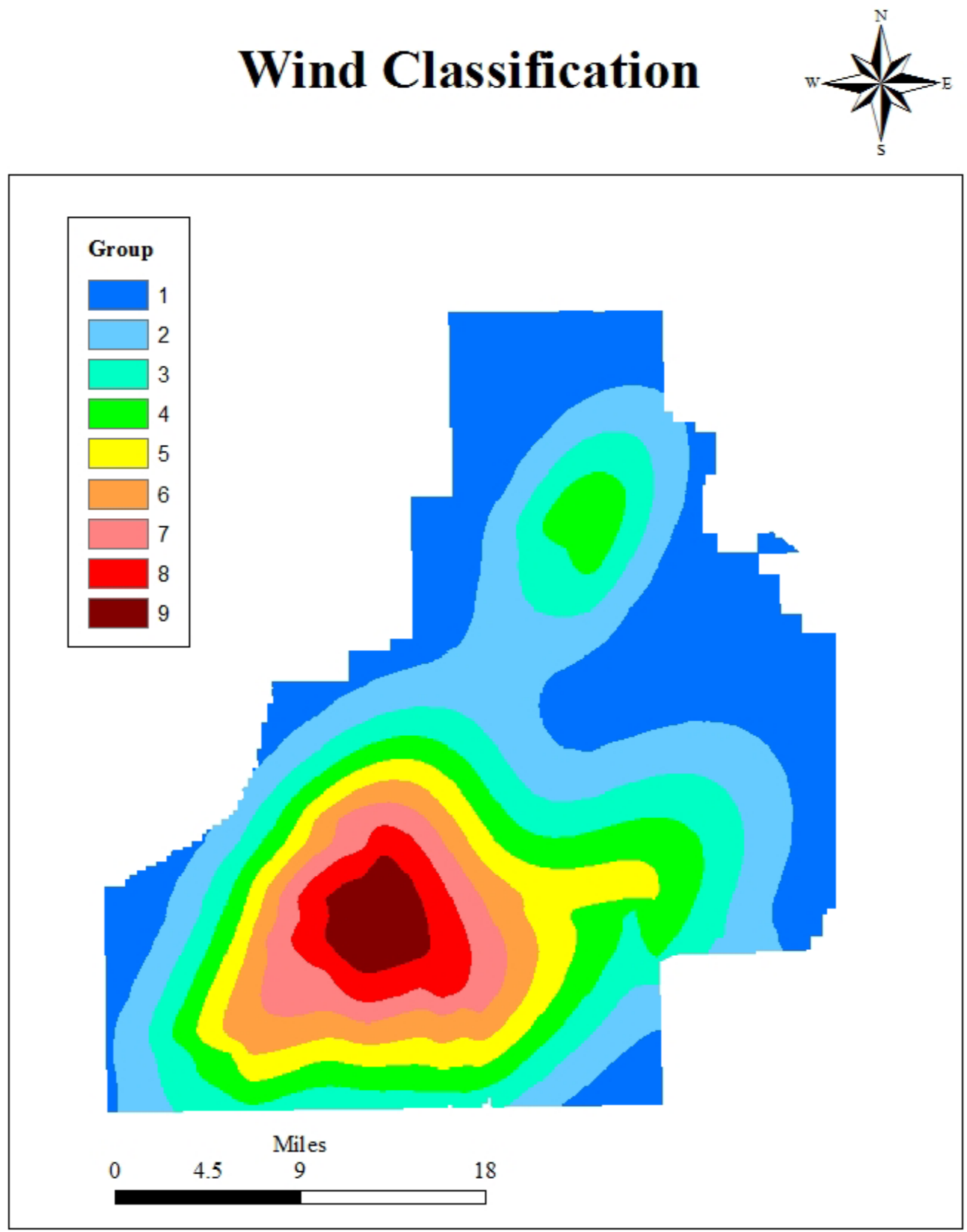

Figure B.5. Wind classification map. 


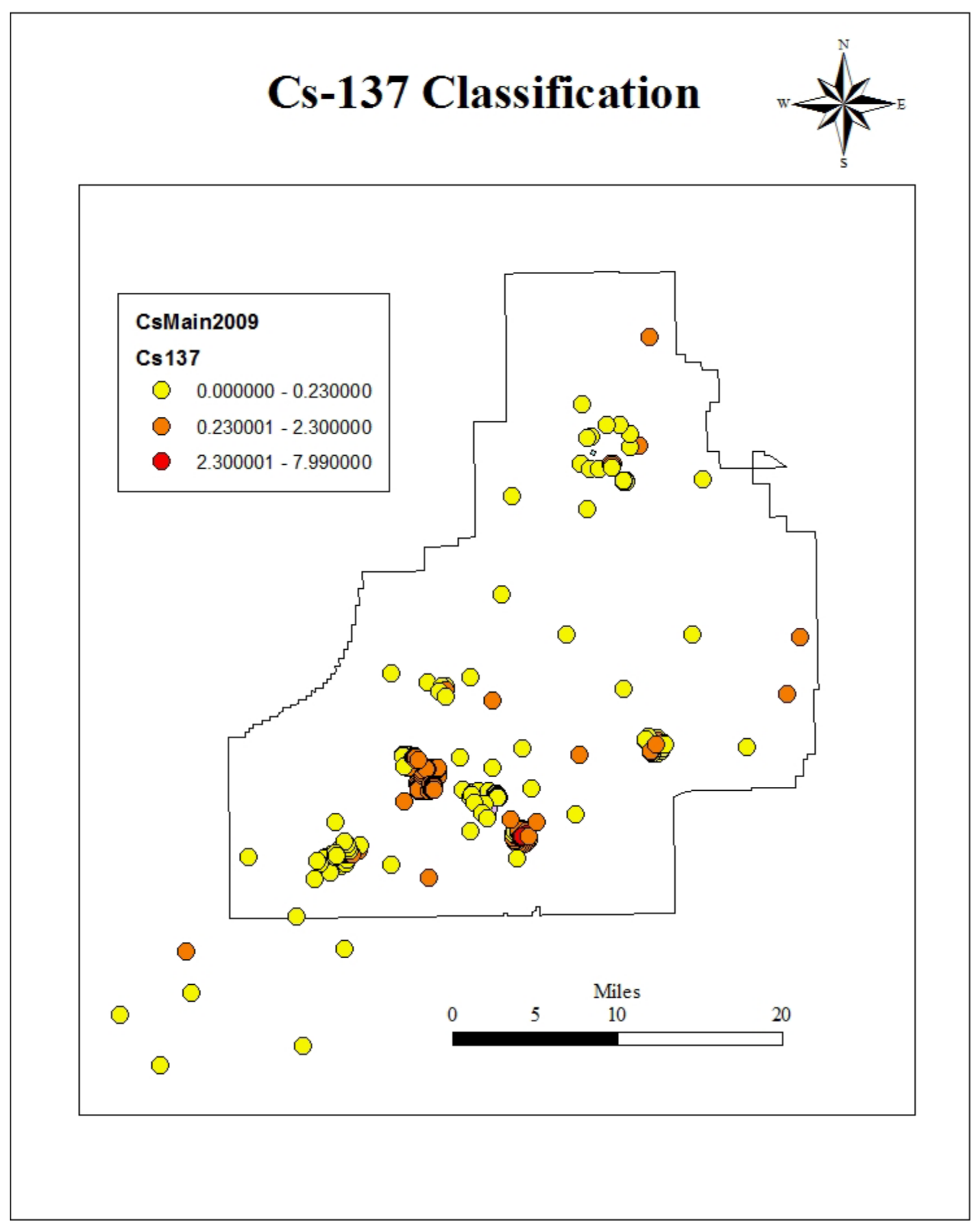

Figure B.6. Cs-137 classification map. 


\section{APPENDIX C. SPATIAL DEPENDENCE MODELING FOR THE 2009 Cs-137 DATA}

Direction: $\quad \mathrm{dr}=35.0 \quad$ Tolerance angle: $\quad$ to $=10.0$

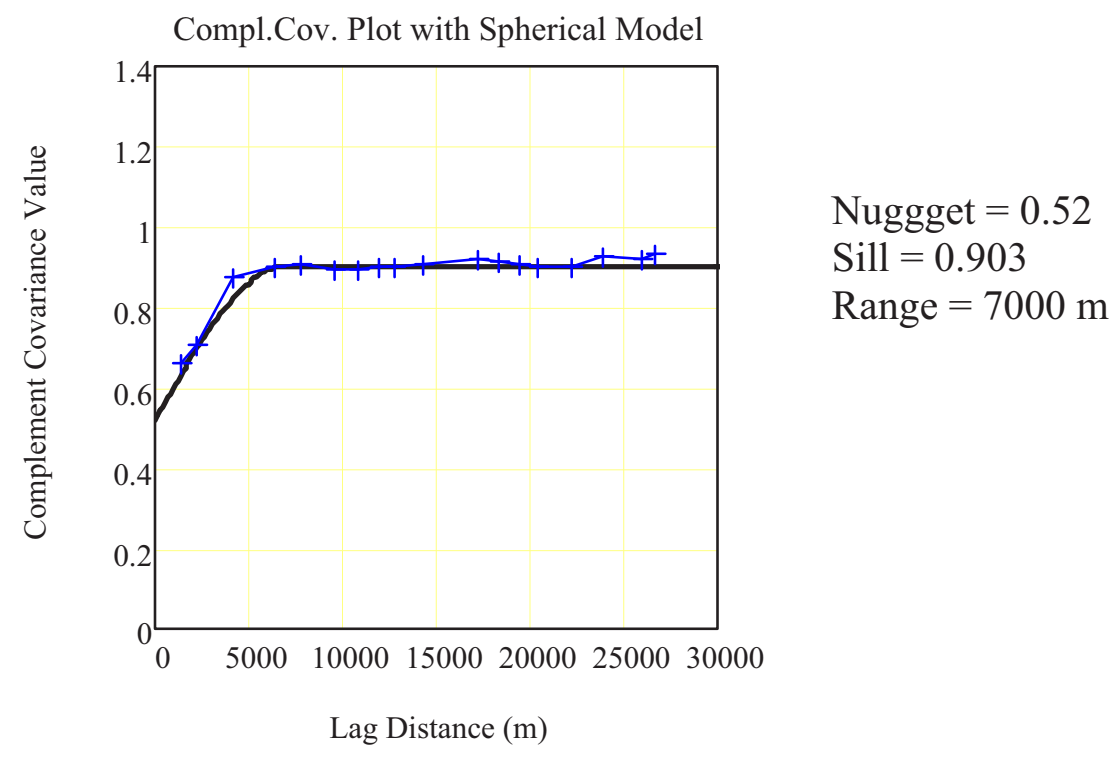

Figure C.1. Complementary covariance plot at $35^{\circ}$ (major range) with fitted model.

Direction: $\quad \mathrm{dr}=125.0 \quad$ Tolerance angle: $\quad$ to $=10.0$

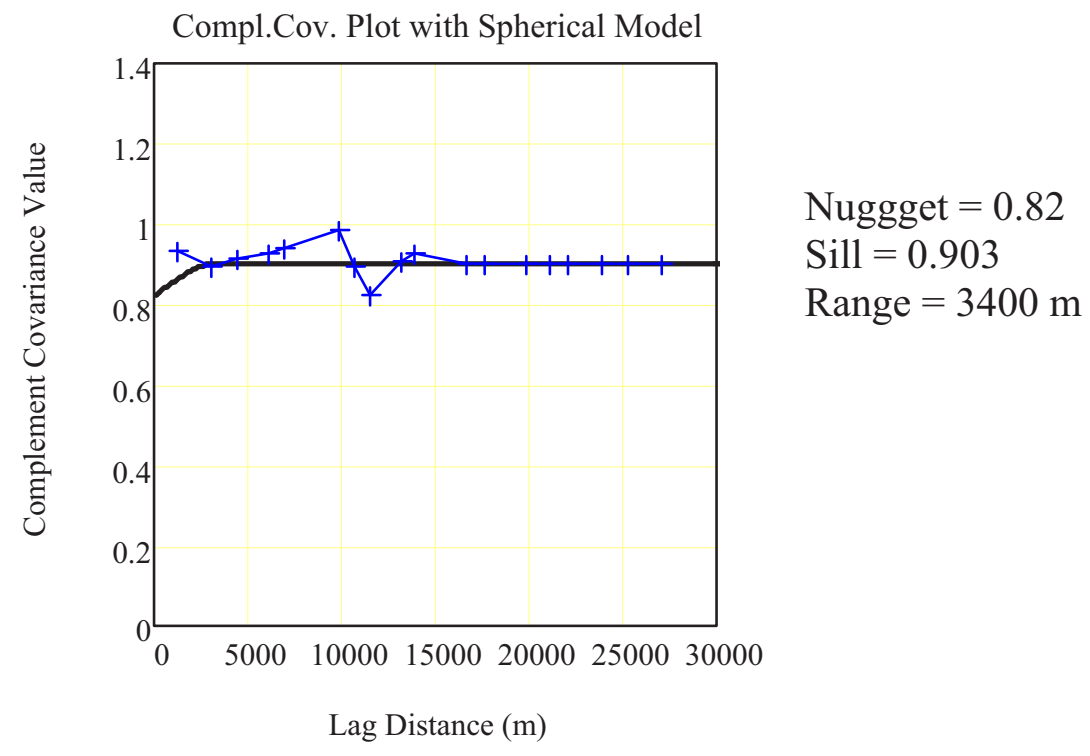

Figure C.2. Complementary covariance plot at $125^{\circ}$ (minor range) with fitted model. 


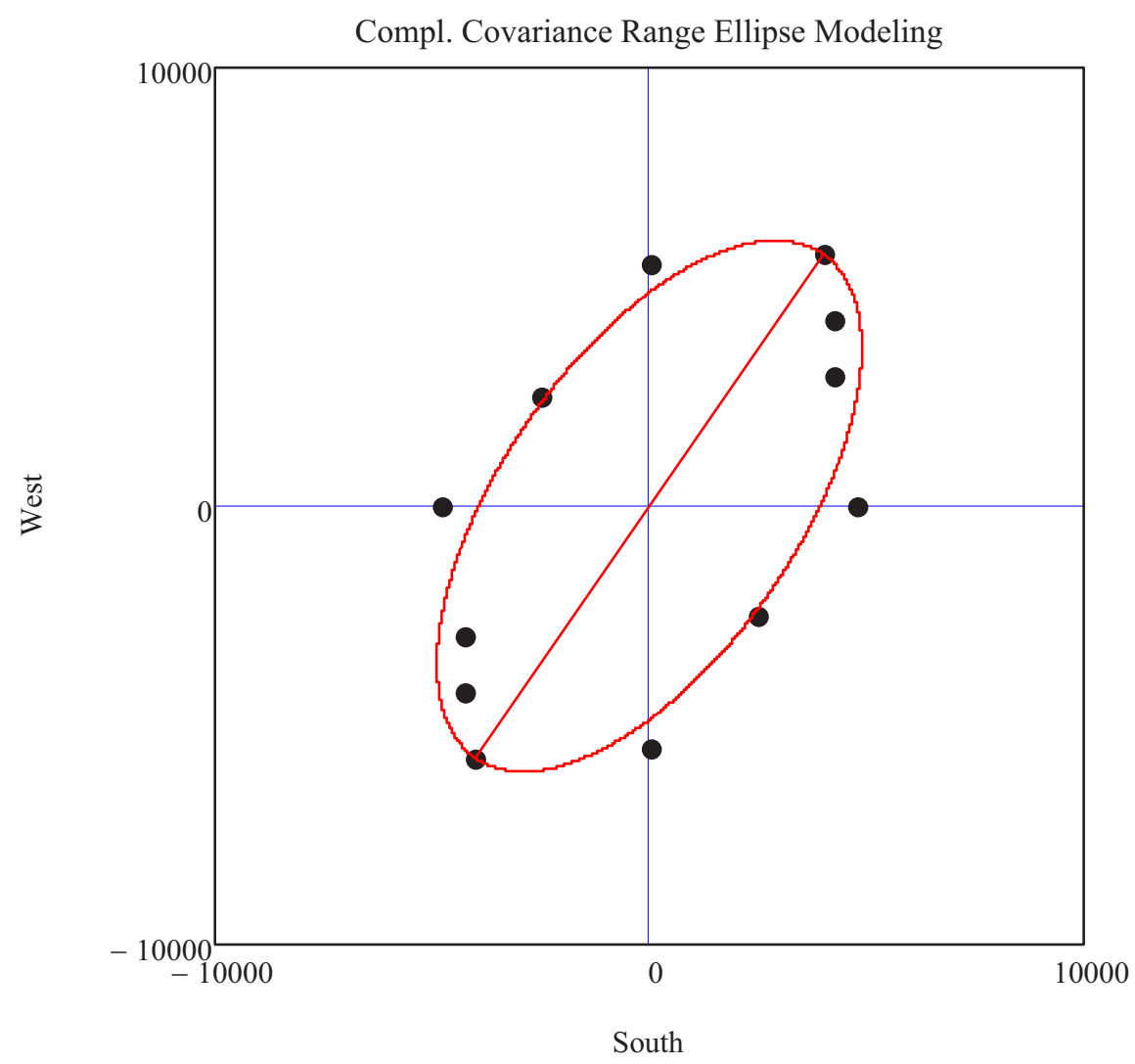

Figure C3. Fitted range ellipse for the directional complementary covariance (major range $=7000 \mathrm{~m}$; minor range $=3400 \mathrm{~m}$; angle to major axis $=35^{\circ}$; nugget $=0.4$, based on the smallest nugget at $45^{\circ}$ for all directional plots). 